THE EFFECTS OF BIOCHEMICAL CHANGES TO FILLING MEDIA DURING URODYNAMIC TESTING IN WOMEN WITH LOWER URINARY TRACT SYMPTOMS

THESIS SUBMITTED FOR MD UNIVERSITY OF LONDON

TIMOTHY ADAM GLUCK

UNIVERSITY COLLEGE LONDON

2002

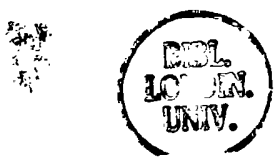


ProQuest Number: U642504

All rights reserved

INFORMATION TO ALL USERS

The quality of this reproduction is dependent upon the quality of the copy submitted.

In the unlikely event that the author did not send a complete manuscript and there are missing pages, these will be noted. Also, if material had to be removed, a note will indicate the deletion.

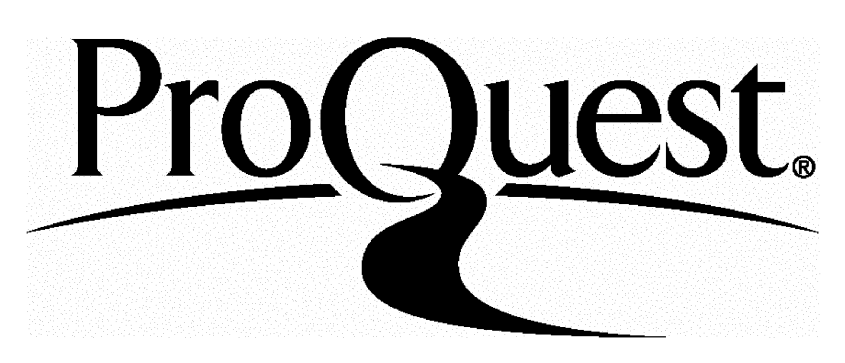

ProQuest U642504

Published by ProQuest LLC(2015). Copyright of the Dissertation is held by the Author.

All rights reserved.

This work is protected against unauthorized copying under Title 17, United States Code. Microform Edition (c) ProQuest LLC.

\author{
ProQuest LLC \\ 789 East Eisenhower Parkway \\ P.O. Box 1346 \\ Ann Arbor, MI 48106-1346
}




\section{THE EFFECTS OF BIOCHEMICAL CHANGES TO FILLING MEDIA DURING URODYNAMIC TESTING IN WOMEN WITH LOWER URINARY TRACT SYMPTOMS}

\section{ABSTRACT \\ Introduction}

Detrusor (bladder) muscle is sensitive, in vitro, to changes in the chemistry of its environment. Changes in osmolality and potassium concentration are known to affect its contractility, as are changes in the intracellular and extracellular $\mathrm{pH}$. Urine composition varies greatly both in health and in disease. It is not clear however, the extent to which the intravesical environment influences bladder function. Urodynamic testing uses a standardised filling medium, usually normal saline. This study was designed to assess the impact of changes to the intravesical biochemical environment on urodynamic testing, when compared to a normal saline control.

\section{Methods}

Ninety four women, who were being investigated for lower urinary tract symptoms, consented to a repeat filling procedure. The filling phase of urodynamics was performed then repeated immediately. Each study used a test solution and a control with normal saline, in random order. The solutions used were : hyperosmolar solution; high potassium solution; a solution designed to change extracellular $\mathrm{pH}$ only (extracellular alkalosis); and solutions designed to affect both intracellular and extracellular $\mathrm{pH}$ (a hypercapnic solution to result in intracellular acidosis and a normocapnic control). 


\section{Results}

There were no significant effects of any changes in filling solution when compared to normal saline controls. This allowed an analysis of effect of order of fill, which also had no significant effect on urodynamic testing.

\section{Conclusions}

Urodynamic testing was unaffected by changes to intravesical chemistry that are known to affect detrusor cells in vitro. This suggests that the homeostatic mechanisms of the bladder are able to maintain a stable microenvironment for detrusor cells despite changes to bladder contents. 


\section{ACKNOWLEDGEMENTS}

I would like to thank my two supervisors- Professor James Malone-Lee for his encouragement, patience and for the training in clinical science, and Professor Chris Fry for his constructive criticism and thoughtful comments.

I gratefully acknowledge the help of Dr Adrian Wagg in initiating and designing the study.

I also acknowledge the support my two employers- Camden and Islington Community NHS trust, where I was senior registrar at the beginning of the study, and of Barnet General Hospital, where I am now a consultant. I also thank in particular the excellent library service at Barnet.

I would also like to thank my wife Dr Nicola Cowap, for her support and encouragement. 
TABLE OF CONTENTS

$\begin{array}{ll}\text { LIST OF FIGURES } & 8\end{array}$

LIST OF TABLES

$\begin{array}{ll}\text { GLOSSARY } & 13\end{array}$

1 INTRODUCTION- PART $1 . \quad$ THE EFFECTS OF

CHANGES TO THE BIOCHEMICAL ENVIRONMENT ON DETRUSOR $\begin{array}{ll}\text { FUNCTION } & 14\end{array}$

$\begin{array}{lll}1.1 & \text { Cellular mechanisms of detrusor function } & 15\end{array}$

$\begin{array}{lll}1.2 & \text { The effect of } \mathrm{pH} \text { on detrusor function } & 17\end{array}$

1.3 The influence of osmolality on detrusor function 25

1.4 The influence of potassium on detrusor function 27

$1.5 \quad$ Permeability of the Bladder 30

1.6 The sensory function of the urothelium 36

$\begin{array}{lll}1.7 & \text { Summary } & 38\end{array}$

2 INTRODUCTION- PART 2 -THE URODYNAMIC TEST

2.1 The history and development of urodynamics science $\quad 39$

2.2 The mechanics of bladder contraction 40

$\begin{array}{lll}2.3 & \text { Gas cystometry } & 44\end{array}$

$\begin{array}{lll}2.4 & \text { Ambulatory urodynamics } & 46\end{array}$

$\begin{array}{lll}2.5 & \text { Repeatability of urodynamics }\end{array}$

$\begin{array}{lll}2.6 & \text { Summary } & 55\end{array}$

3 METHODS

$\begin{array}{lll}3.1 & \text { Experimental methods } & 56\end{array}$

$\begin{array}{lll}3.2 & \text { Filling solutions } & 61\end{array}$ 
$\begin{array}{lll}3.3 & \text { Statistical methods } & 64\end{array}$

$\begin{array}{lll}3.4 & \text { Normality of data } & 66\end{array}$

$\begin{array}{lll}3.5 & \text { Sample size and power calculations } & 67\end{array}$

$4 \quad$ RESULTS

$\begin{array}{lll}4.1 & \text { Hyperosmolar study } & 68\end{array}$

$\begin{array}{lll}4.2 & \text { Extracellular alkalosis study } & 77\end{array}$

$\begin{array}{lll}4.3 & \text { Intracellular and extracellular } \mathrm{pH} \text { variation study } & 87\end{array}$

$\begin{array}{lll}4.4 & \text { Potassium study } & 107\end{array}$

$\begin{array}{lll}4.5 & \text { Order of fill data } & 116\end{array}$

$\begin{array}{lll}4.6 & \text { Urgency and instability } & 123\end{array}$

$\begin{array}{lll}4.7 & \text { Interaction of variables } & 124\end{array}$

$5 \quad$ DISCUSSION

$\begin{array}{lll}5.1 & \text { Hyperosmolar study } & 126\end{array}$

$\begin{array}{lll}5.2 & \text { Extracellular alkalosis study } & 128\end{array}$

5.3 Intracellular and extracellular $\mathrm{pH}$ variation study $\quad 130$

$\begin{array}{lll}5.4 & \text { Potassium study } & 132\end{array}$

$\begin{array}{lll}5.5 & \text { Order of fill study } & 134\end{array}$

5.6 Limitations and criticisms of the study 136

$\begin{array}{lll}5.7 & \text { Future studies } & 139\end{array}$

$\begin{array}{lll}5.8 & \text { Conclusions } & 140\end{array}$

6 REFERENCES 142 
APPENDICES

APPENDIX 1-

Patient information sheet

Consent form

161

Standardised neurological examination

162

APPENDIX 2

Data used for sample size calculation

163

APPENDIX 3

Examples of urodynamic tracings

165

APPENDIX 4 Parametric data analysis

170 


\section{LIST OF FIGURES}

Figure 1.1 Diagram of factors involved in contractile activation and relaxation of detrusor smooth muscle

Figure 1.2 The Henderson- Hasselbalch equation represented in graphical form

Figure 1.3 The effectiveness of buffer solutions

Figure 2.1 The relationship between pressure and tension against volume

Figure 3.1 Modified urodynamics setup

\section{Hyperosmolar study figures}

Figure 4.1 Histogram of \% FSF difference $\quad 73$

Figure 4.2 Histogram of \% FDV difference 73

$\begin{array}{lll}\text { Figure } 4.3 \quad \text { Histogram of \% CC difference } & 74\end{array}$

Figure 4.4 Normal QQ plot of \% CC difference $\quad 74$

Figure 4.5 Scatter plot of \% CC difference 75

Figure 4.6 Boxplot of \% FSF difference- urgency subgroups 75

Figure 4.7 Boxplot of \% FDV difference- urgency subgroups 76

Figure 4.8 Boxplot of \% CC difference- urgency subgroups 76

'Extracellular' alkalosis study figures

$\begin{array}{lll}\text { Figure } 4.9 \quad \text { Histogram of \% FSF difference } & 83\end{array}$

$\begin{array}{lll}\text { Figure 4.10 Histogram of \% FDV difference } & 83\end{array}$

$\begin{array}{lll}\text { Figure 4.11 Histogram of \% CC difference } & 84\end{array}$

Figure 4.12 Normal QQ plot of \% CC difference 84

Figure 4.13 Scatter plot of \% CC difference 85 
Figure 4.14 Boxplot of \% FSF difference- urgency subgroups 85

Figure 4.15 Boxplot of \% FDV difference- urgency subgroups 86

Figure 4.16 Boxplot of \% CC difference- urgency subgroups 86

Intracellular and extracellular pH variation study

Normocapnic study figures

Figure 4.17 Histogram of \% FSF difference 97

Figure 4.18 Histogram of \% FDV difference 97

Figure 4.19 Histogram of \% CC difference 98

Figure 4.20 Normal QQ plot of \% CC difference 98

Figure 4.21 Scatter plot of \% CC difference 99

Figure 4.22 Boxplot of \% FSF difference- urgency subgroups 99

Figure 4.23 Boxplot of \% FDV difference- urgency subgroups 100

Figure 4.24 Boxplot of \% CC difference- urgency subgroups $\quad 100$

Intracellular and extracellular $\mathrm{pH}$ variation study

Hypercapnic study figures

Figure 4.25 Histogram of \% FSF difference 101

Figure 4.26 Histogram of \% FDV difference 101

Figure 4.27 Histogram of \% CC difference 102

$\begin{array}{lll}\text { Figure 4.28 Normal QQ plot of \% CC difference } & 102\end{array}$

Figure 4.29 Scatter plot of \% CC difference 103

Figure 4.30 Boxplot of \% FSF difference- urgency subgroups 103

Figure 4.31 Boxplot of \% FDV difference- urgency subgroups 104

Figure 4.32 Boxplot of \% CC difference- urgency subgroups 104 
Intracellular and extracellular pH variation study-

Hypercapnic vs normocapnic control

Figure 4.33 Histogram of \% FSF difference 105

Figure 4.34 Histogram of \% FDV difference 105

Figure 4.35 Histogram of \% CC difference 106

Figure 4.36 Normal QQ plot of \% CC difference 106

Potassium study

Figure 4.37 Histogram of \% FSF difference 112

$\begin{array}{lll}\text { Figure } 4.38 \text { Histogram of \% FDV difference } & 112\end{array}$

Figure 4.39 Histogram of \% CC difference 113

Figure 4.40 Normal QQ plot of \% CC difference 113

$\begin{array}{lll}\text { Figure } 4.41 & \text { Scatter plot of \% CC difference } & 114\end{array}$

Figure 4.42 Boxplot of \% FSF difference- urgency subgroups $\quad 114$

Figure 4.43 Boxplot of \% FDV difference- urgency subgroups 115

Figure 4.44 Boxplot of \% CC difference- urgency subgroups 115

Order of fill data figures

Figure 4.45 Histogram of \% FSF difference 119

Figure 4.46 Histogram of \% FDV difference 119

Figure 4.47 Histogram of \% CC difference 120

Figure 4.48 Normal QQ plot of \% CC difference 120

$\begin{array}{lll}\text { Figure 4.49 Scatter plot of \% CC difference } & 121\end{array}$

Figure 4.50 Boxplot of \% FSF difference- urgency subgroups 121

Figure 4.51 Boxplot of \% FDV difference- urgency subgroups 122

Figure 4.52 Boxplot of \% CC difference- urgency subgroups 122 


\section{LIST OF TABLES}

$\begin{array}{ll}\text { Key to results tables } & 70\end{array}$

$\begin{array}{lll}\text { Table 4.1 Hyperosmolar study - results table } & 71\end{array}$

Table 4.2 Results analysis for hyperosmolar fill study 72

$\begin{array}{lll}\text { Table } 4.3 \quad \text { Extracellular alkalosis study }- \text { results table } & 80\end{array}$

$\begin{array}{lll}\text { Table 4.4 Results analysis for extracellular alkalosis study } & 81\end{array}$

$\begin{array}{lll}\text { Table 4.5 } & \mathrm{pH} \text { values for extracellular alkalosis study } & 82\end{array}$

Table 4.6 Intracellular and extracellular $\mathrm{pH}$ variation study-

$\begin{array}{ll}\text { normocapnic study results table } & 91\end{array}$

Table 4.7 Intracellular and extracellular $\mathrm{pH}$ variation study-

$\begin{array}{ll}\text { hypercapnic study results table } & 92\end{array}$

Table 4.8 Results analysis for intracellular and extracellular

$\mathrm{pH}$ variation study- normocapnic study

Table 4.9 Results analysis for intracellular and extracellular

pH variation study- hypercapnic study $\quad 94$

Table 4.10 Results analysis for hypercapnic (test) vs

$\begin{array}{ll}\text { normocapnic (control) } & 95\end{array}$

Table 4.11 $\mathrm{pH}$ values for Intracellular and extracellular

$\begin{array}{ll}\mathrm{pH} \text { variation study } & 96\end{array}$

Table 4.12 Potassium study- results table 110

Table 4.13 Results analysis for potassium study 111

$\begin{array}{lll}\text { Table } 4.14 & \text { Results analysis - order of fill data } & 118\end{array}$

Table 4.15 Crosstabulation of urgency and instability 123

Table 4.16 Multivariate analysis of interaction of variables against

$\begin{array}{lr}\text { urgency and instability } & 124\end{array}$ 
Table 7.1 Data used for calculation of sample size 164

Table 7.2 Parametric data analysis for hyperosmolar study 171

Table 7.3 Parametric data analysis for extracellular alkalosis study 172

Table 7.4 Parametric data analysis for normocapnic study 173

$\begin{array}{lll}\text { Table 7.5 Parametric data analysis for hypercapnic study } & 174\end{array}$

Table 7.6 Parametric data analysis for hypercapnic vs

$\begin{array}{ll}\text { normocapnic fills } & 175\end{array}$

Table 7.7 Parametric data analysis for potassium study 176

Table 7.8 Parametric data analysis for order of fill data 177 


\section{Glossary of abbreviations}

\begin{tabular}{ll} 
ATP & Adenosine triphosphate \\
CC & Cystometric capacity \\
DTPA & Diethylene Triamine Pentaacetic Acid \\
DMSO & Dimethyl sulphoxide \\
ENaC's & Amiloride- sensitive epithelial Na Channels \\
FDV & First desire to void \\
FSF & First sensation of filling \\
GAG & Glycosaminoglycans \\
ICS & International continence society \\
NO & Nitric oxide \\
QQ plot & Quantile Quantile plot \\
SR & Sarcoplasmic reticulum \\
SD & Standard deviation \\
UTI & Urinary tract infection \\
\hline
\end{tabular}




\section{INTRODUCTION}

Urodynamic investigation is the major diagnostic investigation in the management of lower urinary tract symptoms. Over the past 30 years, there have been important advances in our understanding of bladder pathophysiology. There remains a need to clarify the relationship between bladder behaviour and its reflection in urodynamics. Before this can be achieved, we need to look at how well the urodynamic technique itself stands up to close scientific analysis. In normal renal tract function, the biochemical constituency of the urine varies greatly. Many of the changes that occur would have significant effects on detrusor function if they were also to change the microenvironment of the detrusor muscle. In this thesis, I will discuss further these changes and the experiments that I have performed to examine this relationship further. 
INTRODUCTION- PART 1. THE EFFECTS OF CHANGES TO THE BIOCHEMICAL ENVIRONMENT ON DETRUSOR FUNCTION

The biochemical constituency of the urine may vary greatly in different physiological and pathophysiological conditions. I will first detail the current understanding of the cellular mechanisms of detrusor contraction, and then I will discuss the relevance of changes in urinary $\mathrm{pH}$, osmolality and potassium to bladder function in relation to previous published work.

\subsection{Cellular mechanisms of detrusor function}

Detrusor muscle, like other smooth and skeletal muscles contains actin and myosin. These interact and cause contraction as a result of an increase in cytosolic calcium ions, released by the sarcoplasmic reticulum. The calcium is stored in the sarcoplasmic reticulum (SR) and has previously been transported into the lumen of the SR by an ATP-dependent calcium pump. The calcium release from the SR through calcium channels is regulated by intracellular second messengers, which in turn are subject to other influences. In healthy detrusor muscle, the initiation of contraction is stimulated by acetyl choline receptors $\left(\mathrm{M}_{3}\right.$ subgroup), which then leads to production of inositol triphosphate $\left(\mathrm{IP}_{3}\right)$. This is the diffusible second messenger, which then stimulates release of $\mathrm{Ca}^{2+}$ from the SR. $\mathrm{Ca}^{2+}$ release may occur in parallel as a result of ATP binding to purinergic $\left(\mathrm{P}_{2 \mathrm{X}}\right)$ receptors. $\mathrm{P}_{2 \mathrm{X}}$ stimulation leads to membrane depolarisation, which in turn will open L-type $\mathrm{Ca}^{2+}$ channels, and so mediate $\mathrm{Ca}^{2+}$ influx. As the intracellular $\mathrm{Ca}^{2+}$ is resequestered into the $\mathrm{SR}$, the levels in the sarcoplasm fall to resting values and the muscle relaxes. A diagram summarises the process (from Fry and Wu 1998) 


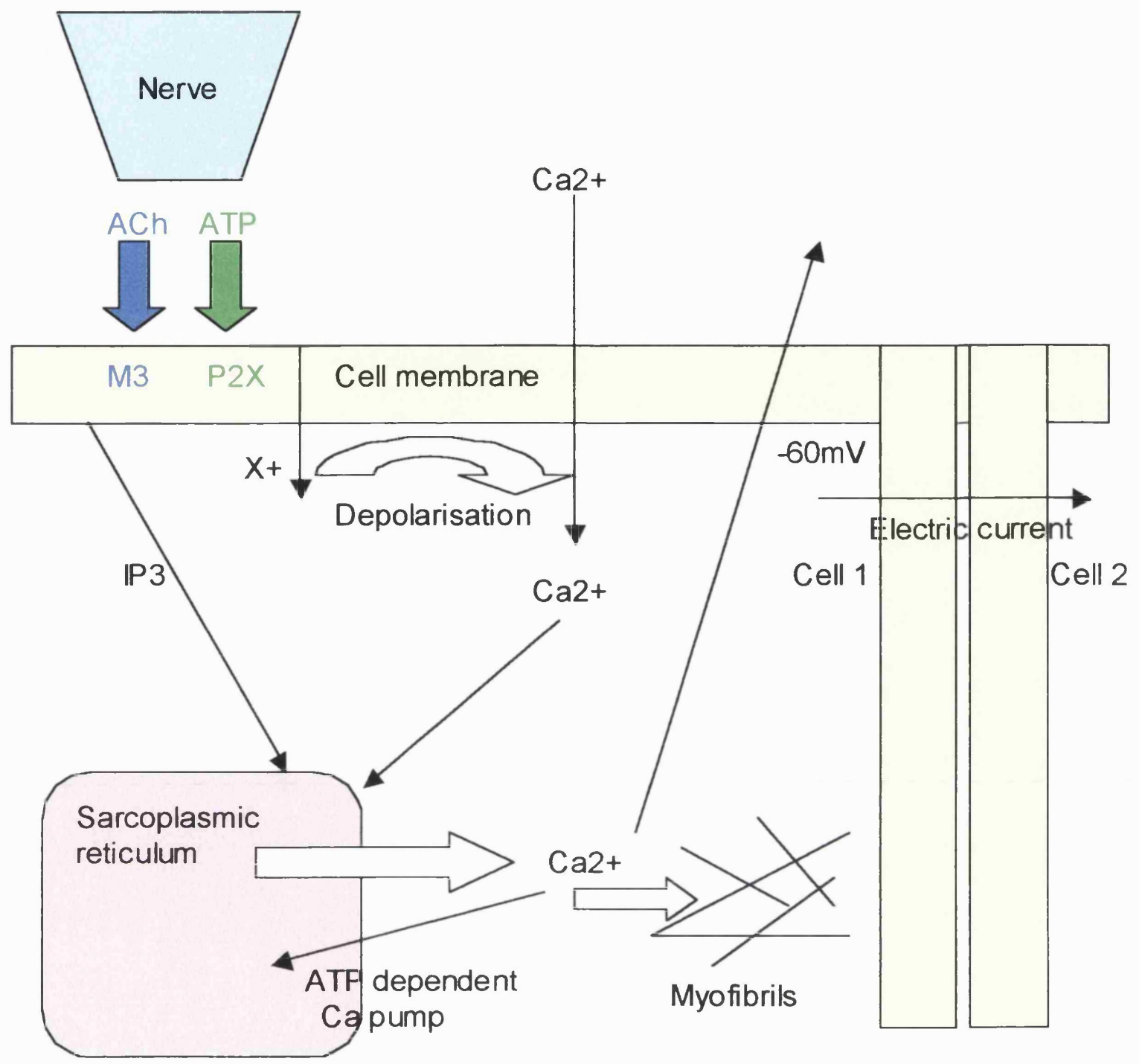

Figure 1.1

Diagram of factors involved in contractile activation and relaxation of detrusor smooth muscle. After Fry and Wu (1998) 


\subsection{The influence of $\mathrm{pH}$ on detrusor muscle}

$\mathrm{pH}$ and $\mathrm{H}^{+}$buffering are important to the thesis, so I will discuss them in some detail. Buffering occurs at all levels- in the intracellular fluid, the extracellular fluid, the blood, and the urine. There are obvious benefits from the maintenance of $\mathrm{pH}$ in the intracellular compartment of muscle within a narrow range, as enzyme catalysed reactions and protein chemistry in general are affected by changes in acidity and alkalinity.

$\mathrm{pH}$ is defined as $-\log _{10}\left[\mathrm{H}^{+}\right]$. Extracellular $\mathrm{pH}$ is around 7.4, whilst intracellular $\mathrm{pH}$ typically is around 7.1-7.2. Therefore, an increase in hydrogen ion concentration from $40 \mathrm{nmol} / 1$ to $100 \mathrm{nmol} / 1$ is equivalent to a $\mathrm{pH}$ change of 7.4 to 7.0 .

The equilibrium between a weak acid (HA) and its salt ( $\left.\mathrm{A}^{-}\right)$is dictated by rate constants

$\mathrm{k} 1$ (the rate towards the weak acid) $\mathrm{HA} \stackrel{k 1}{\longrightarrow} \mathrm{H}^{+}+\mathrm{A}^{-}$

$\mathrm{k} 2$ (the rate towards its salt and hydrogen ion) $\mathrm{HA} \stackrel{k 2}{\longleftarrow} \mathrm{H}^{+}+\mathrm{A}^{-}$ If $\mathrm{k} 2 / \mathrm{k} 1=\mathrm{K}$ and $\mathrm{pK}$ is $-\log _{10} \mathrm{~K}$, then the Henderson Hasselbalch equation may be derived from the mass action condition thus

$$
\mathrm{K}=\frac{k 2}{k 1}=\frac{[H+][A-]}{[H A]}
$$

ie $\quad \mathrm{K}[\mathrm{HA}]=\left[\mathrm{H}^{+}\right]\left[\mathrm{A}^{-}\right]$

$$
\begin{aligned}
& \log _{10} \mathrm{~K}+\log _{10}[\mathrm{HA}]=\log _{10}\left[\mathrm{H}^{+}\right]+\log _{10}\left[\mathrm{~A}^{-}\right] \\
& \mathrm{pK}-\log _{10}[\mathrm{HA}]=\mathrm{pH}-\log _{10}\left(\mathrm{~A}^{-}\right)
\end{aligned}
$$

therefore $\quad \mathrm{pH}=\mathrm{pK}+\log _{10} \frac{[A-]}{[H A]}$

The Henderson Hasselbalch equation is shown in graphical form in figure 1.2 


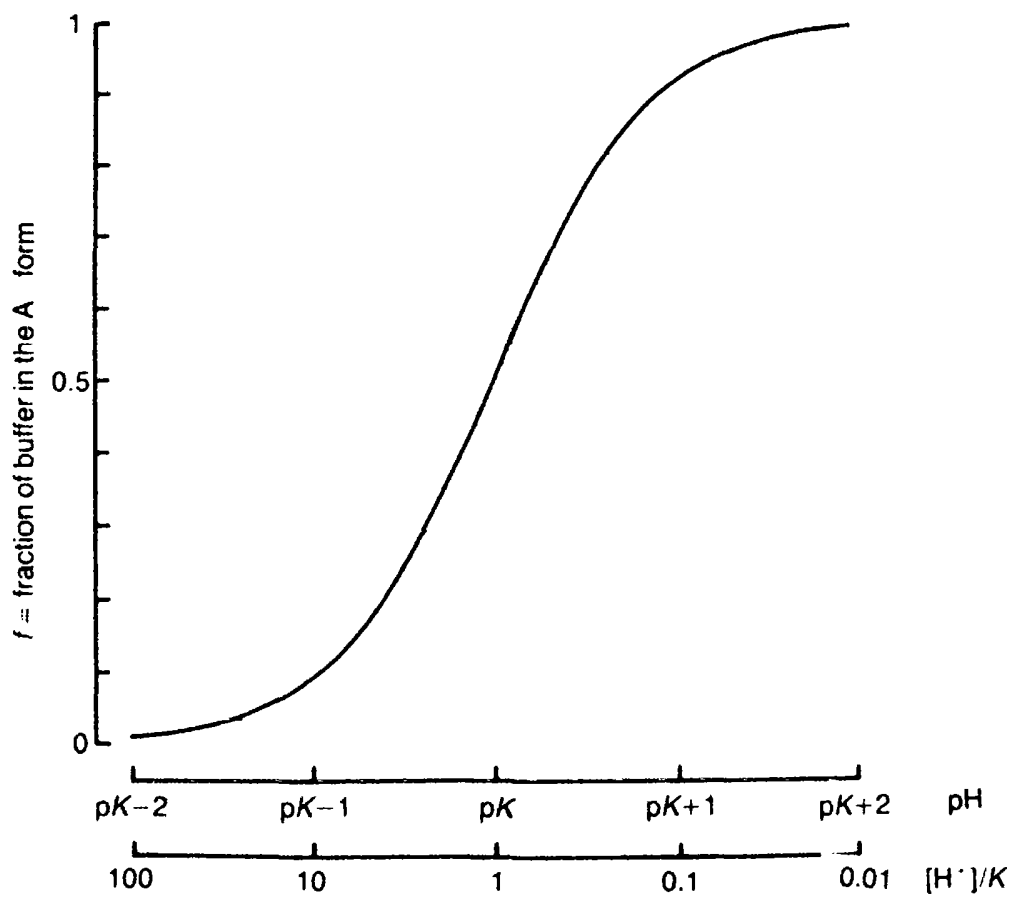

Figure 1.2 The Henderson- Hasselbalch equation represented in graphical form The fraction of the buffer solution in the basic form is plotted against $\mathrm{pH}$. (From Atwell 1986) 


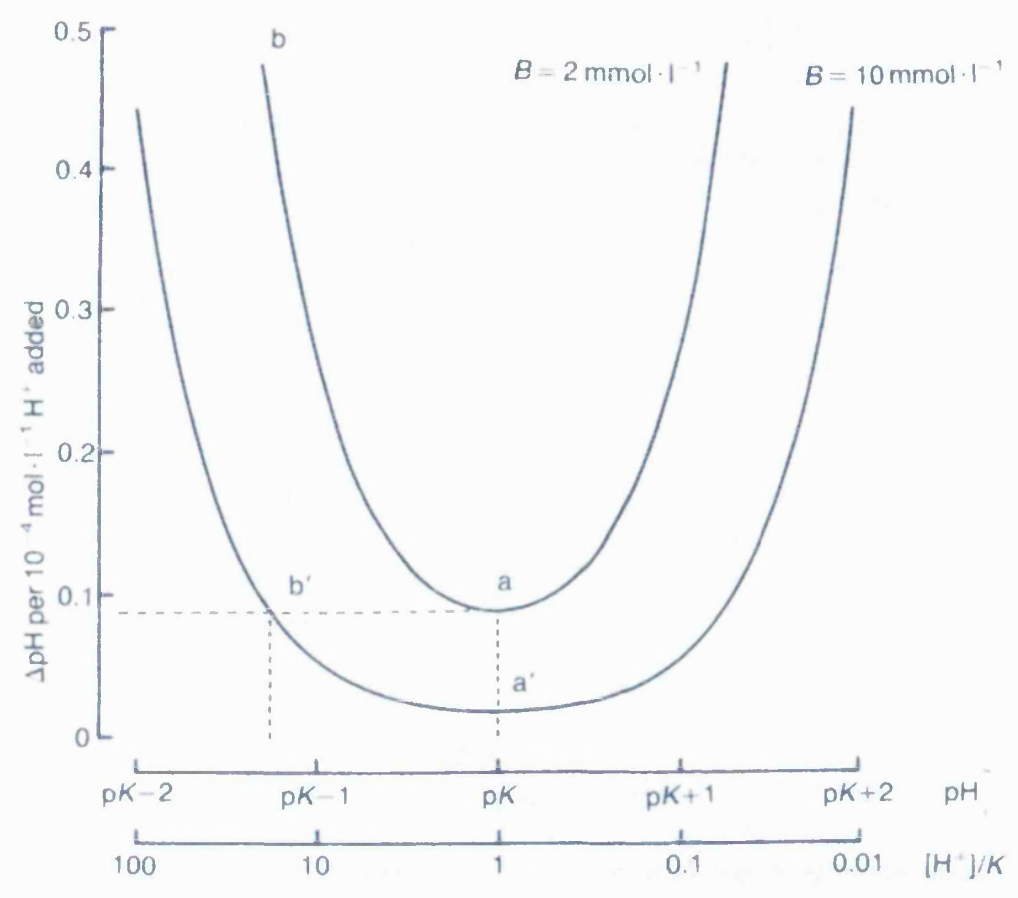

Figure 1.3- The effectiveness of buffer solutions. (From Atwell 1986)

Figure 1.3 shows the relationship between power of the buffer and $\mathrm{pH}$. The power of a buffer, $\beta$ is expressed as the change in hydrogen ion concentration per unit change in $\mathrm{pH}$.

$\beta=\frac{\Delta[H+]}{\Delta p H}$.

The slopes are flattest when the $\mathrm{pH}$ value is closest to the $\mathrm{pK}$. At this point, relatively large amounts of $\mathrm{H}^{+}$ions can be added with relatively little change in $\mathrm{pH}$.

The main buffers in blood can be divided into those in plasma and those in red blood cells. Those in plasma are bicarbonate, inorganic phosphate, and weak acids and bases on protein. Those in red cells are haemoglobin, bicarbonate and inorganic and organic phosphate. The main buffers in the urine are inorganic 
phosphate, ammonia, and bicarbonate. The pK value for $\mathrm{HPO}_{4}{ }^{2-} / \mathrm{H}_{2} \mathrm{PO}_{4}{ }^{-}$ (inorganic phosphate system) is 6.8 , and the effective $\mathrm{pK}$ for the bicarbonate system is 6.1. However the $\mathrm{pK}$ for ammoniagenesis is 9.3 . Therefore, in urine, with normally a much lower $\mathrm{pH}$, ammonia acts not really as a buffer but rather as a $\mathrm{H}^{+}$absorber.

The kidneys have enormous capacity for regulation of acid base balance, by varying the amount of $\mathrm{H}^{+}$that they excrete in the distal tubule, and $\mathrm{HCO}^{-}$that they resorb from the proximal tubule. The urine can itself therefore be subject to vast changes in $\mathrm{pH}$. The $\mathrm{pH}$ of the urine may vary from $\mathrm{pH} 4$ to $\mathrm{pH} 9$ (Georgopoulos et al 1996). The $\mathrm{PCO}_{2}$ of urine varies greatly, because of the fixed acids excreted (Pitts et al 1949, Hong et al 1960), and $\mathrm{CO}_{2}$ diffuses easily across the bladder membrane. Bicarbonate does not cross the bladder membrane readily, although in certain circumstances of bladder damage it seems likely that urinary constituents have greater access to the muscle. These are discussed in the section on permeability (1.5). It is unclear to what extent the urinary $\mathrm{pH}$ affects the $\mathrm{pH}$ of the fluid surrounding the detrusor muscle itself in normal circumstances.

Studies of cardiac muscle have shown the importance of $\mathrm{pH}$ changes in the contractile mechanism (Orchard et al 1990). Contractility of other smooth muscle has also been shown to be dependent on $\mathrm{pH}$. Vascular smooth muscle has been studied extensively (Austin and Wray, 1993, 2000), and its contractile mechanism is sensitive to changes in both intracellular and extracellular $\mathrm{pH}$. Uvelius et al (1990) used a rat detrusor muscle in vitro model to examine the effect of extracellular $\mathrm{pH}$ variation on spontaneous contractile activity and 
response to nerve stimulation. The $\mathrm{pH}$ variation was achieved by changes to the bicarbonate concentration of the bathing solution, and all solutions were gassed through with $96 \% \mathrm{O}_{2}$ and $4 \% \mathrm{CO}_{2}$. At physiological $\mathrm{pH} 7.4$ a continuous low amplitude activity was seen, and at extracellular acidosis pH 6.75 the contractions became more regular with periods of relaxation between the contractions. The contractions increased in amplitude at this $\mathrm{pH}$. At extracellular alkalosis $\mathrm{pH} 7.85$ there was a slight inhibition of contractile activity - the frequency was lower but the amplitude similar to that at $\mathrm{pH} 7.4$. The force output was therefore essentially unchanged with these $\mathrm{pH}$ variations. The contractile response to carbachol was unchanged at a lowered $\mathrm{pH}$, which led the authors to conclude that the effect of lowered extracellular $\mathrm{pH}$ acts at a pre junctional, rather than at a muscular level (even though the spontaneous contractions were altered).

Liston et al (1991) examined the effect of changes to the $\mathrm{pH}$ on detrusor muscle function in vitro. They used a preparation of isolated ferret and human detrusor cells, and measured intracellular $\mathrm{pH}$ and extracellular $\mathrm{pH}$ separately. They measured intracellular $\mathrm{pH}$ by epifluorescence microscopy. The intracellular $\mathrm{pH}$ was modified by changing the $\mathrm{PCO}_{2}$ of the superfusate $\left(\right.$ as $\mathrm{CO}_{2}$ diffuses across the cell membrane), whereas the extracellular $\mathrm{pH}$ was modified by changing the bicarbonate $\left(\mathrm{HCO}_{3}{ }^{-}\right)$ion concentration (which does not readily cross into the cell). The effects seen were different: intracellular acidosis increased the phasic contraction, but extracellular acidosis decreased contraction. Tonic ('resting') tension was decreased by both intracellular and extracellular acidosis. The effect of extracellular acidosis on depressing detrusor function was not seen in ureteric muscle (Fry et al 1990). The differences between this study and that of 
Uvelius et al (1990) could be explained partly by the technique and measurement-each distinguished in a different way between contractures and contractions. The Uvelius study was not designed to differentiate between intracellular and extracellular $\mathrm{pH}$ changes.

The mechanism for the effects of extracellular $\mathrm{pH}$ is likely to be via changes to the $\mathrm{Ca}^{2+}$ influx. Extracellular acidosis decreases the magnitude of $\mathrm{Ca}^{2+}$ influx through L-type $\mathrm{Ca}^{2+}$ channels and therefore decreases contraction (Wu and Fry 1998). Intracellular acidosis however may act in a different way.

There are several possible explanations. The myofibrils may be more sensitive to $\mathrm{Ca}^{2+}$ in an acid environment. The same laboratory (Wu et al 1995) examined the sensitivity of myofibrils to $\mathrm{Ca}^{2+}$ concentrations at various $\mathrm{pH}$ values. They concluded that an increased sensitivity to $\mathrm{Ca}^{2+}$ ions in an acid environment was not the explanation for the positively inotropic effect of this condition, but might be responsible partly for the negatively inotropic effect of intracellular alkalosis. There are other possible mechanisms to invoke an increased $\mathrm{Ca}^{2+}$ in intracellular acidosis- raised intracellular $\mathrm{H}^{+}$could in turn increase the intracellular $\mathrm{Na}^{+}$via $\mathrm{Na}^{+} / \mathrm{H}^{+}$exchange, and then via a separate $\mathrm{Na}^{+} / \mathrm{Ca}^{2+}$ exchange increase the intracellular $\mathrm{Ca}^{2+}$, and thus the force of contraction. The other possibility is that because of decreased resting tension, the constant release of small amounts of intracellular $\mathrm{Ca}^{2+}$ from the sarcoplasmic reticulum is decreased, and therefore that when a contraction does occur, the intracellular $\mathrm{Ca}^{2+}$ is relatively preserved thus the magnitude of the increase is high and the contraction of higher force (Liston et al 1991). It has been shown (Wu and Fry 1998) that intracellular acidosis results in enhanced uptake of $\mathrm{Ca}^{2+}$ into the intracellular stores as a result of this raised resting $\left[\mathrm{Ca}^{2+}\right]_{i}\left(\right.$ intracellular $\mathrm{Ca}^{2+}$ ) 
The relevance of these findings to bladder function in vivo is not yet clear. Hohlbrugger and Lentsch (1985) used an anaesthetised rat preparation to study the volume pressure response in the bladder. They instilled a variety of different solutions into the bladder, and re-examined after dimethyl sulfoxide (DMSO) exposure (to produce an experimental cystitis). This substance is discussed further in section 1.5 , and in this case was used to induce an inflammatory state. They found that the bladder capacity was decreased by pH5 intravesical solution and increased by $\mathrm{pH} 8$ intravesical contents. These effects were exaggerated by DMSO exposure, which increases the permeability of the bladder (Hohlbrugger et al 1985), and thus increases the access of the urine constituents to the bladder nerves and muscle. This study also examined the effects of osmolality and $\mathrm{K}^{+}$concentrations in the bladder contents, and these will be discussed in other sections.

The most clinically relevant of published work in this area is that of Sethia and Smith (1987). The authors investigated the clinical observation that alkalinisation of the urine causes an improvement in symptoms of overactive bladder. They were investigating the effect of local anaesthetics on the bladderthese had previously been noted to increase bladder capacity in the overactive bladder (Bors 1958). Sethia and Smith used an alkali medium to instil lignocaine into the bladder to improve its absorption. They used two separate controls- firstly an alkaline medium (50 mM Sodium Bicarbonate solution) without lignocaine and secondly normal saline. they performed three cystometrograms on each of 58 patients ( 42 with detrusor instability, 8 with 'low compliance' and 8 with normal bladders). The alkali medium used was 50 $\mathrm{mM}$ sodium bicarbonate solution either with or without $5 \mathrm{mM}$ lignocaine and its 
$\mathrm{pH}$ was 8.5. The instilled solution was therefore not controlled for osmolality. A 15 minute gap was left between the fills, which were always in the same order (saline, bicarbonate, lignocaine in bicarbonate). They showed an increase in bladder capacity in low compliance and unstable patients when the $\mathrm{pH}$ was 8.5 compared to normal saline. The lignocaine fills resulted in a fall in bladder capacity to around that of the saline fill. This was significant only in unstable and low compliance groups, and more marked in those with bladder outflow obstruction. Details of numbers in the subgroups of obstructed and unobstructed are not given. It must be emphasized that their findings were identified on a sub-analysis, not planned in the original protocol, and therefore there is a considerable risk of a Type I error. To be less uncertain it is necessary to repeat the experiment testing the secondary hypothesis, ie that an alkali medium changes urodynamic results (rather than to look at the alkalinity incidentally). It would be appropriate to do so with a crossover study in order to analyse the effects separately. However, the work is important in that it attempted to evaluate scientifically, in a clinical setting, the effects of changes in local intravesical environment on the bladder. 


\subsection{The influence of osmolality on detrusor function}

The osmolality of urine can vary greatly depending on the need for excretion of water and solutes. It is a common observation that the voided volumes of a high osmolality ('dark coloured') urine are smaller than those of more dilute urine (Hohlbrugger 1997). Investigators have looked at the influence of osmolality on muscle, both in vivo and in vitro. Uvelius (1985) used strips of rat detrusor muscle and studied their spontaneous activity and response to nerve stimulation. He varied the superfusate solution, using hyperosmolal (390 and $590 \mathrm{mosm} / \mathrm{kg}$ ) and hypoosmolal $(260 \mathrm{mosm} / \mathrm{kg})$ solutions, as well as an isoosmolal $(290 \mathrm{mosm} / \mathrm{kg})$ control. In the hyperosmolal solutions, the spontaneous contractions were decreased in frequency $(390 \mathrm{mosm} / \mathrm{kg}$ ) or absent $(590$ $\operatorname{mosm} / \mathrm{kg}$ ) and the nerve induced contraction was increased in amplitude $(390 \mathrm{mosm} / \mathrm{kg})$ or became a tetanic contraction $(590 \mathrm{mosm} / \mathrm{kg})$. The mildly hypoosmolal solution $(260 \mathrm{mosm} / \mathrm{kg})$ had no significant effect on either spontaneous or nerve induced contractions. Uvelius commented "whereas osmolar variations are an important regulator of smooth muscle tone and one would therefore expect vascular smooth muscle to be sensitive to these changes, it is a surprise that detrusor muscle has not developed adaptive mechanisms to protect itself from these variations in its microenvironment". Hohlbrugger has developed the chemical and teleological arguments further. He used the rat bladder volume-pressure response to look at the response of detrusor muscle to intravesical ions, $\mathrm{pH}$ and various osmolalities of solution (Hohlbrugger and Lentsch 1985). They used different sequences of solution fills, and left the solution in the bladder for 20 minutes before testing the volume pressure curve. They found that hyperosmolar contents $(700 \mathrm{mmol} / 1$ 
$\mathrm{NaCl})$ decreased the bladder capacity and that hypoosmolar contents $(70 \mathrm{mmol} / 1$ $\mathrm{NaCl}$ ) increased the bladder capacity. This effect was greater after chemical cystitis had been induced with DMSO. This substance is discussed further in section 1.5. Hohlbrugger also examined permeability of normal rat bladder to hypoosmolar and hyperosmolar sodium chloride solutions at various stages of filling (Hohlbrugger 1987). He developed a theory that urinary urgency and frequency are linked to increased access of bladder contents to the detrusor muscle, especially in diseased bladders with increased permeability. 


\subsection{The influence of potassium on detrusor function}

Potassium is an important ion involved in smooth muscle contraction. There is an inward flux of $\mathrm{Ca}^{2+}$ during the rising phase of the action potential, and during the descending phase of the spike the $\mathrm{Ca}^{2+}$ influx stops and there is an outward shift of $\mathrm{K}^{+}$that is partly dependant on intracellular $\mathrm{Ca}^{2+}$ (Brading 1987). Thus, calcium channel blockers and potassium channel openers have some activity stabilising bladder muscle i.e. reducing the force of contraction. (Zimmern et al 1996). High levels of potassium in the sub epithelial space could lead to sensory nerve triggering and thus muscle depolarisation in this way. This was hypothesised by Parsons et al (1998). As the $\left[\mathrm{K}^{+}\right]$(potassium ion concentration) in normal urine can be up to ten times the concentration in the blood plasma, it could also be presumed that contact of urine directly with detrusor muscle could cause immediate depolarisation and contraction.

Potassium ions are central to Hohlbrugger's theories about the overactive bladder. His earlier work showed that in a rat whole bladder model, the capacity was decreased by high intravesical $\left[\mathrm{K}^{+}\right]$, and that this, like the other manipulations that decreased capacity, was more pronounced after experimental cystitis by Dimethyl sulphuxide (DMSO) exposure (Hohlbrugger and Lentsch 1985). He also has shown by blood flow measurements in asymptomatic individuals during comparative cystometry, that the intravesical $\left[\mathrm{K}^{+}\right]$increases the muscle blood flow, as assessed by doppler methods (Hohlbrugger et al 1999). These two results supported his hypothesis that potassium lies at the centre of physiological and pathological control of the bladder (Hohlbrugger 1999). 
He believed that during distension of the bladder, the structural elements to control the permeability of the urothelium become less effective. Thus, in order to maintain a normal extracellular environment around the detrusor muscle, a submucosal circulation occurs, through an arteriovenous counter current mechanism. This allows 'equilibration between the urine and suburothelial tissues on the one hand and prevents recirculation of waste on the other'. The increase in blood flow associated with increased intravesical potassium observed experimentally reduces the efficiency of the counter current mechanism (which requires low blood flow). However it increases the lumen directed filtration pressure, leading to more washout of reabsorbed potassium ions and better maintenance of the detrusor environment and better stability of the muscle.

In disease states associated with increased permeability, Hohlbrugger wrote that 'the principle of survival overrides bladder control' (Hohlbrugger 1999). The increase of permeability with normal blood flow would lead to loss of blood homeostasis, and disturbance to the whole organism. Thus, increased permeability must be accompanied by relative ischaemia. This ischaemia reduces the efficiency of the counter-current mechanism, and thus leads to the exposure of detrusor muscle to potassium ions leading to the subsequent bladder contraction and also pain secondary to activation of $\mathrm{C}$ fibres and A- $\delta$ fibres. This contraction results in a smaller bladder volume and less surface area of diseased (increased permeability) bladder, thus less recirculation of renal waste and therefore less threat to the organism as a whole.

These theories are attractive in their coherence, and give a possibility of a pathophysiological 'reason' for urgency and frequency, which are such 
troubling symptoms in many bladder diseases. However, whilst they are very broadly supported by some of the available evidence, the details are less easy to prove. It could be argued that his pursuit of an overriding theory and a need to give reasons for the symptoms has come at the cost of scientific detail to support it. It does seem clear, however that we can no longer view the bladder as an impermeable organ. 


\subsection{Permeability of the bladder}

The bladder epithelium has been viewed traditionally as a structure with low permeability of ions and small molecules (Kerr et al 1963). The maintenance of the 'blood urine barrier' and the consequences of its damage, have been the subject of investigation over the past few years. The presence of a blood-urine barrier was validated experimentally by Lewis and Diamond in 1975 . They investigated isolated rabbit bladder epithelium, and measured a high electrical resistance across the urothelium. They deduced that the high resistance represented a low magnitude of ion flux across the urothelium, which acts to maintain the osmotic and ion differences, which have been established in the kidney. Mechanical damage leads to a decreased electrical resistance and reduction in the osmotic gradient.

This 'barrier' was initially explained as being due to a combination of structural specialization and biochemical specialisation. The structural specialisation was attributed to tight junctions between the cells to protect the cytoplasm and an asymmetrical lumen membrane (Hicks et al 1974, Staehelin et al 1972). The membrane was shown on freeze etch electron microscopy to have a thicker, particulate luminal leaflet and a thinner cytoplasmic one (Staehelin 1972). However, this appearance was not seen throughout the surface that is in contact with the urine, and the work of Eldrup et al (1983) suggests that the tight junctions are more clinically important, as they appear to be structurally deficient in patients with diseases associated with a leaky epithelium such as bladder tumours and interstitial cystitis.

The membrane is also biochemically asymmetrical, as it has different ion transport mechanisms on either side of the cells. Amiloride- sensitive epithelial 
$\mathrm{Na}$ Channels (ENaC's) are channels which allow sodium to enter the cell from the outside, and are situated on the luminal membrane only, whereas the less specialised $\mathrm{Na}^{+} / \mathrm{K}^{+}$ATPase channels only on the non luminal surface of the epithelial cells (Garty and Palmer 1997).

There was also thought to be a degree of biochemical specialization with a mucin layer outside the membrane made up of glycosaminoglycans (GAG layer) (Parsons and Mulholland 1978). This layer was thought to be highly negatively charged and to repel bacterial adherence and membrane-penetration of some substances (Parsons et al 1977, Parsons et al 1990). However the nature and function of the GAG layer has more recently been put in doubt: The staining for GAG may have highlighted intracellular epithelial mucinous material, rather than a separate extracellular layer (Grist and Chakraboty 1994), and it is likely that experiments which claimed to selectively remove the GAG layer, actually destroyed the epithelial cells (Elbadawi 1997).

The integrity of the epithelial barrier can however be compromised in some clinical circumstances in which increased permeability may be important. These include interstitial cystitis, overdistension and obstruction, and infective, haemorrhagic and radiation cystitis. Experimental models for damage include obstruction, overdistension, and experimental cystitis with dimethyl sulfoxide (DMSO), or xylene and E Coli (Hohlbrugger et al 1985). Dimethyl sulfoxide (DMSO) is a substance which has also been used to treat interstitial cystitis (Peeker et al 2000), as well as eosinophilic cystitis (Silbert et al 2000) and primary amyloidosis of the bladder (Malek et al 2002). It probably acts to first stimulate the $\mathrm{c}$ fibre afferents and then to desensetise the afferent nociceptive pathways (Birder et al 1997). Whilst inducing inflammation the substance 
stimulates Nitric Oxide release from these cells (Evans et al 1993) which it is hypothesised could be the initial event in nociceptive desensetisation Much of the discussion in the literature on permeability involves interstitial cystitis. Although this has little direct relevance to my work, I have gone into some detail on the entity of interstitial cystitis and the conclusions that have been drawn from this work on permeability in general.

The pathophysiology of interstitial cystitis remains an area of controversy. The disease is characterised by irritative voiding symptoms and pain. These are accompanied by characteristic, but not pathognomonic features at cystoscopy. The diagnosis is essentially one of exclusion, with no specific or clear criteria (Elbadawi 1997). The aetiology was thought, 10-20 years ago, to be that of a deficient GAG layer causing a leaky epithelium and consequent inflammatory change, with symptoms due to increased access of urinary constituents to the muscle (Parsons et al 1983). More recent work suggests a multifactorial aetiology, with mast cell activation mediating a sensory nerve excitation via release of neuropeptides (Theoharides et al 1998, Elbadawi 1997). It is no longer reasonable to propose interstitial cystitis as a pure model for an absent GAG layer causing a leaky epithelium.

The GAG layer deficiency in interstitial cystitis has not been proved ultrastructurally (Nickel et al 1993), although there may be a subtle chemical difference in the glycoprotein component (Moskowitz et al 1994). Eldrup et al (1983) found leaky tight junctions on elctron microscopy of bladder tissue from patients with interstitial cystitis. The permeability in vivo of bladder to DTPA (diethylene-triamine-pentaactic-acid) was measured directly by Chelsky et al (1994), and whilst they did find a large variability in permeability between 
individuals, they found no difference between those with interstitial cystitis and normal subjects. Permeability however, is also dependent on blood flow, and Hohlbrugger (1993), suggested that mucosal ischaemia, which has been postulated to be one of the features of interstitial cystitis, may complicate the measurement of permeability.

The blood flow in the bladder wall during filling has been subject to some debate. It has generally been believed that blood flow decreases during filling, and this has been supported by animal studies (Greenland and Brading 1996, Azadzoi et al 1996).

However, two human studies have suggested that this may not be the usual case. Irwin and Galloway in 1993 studied bladder blood flow using laser Doppler flowmetry. They studied 16 patients with interstitial cystitis and 18 as a control group (actually referred for cystoscopy for a variety of other urinary symptoms). They found that in 'normal' patients the blood flow increased very substantially during filling, but only marginally in interstitial cystitis patients. The bladder capacity under general anaesthesia was lower in interstitial cystitis patients than 'normals (means of 562 and $828 \mathrm{mls}$ respectively) They infer from this that some of the pain of interstitial cystitis could be ischaemic in origin, and that ischaemia itself could either be an aetiological factor or a consequence of disease in interstitial cystitis. Pontari et al (1999) also measured blood flow via Doppler flowmetry and showed that blood flow increased during filling in 30 normal controls and decreased during filling in 43 interstitial cystitis patients. This supported Irwin and Galloway's findings. Both these studies used a similar Doppler flow probe applied lightly to the bladder wall, and left until movement artefact was absent. 
A single study with a different method, by Batista et al (1996) suggested an overall decrease in bladder blood flow during filling. Batista et al looked at 18 patients ( 8 open surgical and 10 endoscopic) with a variety of diseases, predominantly cancer of the prostate for the open cases and benign postatic hyperplasia (BPH) for the endoscopic cases. They used a Doppler laser probe, which they implanted into the bladder wall. This was likely to measure only muscle blood flow, but could do so continuously. They argued that when Pontari et al (1999), and Irwin and Galloway (1993) used the endoscopic laser Doppler probe as it was only lightly applied, it probably measured mucosal blood flow as well.

Pontari unifies the work, and interprets the differences as suggesting an initial increase in mucosal blood flow during filling rather than muscle blood flow. This would allow energy for the mucosal functions such as antibacterial adherence and impermeability, which would otherwise have been compromised by further distension (as shown in Ruggieri et al 1986).

Parsons et al (1998) have suggested that urinary potassium may be an important factor in the pathogenesis of interstitial cystitis. They hypothesised that potassium ions from the urine diffuse through an abnormal epithelium and cause a cascade of events which results in sensory nerve activation and muscle depolarisation, thus causing urgency and instability. They then used a potassium instillate $(0.4 \mathrm{M} \mathrm{KCl})$ or controls with water or sodium $(0.4 \mathrm{M} \mathrm{NaCl})$. They observed symptoms of pain and urgency following instillation of the potassium. They found sensitivity to the potassium solution in $75 \%$ of the patients with interstitial cystitis (231 subjects). and in only $4 \%$ of the 41 controls. The small numbers in the study with other diseases ( subgroups of radiation cystitis, acute 
and chronic infections, detrusor instability, and $\mathrm{BPH}$ ) make comment difficult. However, the test has not stood up well to further scientific analysis. The use of intravesical potassium as a diagnostic test for interstitial cystitis was assessed by Chambers et al (1999). They used it blinded in 39 patients and found a poor sensitivity of $69.5 \%$ and specificity of $50 \%$ when used against NIH criteria. It is not now used widely in clinical practice. 


\subsection{The sensory function of the urothelium}

The urothelium has sensory functions which are likely to become more closely understood as research continues to examine this role. As yet, this is a relatively under researched field and there are many unresolved questions (Ferguson 1999). The bladder itself is innervated by 2 types of afferent nerve and possibly more. Gabella and Davis (1998) have shown very extensive afferent innervation of the epithelium, blood vessels and muscle bundles. The A delta fibres are mechanoceptive and are activated by both low and high intravesical pressures. The C fibres are sensitive to cold or to chemical irritation of the bladder, but can also be involved in micturition if other mechanisms are damaged. However, both Nitric Oxide (NO) and Adenosine Triphosphate (ATP) are released by the urothelium in response to stress, and their roles as well as those of the 'classical' sensory nerves are now under scrutiny.

Ferguson et al (1997) investigated possible sensory transduction mechanisms in the bladder. He examined the electrical potential difference across the bladder urothelium in a Ussing chamber. He showed that the epithelial cells had sodium channels (ENaCs, as discussed in the previous section) which open when the epithelium is moved in one direction, but not in the other. ATP is likely to be the mediator, stimulating sensory nerves, but the cellular mechanism for its release is not clear. This all suggested a sensory role, mediating the degree of distension. Pandita and Andersson (2002) have shown that intravesical ATP can induce bladder overactivity in rats, presumably by stimulating $\mathrm{C}$ fibres, and suggesting a superficial mechanism. This mechanism is also adapted to change its function dependant on urinary composition. Thus the membrane can remove and reinsert amiloride sensitive sodium channels within a 15 minute period 
(Ferguson 1999), removing in the presence of high sodium concentrations, and reinserting if the sodium concentration falls.

There is indirect evidence that nitric oxide may be involved in regulation of afferent nerves in the bladder- as the nitric oxide scavenger, oxyhaemoglobin, induces bladder overactivity when given intravesically (Pandita et al 2000). Oxyhaemoglobin does not cross the urothelium, and therefore must have interfered with nitric oxide activity very superficially. It has been argued that the sensory function of the urothelium has major implications on bladder function in health and disease. It is likely to have impact on the development of future pharmacological therapies. 


\subsection{Summary}

From the published work described above, several questions are raised. It is clear that in various preparations, bladder shows changes in its contractile and sensory behaviour, which are dependant on its biochemical environment. It is also clear that there are certain circumstances in which the constituents of the urine have greater access to the bladder muscle itself. The question arising is whether the behaviour of the whole bladder can be affected to a clinically important degree by similar changes in the urine or intravesical environment. If it could be, then there would follow questions about the validity of clinical assessment of bladder function by urodynamic testing, which uses a standard intravesical environment, that may contrast greatly to the urine environment at the time when symptoms are present. In attempting to address the questions above, the experiments performed in the present study use the urodynamic test itself to assess bladder function. In the next section, I will discuss the urodynamic test itself to give further background to the design of the study. 


\section{INTRODUCTION- PART 2 THE URODYNAMIC TEST}

\subsection{History and development of urodynamic science}

Bladder pressures have been measured since the $19^{\text {th }}$ century, and equipment and interpretation have progressed in the early part of the $20^{\text {th }}$ century (Rose 1927, Rose 1936). However, urinary flow has only been measured since 1956 when van Garrelts designed equipment with a pressure transducer to measure urinary flow rates, by deriving volume measured against time. Other workers soon studied flow rates and bladder pressures together and this informed definitions of obstructed and unobstructed voiding. (Claridge 1966). This made an important link was made between observations and clinical situations. The developments since then to create the modern science of urodynamics have been both technical ones and those of interpretation. The underlying aim is to interpret results of urodynamics in terms of disease and relate this to pathophysiology. Abrams (1997) observed that the technique of urodynamics has basically remained unchanged throughout the 1980s and 1990s. However the interpretation continues to change as more is known about bladder pathophysiology and disease patterns. 


\subsection{The mechanics of bladder contraction}

It is useful to discuss the mechanics of bladder contraction as it affects these experiments.

Pressure in the bladder is the average force per unit area imposed on the bladder wall, assuming that it is a thin-walled sphere. When the bladder contracts, it generates a wall tension, $\mathrm{T}$, tangential to the circumference of the organ (radius R). This tension, in turn, generates a luminal pressure. If the bladder is treated as a thin-walled sphere, then the relationship between pressure $\left(\mathrm{P}_{\mathrm{det}}\right)$ and wall tension can be expressed as $P_{\text {det }}=T /\left(\pi R^{2}\right)$

As pressure is force per unit area, $F=P d e t \pi R^{2}$

The volume of the sphere $V=4 / 3 \pi R^{3}$

This means that the pressure is inversely related to the bladder area. Hence the same wall tension at lower volumes will generate higher pressures than that at higher volumes. This relationship is described in the the law of Laplace which can be summarised as $\mathrm{P}=\frac{2 T}{R}$

Thus, the relationship between pressure and tension can be plotted. Figure 2.1 shows this relationship graphically (James Malone-Lee, personal communication). It demonstrates two curves, the first being the pressure plotted against volume, the second the tension against volume for a spherical thinwalled bladder. The pressure in this figure is the resultant of a tension which would generate a pressure of $15 \mathrm{~cm} \mathrm{H}_{2} \mathrm{O}$ at $100 \mathrm{ml}$ volume. The tension is that required to generate a pressure of $15 \mathrm{~cm} \mathrm{H}_{2} \mathrm{O}$ at each volume. A constant tension will generate very different pressures dependant on the bladder volume. This implies that pressure is an insensitive measure of the contractile activity in the detrusor, and that sensation may be more informative. 


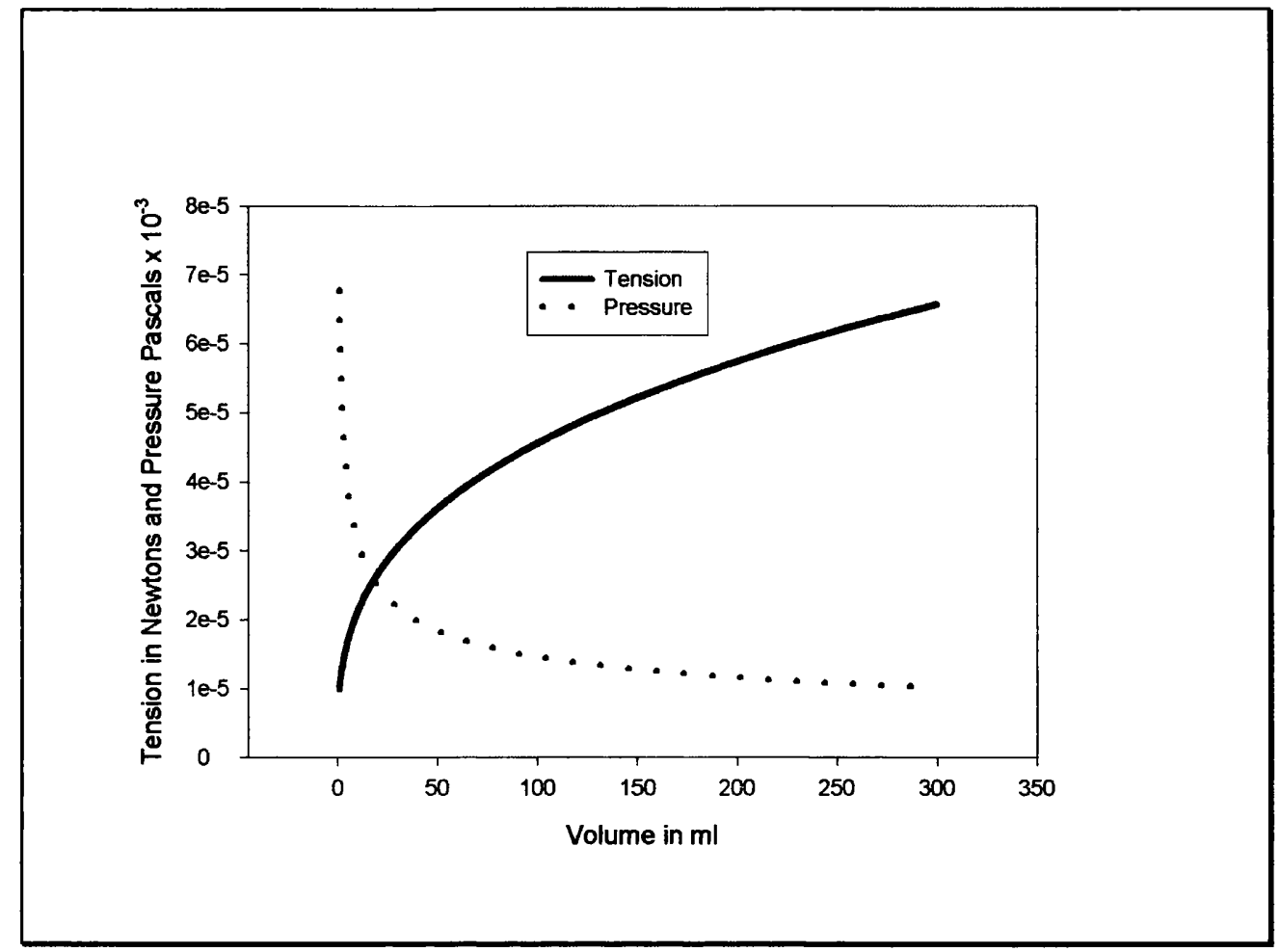

Figure 2.1- The relationship between pressure and tension against volume The pressure is in Pascals $\left(\times 10^{-3}\right)$ and equivalent to $15 \mathrm{~cm} \mathrm{H}_{2} \mathrm{O}$. The tension is in Newtons and would give a pressure of $15 \mathrm{CmH}_{2} \mathrm{O}$ at $100 \mathrm{ml}$ volume 
Detrusor overactivity is described by International Continence Society criteria as a urodynamic observation characterised by involuntary detrusor contractions during the filling phase which may be spontaneous or provoked (Abrams et al 2002). The term detrusor overactivity, does not imply causality, but can be split into idiopathic detrusor overactivity and neurogenic detrusor overactivity. The main symptoms associated with this are those of urgency, frequency and nocturia, which are described as the overactive bladder syndrome, urge syndrome, or urge frequency syndrome Urgency is an important symptom in describing the overactive bladder. Urgency is defined by the International Continence Society (ICS) as the complaint of a sudden compelling desire to void urine which is difficult to defer (Abrams et al 2002). This is presumed to represent changes in tension in the muscle wall. The overactive bladder responds to anticholinergic medications, which work at the neuromuscular junction- this is presumed to be a motor effect. Studies looking at the response to anticholinergics show an effect on bladder capacity and sensory function, not unstable contractions (Jonas et al 1997). It is clear from the discussion above that there can be a significant change in tension without necessarily a large change in pressure in the fluid in the bladder (therefore not easily detectable on cystometrogram). This is why the description of symptoms during urodynamics is critical to the study. We will see later that these symptoms and sensations are reproducible in repeat studies.

From the 1970s, most clinical trials of anticholinergic treatments excluded people with symptoms of instability but no proven detrusor overactivity on urodynamics (eg Suigos et al 1977, Thuroff et al 1991, Rentzhog et al 1998). These patients were classified as having sensory urgency and treatment of them 
has been controversial. In some more recent work, these patients have been included in large clinical trials for instability (Malone-Lee et al $2001 \mathrm{a}$ and b). These trials recruited by symptoms and did not use urodynamic criteria for diagnosis. They therefore included by default some patients who would have had negative urodynamics. The patients on treatment had a significant response above that of the placebo group and this was similar to the magnitude of the response of other trials. It might therefore be assumed that the group with negative urodynamics, but symptoms of instability have similar characteristics to those with urodynamically proven overactivity.

Thus the notion that urodynamics is an investigation which rigorously defines disease is open to question.

Some of the newer techniques of urodynamics have been evaluated in comparison to the standard techniques- for example, gas cystometry and ambulatory urodynamics. I will first describe these studies, and then examine the published work on the repeatability of the study. 


\subsection{Gas cystometry}

Gas cystometry was developed in the 1970s in USA. It had the advantage of being relatively free of mess and easier to perform in an 'office' setting. The obvious disadvantage is that the medium used is unphysiological. This criticism has lead to some evaluations made comparing the newer technique to standard saline cystometry.

Wein et al (1978) looked at the reproducibility of the technique, studying 20 men for day to day variability (on 2 consecutive days) and 5 men additionally at $60,90,120,180$ and 240 minutes. All studies were with carbon dioxide. They found that there was a consistent decrease in cystometric capacity on day 2 , and a similar decrease on repeated same day fills. They found a variability of $30 \%$ with repeated gas fills. Torrens 1977 compared carbon dioxide cystometry to standard water cystometry by repeated fills of the same patient with both media. He found that gas cystometry with carbon dioxide underestimated the cystometric capacity by $20 \%$ compared with the saline fill. His interpretation was that as carbon dioxide is highly soluble in water, it would create an acid milieu, and would be irritating to the patient, producing more instability. Godec and Cass (1979) examined the difference that the rate of fill made in gas cystometry in 72 patients. They found that capacity with slow fill gas cystometry was on average smaller than with fast fill gas cystometry. They also found that the diagnosis of hyperreflexia was more often made with slow fill cystometry. This was the reverse of the expectation that some hyperreflexia would be an 'artefact' of rapid fills. The range of filling rates for the slow fill was very broad in this study $(10-70 \mathrm{ml} / \mathrm{min}$ for adults), and the population was a heterogeneous one. It is therefore possible that higher $\mathrm{CO}_{2}$ infusion rates 
inhibit overactivity, at the same time as irritating the mucosa by combining with water to produce carbonic acid (Abrams 1997).

Drutz et al (1981) examined two different methods of gas fill cystometrycatheter fill gas cystometry and retrograde urethrocystometry via a 0 urethroscope. They studied repeated consecutive fills with the different techniques, and examined 26 female patients in one order, then the next 26 in reverse order. They found no significant difference at the $10 \%$ significance level, but found that the second fill, whatever technique used, produced more uninhibited contractions. They used carbon dioxide on both fills, and did not compare different filling media.

Gas cystometry is now seldom performed, and the published work demonstrates the difficulties in interpretation of urodynamic studies with different media or repeated fills. 


\subsection{Ambulatory urodynamics}

Ambulatory urodynamics was developed in the late 1980 s to allow patients to reproduce the circumstances and activities that produce incontinence. There were also expectations that in this more ' natural' filling of the bladder, results may be more meaningful. However, there has been some controversy in interpretation of results of ambulatory urodynamics, and when compared directly with conventional studies, there are some interesting differences in the results of two techniques.

The aim of urodynamics is to find a pathophysiological explanation for symptoms, and when conventional studies fail to provide this, many centres go on to use ambulatory studies. Hence, a large group are identified with symptoms and negative conventional cystometry, but positive ambulatory urodynamics. It is not clear however, how these individuals differ from those without symptoms but with the same urodynamic characteristics. Van Waalwijk van Doorn (1992) recruited 50 healthy female volunteers and excluded those with lower urinary tract symptoms. They performed conventional and ambulatory urodynamics on 36 of them, and found instability in $18 \%$ on conventional testing and $69 \%$ on ambulatory testing. It is argued in response to this paper (Blaivas, 1992), that the most important factor in assessment is the correlation between symptoms and urodynamic tests, and that without symptoms, instability on testing has no significance. However, if phenomena such as unstable contractions are considered insignificant in the absence of symptoms, the question remains as to how they are to be interpreted even with symptoms. 
Webb (1991) and then Robertson (1994) found differences in the voiding pressures between ambulatory and conventional urodynamics. They found higher voiding pressures in ambulatory studies than in conventional studies. This difference is not fully explained, and Robertson and his coworkers (Robertson et al 1996) tested the hypothesis that the ambulatory studies may be more reliable in the diagnosis of obstruction in men. However they did not find that ambulatory studies predicted outcome any better than conventional studies. Thus, the goal of a pathophysiological explanation for symptoms is not yet achieved.

Swithinbank et al (1999) retrospectively examined 125 ambulatory monitoring studies, and their preceding conventional cystometrograms. They found that in 79 of 125 tests (63\%), ambulatory monitoring was shown to produce findings which correlated with symptoms, and in $92 \%$ of cases it was felt to have influenced clinical management.

One area in which ambulatory studies have aided our knowledge of physiology is in the field of compliance. The term compliance is defined as the change in volume per unit change in pressure. At physiological volumes, the bladder is a very compliant organ. However, compliance is a static measure and using the standard urodynamic method there is no opportunity to measure compliance properly. The ICS in their standardisation guidance (Abrams et al 1998, and Abrams et al 2002) acknowledged this and pointed out the difficulties and variable factors involved in measuring and interpreting compliance. The real relationship between volume and pressure partly reflects the stiffness of the bladder caused by its viscoelastic properties, which can be active or passive. Finkbeiner and O'Donnell (1990) performed an in vitro study of 
detrusor response to stretch and relaxation. They confirmed that intravesical pressure ('tension') was dependent on filling rate ('stretch'). However, they also proposed that the differences seen at differing rates of stretch are caused mainly by the length rather than by the rate of fill. They also found that the rate of decrease in tension after finishing the stretch of the muscle strip was influenced by the rate of the preceding stretch.

In a comparison between ambulatory and conventional studies of healthy volunteers (Robertson et al 1991), small pressure rises were seen on conventional filling which were not replicated in the ambulatory studies. Klevmark (1974), in studies on cats, suggests that only in periods of very high diuresis could the viscoelastic properties of the bladder be activated and become significant.

"Poor compliance" has been promoted as a pathophysiological phenomenon seen in conventional studies. It may be less interpretable than is generally assumed. 


\section{$2.5 \quad$ Repeatability of urodynamics}

Many studies of pharmacology of the bladder involve serial urodynamic fills. The assumption is often made that the test is repeatable. This has been studied in some detail with emphasis on different variables.

Rose (1936) suggested that performing two cystometrograms, rather than one may lead to 'enhanced interpretation of the results'. He gives one example of a bladder in which on second filling shows greater capacity, diminished sensations, and lower pressure than the first curve. Grynderup (1966) studied 60 patients with neurogenic (uninhibited) bladders, due to presumed multiple sclerosis. In 20 patients he discontinued the initial fill at the first uninhibited contraction and then repeated it within 5 minutes. He found no difference in the capacities of the neurogenic bladder on the second fill (when both were at 50 mls/minute). However he did find that the second capacity was smaller if the rate of filling was higher in the second fill (200 mls/minute).

Cass et al (1970) examined normal bladders with repeated fills (26 patients). No note is made of any delay between fills. Slow fill ( $31 \mathrm{mls} / \mathrm{min})$ was compared to standard filling rate $(57 \mathrm{mls} / \mathrm{min})$. (Air cystometry was also compared- see section on gas cystometry). They did not find a difference based on rate of filling, either in the cystometric capacity or in the volumes at first sensation of bladder fullness.

Animal work has also been used to study repeat filling. Tang and Ruch 1955 used a spinal model, and found that repeated filling led to a reduction in capacity. Klevmark (1974 or 1977) studied neurologically intact cats and found that during the second consecutive fill the pressure at a given volume was lower. Higher filling rates were used in these experiments, and when he used 
'physiological' rates of filling in normal animals, he found the pressure increase at a given volume was similar in the repeat fill.

Much of the further work that has been done has attempted to look at the effect of both rate of filling and of repeated fills.

Sorensen et al (1984) studied repeated cystometry up to four times in 56 patients. The group were among those referred for urodynamics investigation, but those with significant residual volumes or neurogenic bladder dysfunction were excluded. They varied filling rates and orders, as well as filling positions (lying or supine). They found an increase in maximal bladder capacities from the first to the fourth fill. This was most marked when fast filling followed medium filling rates. In these cases, the mean change at the second study was around $30 \%$. They found, however, that neither filling rate alone, nor patient position affected the capacity. The test seemed to be more reproducible the higher the volumes noted at first cystometry. No note is made of delays between the fills.

Ramsden et al (1977) examined a diverse group of 100 patients referred for urodynamic investigations. These included patients with idiopathic instability, overactivity secondary to neurological disease, and normal findings on urodynamics. Repeat testing was performed, and the delay between tests is not recorded. A variety of forms of repeat test were performed- at different rates, in different positions (erect and supine). Although the total number in the study is large (395 cystometrograms on 179 occasions in 100 patients), the subgroups are small. In 14 patients with instability on the first test,(filling at $100 \mathrm{mls} / \mathrm{min}$ ), the repeat tests were at a slower rate of filling on a different occasion. These repeat tests showed no significant increase in bladder capacity, although the 
trend was towards an increased capacity with the 'physiological' fill (mean increase in capacity of $66 \mathrm{mls}$, but standard error of the mean was $45.4 \mathrm{mls})$. A smaller number of tests were repeated several times in identical conditions of filling rates $(100 \mathrm{mls} / \mathrm{min})$ and position (supine). Eight of these examinations were stable and 23 were unstable (its not clear in how many patients this was). Bladder capacity and presence or absence of instability were highly consistent and repeatable phenomena. In patients who had instability detected at some point during repeated fills, $97 \%$ were detected in an initial cystometrogram if this included elevation to erect position from supine. The main criticism of this study is the large number of subgroups of differently repeated studies, leading to less convincing conclusions because of the diversity of tests and groups. Poulsen et al (1989) examined eight men with symptoms of bladder neck obstruction and performed four cystometries on one day followed by two further cystometries eight days later. The length of delay between the two cystometries on day 8 is not documented. They used filling rates of $60 \mathrm{mls} / \mathrm{min}$ or $120 \mathrm{mls} / \mathrm{min}$ and positions of either lying or sitting. They found no differences between capacity or volume at first sensation of filling in different filling rates, positions or orders. However the numbers were small. Their conclusions are that the result is reproducible if repeated within 8 days. Jensen (1981) has studied the largest group of patients to date. He examined a group of 47 patients of whom 33 had neurogenic bladders and the other 14 had normal neurourological findings. He studied repeated filling in a variety of ways. He filled repeatedly (up to six times) either immediately or after a gap of 20 minutes. In the patients with normal bladders, he filled only five subjects repeatedly with no gap, and found capacity increased in the second fill in only 
one patient. All other capacities were identical in the first and second fills. In six normal patients he left 20 minutes between fills and found no change in capacity. All of these patients with 'normal bladders' were referred because of lower urinary tract symptoms thought to be due to neurological disease. These patients had cystometric capacities varying between 270 and $600 \mathrm{mls}$, but it is not made clear why filling was stopped at the lower values if the bladder was 'normal' (ie no contraction seen to define capacity). His conclusion of the need for 20 minutes to be left between fills seems unjustified in the context of his data on normal bladders.

Jensen also performed repeat fills in patients with uninhibited neurogenic bladders. In 15 neurogenic patients the fills were repeated 2 times and he found a tendency to increased capacity with repeated filling. These data were treated parametrically and the mean capacity rose from $60 \mathrm{mls}$ to $99 \mathrm{mls}$. The increase in capacity was not seen if a gap of 20 minutes was left between fills, but only 5 patients were studied in this way. In these patients with neurogenic bladders, his conclusions that the test was repeatable if a gap of 20 minutes was left between the fills would seem to be justified. He also presented data on the pressures in the bladder, and on the amplitude of the uninhibited contraction. His data on pressure comparisons was inconclusive, largely again due to small numbers, however he found a trend towards smaller amplitude uninhibited contractions in the repeat fills without interval. This again was abolished in those after a 20 minute gap. This, combined with the data on capacity suggests that there is a biological explanation for these changes after immediate repeat filling in neurogenic bladders. However, the numbers were small, and the group was split into many different studies and subgroups, which weakened the data. 
The effect of repeat filling on the perception of sensory variables has also been studied. Wyndaele (1992) repeated cystometrograms to examine short and long term reproducibility. He repeated ten cystometrograms immediately ( no time interval), and found the sensations and volumes highly reproducible in the short term. The main experiment was designed to examine the reproducibility of sensations rather than volumes and he tested a further 95 after a varying delay (mean delay 15 months, range 5-23 months). He found that the sensations during cystometry were generally well reproduced at these longer time delays before repeated testing. This suggests that the sensations themselves are reliable as markers and data on pressures and volumes at particular sensations during cystometry can be examined in their own right.

Wyndaele has since then examined in detail the sensations during cystometry in normal volunteers he found that the sensations of first sensation of filling, first desire to void, and strong desire to void are easily separated and occur at interrelated volumes, thus probably correspond with specific physiological mechanisms. (Wyndaele 1998).

There have been more studies looking at the reproducibility of pressure flow analyses during urodynamics (Madsen 1995, Rosier 1995, Hansen 1999). Rosier et al studied 75 patients with repeated cystometries. He describes them as having taken place during the same urodynamic session but is not specific as regards a time delay. Whilst his main interest was the void, he also gives data on the volumes during the fill. Both the volumes and pressures at first sensation, strong desire, and end filling volume were not significantly different between first and second fill. The data was analysed non-parametrically with a Wilcoxon test on the differences between first and second fillings. The voids, however 
showed more intra individual variability and this was predictably bigger the more refined a method of analysis and computation of degree of obstruction. However in only a small proportion did the two tests lead to a different class of obstruction being diagnosed. Madsen et al (1995) examined patients with symptomatic benign prostatic hyperplasia with repeated pressure flow studiesthree tests were performed but again no note is made of time delay, although it is noted that each test took 30 minutes. Twenty five men were examined, and a correlation coefficient within patient was calculated. The correlation coefficient was 0.71 for maximum urinary flow rate and 0.84 for detrusor pressure at maximum flow. These figures were good but what concerned the authors was the significant number $(26 \%)$ of patients in whom the maximum flow rates differed by more than $3 \mathrm{ml} / \mathrm{s}$, or the detrusor pressure changed by more than 20 $\mathrm{cmH}_{2} \mathrm{O}$. This led them to the conclusion that multiple repeated tests are appropriate for the diagnosis of obstruction, but they do not suggest which result to take notice of in cases where the results differ. Presumably, if a patient is capable of one unobstructed void, they should not be classified as obstructed. Hansen et al (1999) examined 22 patients with repeated pressure flow studies (two tests within 1 month). They found interesting variations, which suggested a consistent effect of a reduction in the degree of obstruction with consecutive tests, suggesting a 'physiological' phenomenon. The vast majority $(85 \%)$, however, were in the same diagnostic group in terms of the classification of obstruction in both tests. 


\subsection{Summary}

In this part of the introduction I have reviewed the literature on the scientific evaluation of the urodynamic test itself. Whilst the test and associated variations have been subjected to much scientific analysis, there are still some outstanding questions that arise from the published work. It is not clear how presenting symptoms relate to findings on urodynamic testing- much work has been done to clarify this and progress is no doubt being made. The study of the test itself has brought a greater understanding of bladder function, but there remain some questions as to the repeatability of the test. Repeat studies are widely used in the pharmaceutical industry, as well as in the previously published literature on biochemical interventions. The present study has used the repeat fill design to assess the impact of biochemical interventions, but also used the data collected to assess the repeat fill technique itself.

The aim of the study was to investigate the influence of intravesical biochemistry on the urodynamic test.

The questions I therefore set out to answer in this thesis are as follows: How much is the urodynamic test influenced by manipulations to the infusate $\mathrm{pH}$, osmolality and potassium concentration, manipulations which have been shown to influence contractility of detrusor muscle in vitro? And how repeatable is the urodynamic test itself?

The null hypothesis is that the biochemical manipulations to the infusate had no impact on the test. 


\section{METHODS}

\subsection{EXPERIMENTAL METHODS}

Ethical approval was obtained from Camden and Islington Community NHS Trust Research Ethics committee. The study was performed at St Pancras Hospital. The first twelve studies were performed by Dr Adrian Wagg- the author then performed all subsequent studies.

The study used the same basic design throughout the different subgroups. Women undergoing urodynamic testing as part of the investigation of lower urinary tract symptoms were recruited. An information sheet was given and a consent form signed (appendix 1). A standardised basic neurological examination was performed (appendix 1).

A standardised history protocol was filled in, including urgency. Urgency is defined as a sudden compelling desire pass urine, which is difficult to defer. The history was taken by the author, and standardised questions asked. Urgency was described in interview as 'a sudden need to pass urine, with a feeling that you can't hang on'. In our protocol, the symptom was divided into mild, moderate or severe (or absent). These were not defined more closely. This follows the classification used in previous work from this unit. A frequency volume chart was filed in prior to attendance at the clinic, again as part of the standard clinic protocol in use at the time of the study.

The definitions used for urodynamics were those of ICS (Abrams et al 1988 then Abrams et al 2002). -Thus detrusor overactivity was defined as a urodynamic observation characterised by involuntary detrusor contractions during the filling phase which may be spontaneous or provoked. I have used this term throughout without reference to causation. Some of the published 
work suggests that patients with overactive bladders may represent a different subgroup with respect to their susceptibility to local biochemical change. For example, the work of Sethia and Smith (1977) suggested that subjects with detrusor overactivity may be more susceptible to the effects of $\mathrm{pH}$ than patients with stable bladders. At the beginning of the study, the vast majority of women examined had stable bladders, as a large part of the practice at the time was preoperative assessments for stress incontinence surgery. The first study to be performed was the intracellular and extracellular $\mathrm{pH}$ modification study. Following this part of the study, the recruitment procedure was changed in order to attempt to recruit more women with detrusor overactivity. Patients with symptoms of urgency or mixed symptoms on referral letters were selected for research clinics. If there was a history of neurological disease, they were not selected. It was felt that patients with neurological cause for their bladder overactivity could well, on the basis of previous literature, represent a separate subgroup and it was unlikely that the requisite numbers would be obtained to make any part of the study significant for this group. Therefore it was considered inappropriate to include these patients. 


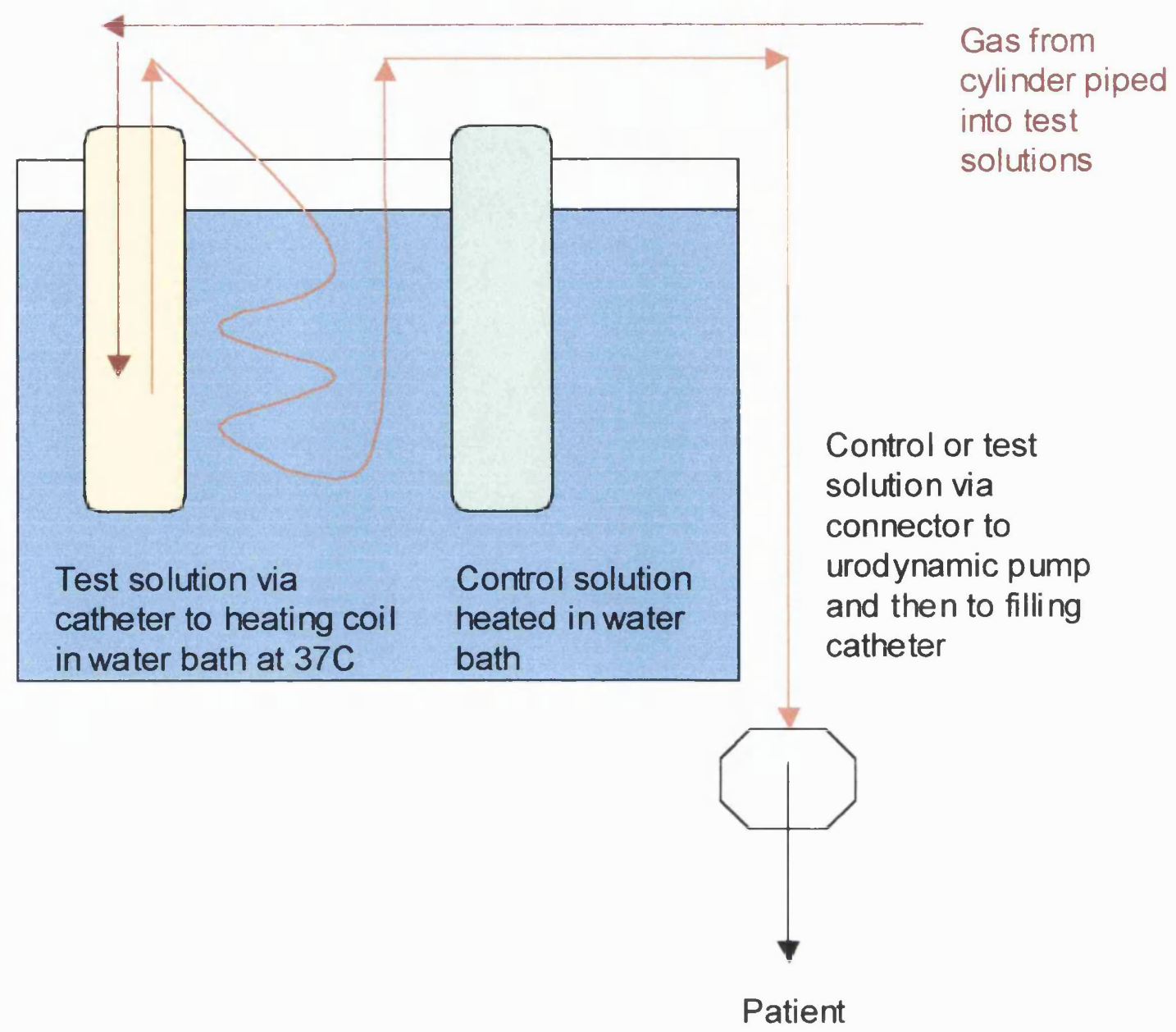

Figure 3.1- Modified urodynamics setup

The basic urodynamic set-up was modified (figure 3.1) to accommodate a water bath to keep the solutions at $37 \mathrm{C}$, and a mechanism for changing the test solutions. The solutions were kept at $37 \mathrm{C}$ in an attempt to reduce the variables from the 'physiological norm'. The solutions were then pumped by the standard pump via an extended tubing round a coil $(8$ coils around a $10 \mathrm{~cm}$ by $10 \mathrm{~cm}$ plastic coil holder) in the water bath, and then via an extension tube to the catheterised subject. The gas was bubbled via sterile catheter tubing into the bottles, and the tubing held in place by a specially designed weighted collar. 
This then allowed the catheter to be moved from one solution to the other between fills, without detaching it from the connector tubing and the heating coil. These elements were changed between patients, but not between fills for the same patient. The solutions were left in the water bath for 40 minutes prior to the study, and the designated gas was bubbled during this time. This was $95 \% \mathrm{O}_{2}, 5 \% \mathrm{CO}_{2}$ for the normocapnic studies- the extracellular alkalosis study and the normocapnic control in the intracellular acidosis study. In the hypercapnic test solution for the intracellular acidosis study the gas used was $80 \% \mathrm{O}_{2}, 20 \% \mathrm{CO}_{2}$ (see section 3.2). Earlier experiments performed by $\mathrm{Dr}$ Adrian Wagg investigated the drop in temperature from bottle to catheter with a temperature probe and found that there was at most a $1.7 \mathrm{C}$ drop in temperature over the time of filling. (A Wagg, personal communication). The solutions were made up in glass bottles, pre ordered from the sterile pharmaceutical department of Camden and Islington Community NHS Trust. The $8.4 \%$ bicarbonate was added at the time of use by syringe and quill.( details in section 3.2). $\mathrm{pH}$ was measured by a Jenway $3030 \mathrm{pH}$ meter calibrated before each session. The $\mathrm{pH}$ measurements were made immediately after the study on residual solution, for reasons of sterility. This is discussed further in section 5.6. Standard urodynamic testing was performed. This was as follows- The patient attended with a full bladder. A free flow void was performed, then residual catheterisation performed with a $\mathrm{CH} 10$ Nelaton Jaques Catheter and a single lumen transducer catheter (CH6) simultaneously. The rectum was then catheterised using a standard rectal transducer line. The catheters were secured, and the patient transferred to a commode. The bladder was then filled using 2 or 3 filling solutions in order to modify the intravesical environment. The bladder 
was filled at $50 \mathrm{mls} /$ minute to cystometric capacity, then at the end of the first fill, the filling catheter was detached from the urodynamic filling tube, and the bladder emptied. The fill was then repeated immediately using the next solution, which was connected at the bottle, and had been pre-warmed in the water bath. The filling solutions were used in orders dictated by random allocation from random number tables. The intracellular and extracellular $\mathrm{pH}$ modification study $\mathrm{pH}$ change used three fills. Other studies used two fills. The patient was blinded to the nature of the filling solution. During filling, the following sensations were noted- first sensation of filling (FSF), first desire to void (FDV), urgency and cystometric capacity (CC). The bladder was filled until a maximum of $500 \mathrm{ml}$ had been infused, unstable detrusor activity prohibited further filling, or discomfort prevented further filling. The void was only performed after the final fill. The solutions were bubbled with the appropriate gas for 20 minutes prior to the test to allow saturation. The voided solution was not checked for osmolality, $\mathrm{pH}$ or composition in general. The urodynamic tests were performed on two machines. Initially, a tailor made machine with software designed by UCL staff was used. This acquired data at 8 $\mathrm{Hz}$ on all channels and ran on a 486 PC. This was used until April 1997 and was also used for all other urodynamics at St Pancras Hospital. The subsequent machine used was a Dantec Duet. This acquires data at $50 \mathrm{~Hz}$ for each channel and uses a Butterworth 3 order filter. The transducers used for all experiments were Dantec MX860. These have a sensitivity of 5 microvolts $/ \mathrm{mmHg}$ and a zero drift of $<2 \mathrm{mmHg}$ in 4 hours (Dantec, communication). 


\subsection{Filling Solutions}

Controls. The controls for all studies were normal saline at $37^{\circ} \mathrm{C}$. The rationale for using this ,(rather than a solution with a composition more similar to extracellular fluid), was that the study was designed to compare test solutions with those usually used in urodynamic studies. The test solutions were all buffered with bicarbonate.

Hyperosmolar study. The filling solution used for this study was $252 \mathrm{mM}$, $24 \mathrm{mM}$. This gave a calculated osmolarity of $552 \mathrm{mosm} / \mathrm{l}$.

(The supplied solution was $\mathrm{NaCl} 252 \mathrm{mmol}$ in $476 \mathrm{mls}$, and $24 \mathrm{mls}$ of $\mathrm{NaHCO}_{3}$ $8.4 \%$ was added.)

Extracellular alkalosis study. The filling solution used for this study was $\mathrm{NaCl}$ $46 \mathrm{mM}, \mathrm{NaHCO}_{3} 96 \mathrm{mM}$. The calculated osmolarity is $284 \mathrm{mosm} / \mathrm{l}$. The solution was gassed with $5 \% \mathrm{CO}_{2}, 95 \% \mathrm{O}_{2}$.

(The supplied solution was $\mathrm{NaCl} 46 \mathrm{mmol}$ in $404 \mathrm{mls}$, and $96 \mathrm{mls}$ of $\mathrm{NaHCO}_{3}$ $8.4 \%$ was added).

The mean $\mathrm{pH}$ of this solution was $\mathrm{pH} 8.3$ (standard deviation [sd] 0.18) (see table 4.5). This was designed to affect extracellular $\mathrm{pH}$ as the low concentration of $\mathrm{H}^{+}$was achieved by manipulation of bicarbonate which would not be expected to rapidly cross the urothelium or the cell membrane of the detrusor cells.

Intracellular and extracellular pH variation studies. The filling solutions used were Normocapnic control - $\mathrm{NaCl} 118 \mathrm{mM}, \mathrm{NaHCO}_{3} 24 \mathrm{mM}$, with gas $5 \% \mathrm{CO}_{2} / 95^{\%}$ $\mathrm{O}_{2}$ (mean infusate $\mathrm{pH} 7.64$ sd 0.11 - see table 4.10) 
Hypercapnic study- $\mathrm{NaCl} 118 \mathrm{mM}, \mathrm{NaHCO}_{3} 24 \mathrm{mM}$, with gas $20 \% \mathrm{CO}_{2} / 80 \% \mathrm{O}_{2}$ (mean infusate $\mathrm{pH} 7.09$ sd $0.09-$ see table 4.10).

(The supplied solutions were $\mathrm{NaCl} 118 \mathrm{mmol}$ in $476 \mathrm{mls}$, and $24 \mathrm{mls}$ of $\mathrm{NaHCO}_{3} 8.4 \%$ was added).

These both gave a calculated osmolarity of $284 \mathrm{mosm} / \mathrm{l}$.

These two studies were designed to replicate the conditions, which in vitro studies have shown to affect intracellular $\mathrm{pH}$. In vitro studies with isolated ferret detrusor cells have measured intracellular $\mathrm{pH}$ with epifluorescence microscopy (Liston et al 1991). They found that a 20\% CO2/ 80\%O2 gassed through the superfusate led to a superfusate $\mathrm{pH}$ of 6.86 and a reduction in intracellular $\mathrm{pH}$ of the order of 0.2 units. This led to an increase in tension generated by the muscle of $20 \%$ above the controls. The two solutions we chose to study were therefore a normocapnic control with $5 \% \mathrm{CO} 2 / 95 \% \mathrm{O} 2$ and a hypercapnic study solution gassed with $20 \% \mathrm{CO} 2 / 80 \% \mathrm{O} 2$. This might be expected to reduce intracellular pH. The $\mathrm{NaCl}$ and $\mathrm{NaHCO}_{3}$ were designed to maintain osmolality. It is not clear why the normocapnic control had a pH as high as 7.6. This was a normal superfusate solution for tissue bath studies, and would usually have a $\mathrm{pH}$ of 7.4. It seems unlikely that error of the $\mathrm{pH}$ meter is responsible, as the figures are consistently similar.

A normal saline control was used as well as the normocapnic control in order to make the study applicable to normal urodynamic technique.

Potassium study. The filling solution used was $\mathrm{NaCl} 76 \mathrm{mM}, \mathrm{NaHCO}_{3} 24 \mathrm{mM}$, and $\mathrm{KCl} 54 \mathrm{mM}$.

( The supplied solution was $\mathrm{NaCl} 76 \mathrm{mmol}$ and $\mathrm{KCl} 54 \mathrm{mmol}$ in $476 \mathrm{mls}$ solution. $24 \mathrm{mls}$ of $\mathrm{NaHCO}_{3} 8.4 \%$ was added.) 
The studies for 'intracellular and extracellular $\mathrm{pH}$ variation' were the first to be done and were done together (ie three fills were attemped on all subjects). Thus, most patients received both study fills and the control fill. However, it was felt that recruitment would be improved if only one study fill and the control fill were attempted, so subsequent limbs of the studies were performed separately. The solutions were designed to be comparable to physiological range of urine, rather than outside this range. Thus the hyperosmolar solution was in the middle of the physiological range (50-1400 mosm $/ \mathrm{kg})$, the acidosis and alkalosis solutions at either end of the normal range ( $\mathrm{pH} 4-9)$, and the potassium solution at the upper range of the normal physiological range $(20-60 \mathrm{mmol} / \mathrm{l})$. The solutions were similar to those which influenced in vitro studies, and are comparable to physiological biochemistry in urine, rather than being designed to take the intravesical biochemistry to extremes. 


\subsection{Statistical methods}

The raw data are presented for each study in table form. The results were analysed on SPSS 10.0 for windows and Microsoft Excel 2000 in the following manner:

The null hypothesis was that, after filling with the specified solutions designed to change the intravesical biochemical environment, the volumes at first sensation of filling (FSF), first desire to void (FDV) and cystometric capacity (CC) would not change significantly from those of the control fill with normal saline. The values for differences between the test and control fills (always control value in mls minus test value in $\mathrm{mls}$ ) were calculated for each patient for each urodynamic variable. Median values and interquartile ranges were calculated. The main outcome measure was the difference between the control and test fills (control minus test). This was expressed as a percentage of the control fill. These values were tested for normality. The Wilcoxon signed rank test was performed on the raw difference (not expressed as a percentage), in order to evaluate the statistical significance of any difference found. This was expressed as a statistic (z) with asymptotic significance. Values of less than 0.05 are considered statistically significant.

Interaction of variables was checked with SPSS general linear model multivariate analysis.

The results were also analysed with respect to the influence of urgency (self reported) or urodynamically proven instability (overactivity) on the study. Graphs help to display visually whether the populations- of unstable and stable, or of patients with urgency and no urgency could have come from different subpopulations. These data were examined statistically for the subgroups. 
The results for all parts of the study were merged and analysed with respect to the effect of fill order. In this case the differences between first and second fill were expressed as a percentage of the second fill. 


\subsection{Normality of data}

The data were analysed for normality on SPSS for windows program. The kurtosis and skewness values were calculated. The kurtosis value is the refection of the cluster around the central point. Positive kurtosis values suggest a tight cluster and a long tail- negative kurtosis values suggest a broad cluster and short tails. The ratio of kurtosis to its standard error is used as a test of normality- if less than -2 or greater than +2 , normality can be rejected. The skewness is also tabulated- a positive skewness signifies a long right tail, and a negative skewness suggests a long left tail. The ratio of skewness to its standard error can be used as a test of normality- a skewness of more than twice its standard error suggests a non normal distribution. The data were not strictly normally distributed. This was largely because of skewness and kurtosis values which were distorted by outliers, as the majority of the data fell within normal distribution. Thus the data were analysed non parametrically in the first instance. However, the non normal distribution cannot be seen as an absolute issue, so the parametric analysis is included in appendix 4 . 


\subsection{Sample size and power calculations}

Data from Jensen (1981) were used as an example to calculate sample size (appendix 2). This was the only published study with full data. This study examined repeat fill studies, and fills from 19 patients in whom studies were repeated without interval are given in the paper. These data were treated in the same way as in the present study. The raw data is shown in appendix 2 . The mean $\%$ change in cystometric capacity was $-31.6 \%$. The standard deviation was 30.3. The null hypothesis is that the mean difference between control and test fill is 0 . In order to disprove this null hypothesis, with the calculated difference of $30 \%$ of control fill, and a statistical significance level of 0.05 , a sample size of 10 patients would have an $80 \%$ power to detect a difference between the groups. Thus a minimum sample size of 10 patients was needed for each study. In view of the possibility that different subgroups of stability would behave as different populations, (see Sethia and Smith 1987) larger sample sizes were used whenever possible.

Power calculations were made on data collected in this study. These were made on the basis of the signed rank test for non parametric data. These were done on SPSS 10 for windows and Sample Power 1.0 for SPSS programs, and were made on the basis of a $5 \%(0.05)$ level of significance. The number of patients that would be needed to disprove the null hypothesis was calculated, based on data from this study. 


\section{RESULTS}

\subsection{Hyperosmolar study}

The aim of this study was to examine whether instillation of a hyperosmolar solution affected urodynamic testing when compared to a normal saline intravesical infusate.

Twenty nine subjects were recruited, (median age 57, range 32 to 88 ). 4 had incomplete data.- two had urinary tract infections (UTI) diagnosed after randomisation (A9 and A26), two had data lost because of a failure of the computer (A 22 and A27).

The results for each patient are shown in table 4.1.

The numbers of subjects classified by urgency were as follows- mild - 7 , moderate-10, severe- 5 .

The diagnoses were as follows- stress urinary incontinence with stable urodynamics 7 , detrusor overactivity- 14 , mixed stress urinary incontinence with detrusor overactivity-3, normal urodynamics-3.

In 1 subject the saline (control) fill alone showed overactivity. This was the first fill.

None had prior urodynamics. One had previous anticholinergic medication, but wasn't on it at the time of the test.

The results analysis is shown in table 4.2. There is a trend for the median percentage change for volumes of sensations to be negative $(-20 \%$ and $-15 \%$ for FSF and FDV respectively) signifying larger volumes at FSF and FDV in the hyperosmolar test solution than in the control fill. However this did not reach significance and the interquartile range about the median differences included zero. The median change for CC was zero. 
The histograms (figures 4.1, 4.2, and 4.3) show that there is a longer negative tail to the data indicating a few patients with much larger test volumes than control. Normal distribution curves are superimposed on study data.

The data were not normally distributed. This is shown in the values for the ratios of skewness to standard error and kurtosis to standard error as well as in the QQ plot (figure 4.4)

The subgroups of instability and urgency do not show any differences in groups with urodynamically proven instability or with different levels of self reported urgency (none, mild, moderate, severe). A scatter plot of \% differences in CC against age is shown in figure 4.5, with the subgroups of stability and instability. This demonstrates graphically the lack of difference between the groups. This is also shown in the boxplots of differences in volumes at FSF, FDV and CC plotted with standard error bars and confidence intervals in figures $4.7,4.8$, and 4.9 with subgroups for urgency.

On the basis of the data of the present study, the power of the study to detect a difference with a $5 \%$ level of significance was $48 \%$. For an $80 \%$ level of power, based on the data from this study, the sample size needed to detect a difference between the groups would have been 4800 patients. This figure demonstrates the closeness of the two groups rather than the lack of power of the study. 
Key for Table 4.2

Urgency- $\quad 0$ - None

1- Mild

2- Moderate

3- Severe

Instability $\quad 0 \quad$ Stable urodynamics

1 Unstable urodynamics

FSF Control Volume in mls at first sensation of filling- Saline control fill

FSF Test Volume in mls at first sensation of filling- Intervention study fill

FSF Diff $\quad$ FSF Control- FSF Test

$\%$ FSF Diff FSF Dif expressed as \% of control fill

FDV Control Volume in mls at first desire to void- Saline control fill

FDV Test Volume in mls at first desire to void- Intervention study fill

FDV Diff FDV Control- FDV Test

\% FDV Diff FDV Diff expressed as \% of control fill

CC Control Volume in mls at cystometric capacity- Saline control fill

CC Test Volume in mls at cystometric capacity- Intervention study fill

CC Diff CC Control- CC Test

$\%$ CC Diff CC Diff expressed as \% of control fill

Order test fill Order of the test fill- 1- Test fill followed by control fill

2- Control fill followed by test fill 


\begin{tabular}{|c|c|c|c|c|c|c|c|c|c|c|c|c|c|c|c|c|c|}
\hline Patient & Age & Urgency & Instability & FSF Controf & FSF Test & FSF Diff & $\%$ FSF Diff & $\overline{\text { FDV Contry }}$ & $\overline{\text { FDV Test }}$ & FDV Diff & $\%$ FDV Diff & CC Control C & $\overline{C C}$ Test & CC Diff & $\%$ CC Diff & Order Test fill & \\
\hline $\mathrm{A} 1$ & 52 & 1 & 1 & 38 & 50 & -12 & -31.57895 & 47 & 81 & -34 & \begin{tabular}{|l|}
-72.34043 \\
\end{tabular} & 198 & 196 & 2 & 1.010101 & 2 & \\
\hline$\overline{A 2}$ & 55 & 2 & 0 & 181 & 142 & 39 & 21.54696 & 199 & 144 & 55 & 27.63819 & 307 & 299 & 8 & \begin{tabular}{|l|l|}
3 & 2.605863 \\
\end{tabular} & 1 & \\
\hline A3 & 41 & 2 & 1 & 120 & 202 & -82 & -68.33333 & 122 & 204 & -82 & $\mid-67.21311$ & 271 & 317 & -46 & $|-16.97417|$ & 2 & \\
\hline A4 & 32 & 1 & 1 & 43 & 41 & 2 & \begin{tabular}{|l|}
4.651163 \\
\end{tabular} & 62 & 68 & -6 & -9.677419 & 103 & 86 & 17 & 16.50485 & 2 & \\
\hline A5 & 51 & 3 & 0 & 61 & 85 & -24 & -39.34426 & 65 & 100 & -35 & -53.84615 & 138 & 210 & -72 & $|-52.17391|$ & 2 & \\
\hline A6 & 76 & 3 & 1 & 98 & 78 & 20 & 20.40816 & 101 & 79 & 22 & 21.78218 & 223 & 134 & 89 & 39.91031 & 2 & \\
\hline A7 & 76 & 1 & 0 & 192 & 159 & 33 & 17.1875 & 230 & 261 & -31 & $\mid-13.47826$ & 447 & 378 & 69 & 15.43624 & 2 & \\
\hline A8 & 76 & 1 & 1 & 146 & 183 & -37 & -25.34247 & 147 & 185 & -38 & -25.85034 & 149 & 191 & -42 & \begin{tabular}{|l|}
-28.18792 \\
\end{tabular} & 1 & \\
\hline A10 & 42 & 3 & 1 & 99 & 84 & 15 & 15.15152 & 122 & 99 & 23 & 18.85246 & 144 & 141 & 3 & \begin{tabular}{|l|l|} 
& 2.083333 \\
\end{tabular} & 2 & \\
\hline A11 & 62 & 2 & 0 & 196 & 232 & -36 & -18.36735 & 229 & 374 & -145 & -63.31878 & 500 & 500 & 0 & 0 & 1 & \\
\hline A12 & 58 & 3 & 0 & \begin{tabular}{|l|l|}
173 \\
\end{tabular} & 208 & -35 & -20.23121 & 220 & 208 & 12 & 5.454545 & 331 & 282 & 49 & \begin{tabular}{|c|}
14.80363 \\
\end{tabular} & 2 & \\
\hline A13 & 55 & 3 & 1 & 42 & 27 & 15 & 35.71429 & 42 & 29 & 13 & 30.95238 & 42 & 71 & -29 & -69.04762 & 2 & \\
\hline A14 & 49 & 2 & 0 & \begin{tabular}{l|l}
63 & \\
\end{tabular} & 88 & -25 & -39.68254 & 367 & 88 & 279 & 76.0218 & 500 & 500 & 0 & 0 & 1 & \\
\hline A15 & 65 & 3 & 1 & 129 & 157 & -28 & -21.70543 & 131 & 160 & -29 & -22.1374 & 157 & 182 & -25 & 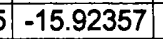 & 2 & \\
\hline A16 & 71 & 3 & 1 & 70 & 148 & -78 & -111.4286 & 70 & 225 & -155 & -221.4286 & 70 & 373 & -303 & \begin{tabular}{|l|l|} 
& -432.8571 \\
\end{tabular} & 1 & \\
\hline A17 & 74 & 2 & 1 & 185 & 150 & 35 & 18.91892 & 198 & 160 & 38 & 19.19192 & 402 & 267 & 135 & \begin{tabular}{|l|l}
33.58209 \\
\end{tabular} & 2 & \\
\hline A18 & 52 & 3 & 1 & 346 & 356 & -10 & -2.890173 & 346 & 479 & -133 & $\mid-38.43931$ & 432 & 500 & -68 & \begin{tabular}{|l|}
-15.74074 \\
\end{tabular} & 1 & \\
\hline A19 & 75 & 3 & 1 & 438 & 400 & 38 & 8.675799 & 467 & 400 & 67 & 14.3469 & 500 & 428 & 72 & 14.4 & 2 & \\
\hline A20 & 70 & 1 & 1 & 39 & 78 & -39 & -100 & 128 & 115 & 13 & 10.15625 & 159 & 179 & -20 & $|-12.57862|$ & 1 & \\
\hline A21 & 53 & 3 & 0 & 365 & 427 & -62 & \begin{tabular}{|l|}
-16.9863 \\
\end{tabular} & 367 & 429 & -62 & $\mid-16.89373$ & 500 & 502 & -2 & -0.4 & 2 & \\
\hline A22 & 81 & 2 & 0 & 40 & 97 & -57 & -142.5 & 99 & 114 & -15 & $\mid-15.15152$ & 99 & 156 & -57 & \begin{tabular}{|l|} 
\\
\end{tabular} & 1 & \\
\hline A24 & 55 & 3 & 1 & 102 & 138 & -36 & -35.29412 & 103 & 139 & -36 & -34.95146 & 134 & 168 & -34 & \begin{tabular}{|l|l|} 
& -25.37313 \\
\end{tabular} & 2 & \\
\hline$\overline{\mathrm{A} 27}$ & 62 & 3 & 0 & & & & & & & & & & & & & 1 & \\
\hline A28 & 40 & 2 & 0 & 24 & 132 & -108 & -450 & 24 & 281 & -257 & -1070.833 & 500 & 500 & 0 & 0 & 2 & \\
\hline A29 & 59 & 2 & 0 & 206 & 129 & 77 & 37.37864 & 257 & 130 & 127 & 49.41634 & 500 & 500 & 0 & 0 & 2 & \\
\hline A25 & 59 & 2 & 1 & 13 & 105 & -92 & -707.6923 & 13 & 106 & -93 & $\mid-715.3846$ & 13 & 126 & -113 & \begin{tabular}{|l|l|}
3 & -869.2308 \\
\end{tabular} & 1 & \\
\hline
\end{tabular}

Table 4.1- Results for each subject in hyperosmolar study (for key see previous page) 


\begin{tabular}{|c|c|c|c|c|c|c|c|c|}
\hline & \multirow{2}{*}{$\begin{array}{l}\text { All } \\
\text { subjects }\end{array}$} & \multicolumn{2}{|c|}{ Urodynamic stability } & \multicolumn{4}{|c|}{ Urgency } \\
\hline & & & Stable & Unstable & 0 & 1 & 2 & 3 \\
\hline \multicolumn{2}{|c|}{ Number of subjects (n) } & 29 & 11 & 15 & 0 & 5 & 9 & 12 \\
\hline \multirow{7}{*}{$\begin{array}{l}\text { FSF } \\
\text { Control- } \\
\text { FSF Test }\end{array}$} & $\begin{array}{l}\text { Median percentage } \\
\text { change (\% of control fill) }\end{array}$ & -20 & 13 & -63 & & -25 & -39 & -16 \\
\hline & First Quartile & -54 & -65 & 18 & & -65 & -296 & -35 \\
\hline & Third Quartile & 16 & -68 & 15 & & 11 & 20 & 15 \\
\hline & Skewness/standard error & -7.1 & & & & & & \\
\hline & Kurtosis/standard error & 11.5 & & & & & & \\
\hline & $\mathrm{Z}$ (test statistic) & 1.897 & & & & & & \\
\hline & Asymptotic significance & 0.058 & & & & & & \\
\hline \multirow{7}{*}{$\begin{array}{l}\text { FDV } \\
\text { Control- } \\
\text { FDV Test }\end{array}$} & $\begin{array}{l}\text { Median percentage } \\
\text { change (\% of control fill) }\end{array}$ & -15 & 28 & 1 & & -13 & -15 & $\begin{array}{l}- \\
16\end{array}$ \\
\hline & First Quartile & -58 & -56 & 33 & & -49 & -391 & - \\
\hline & Third Quartile & 19 & -67 & 18 & & 0 & 38 & 18 \\
\hline & Skewness/standard error & -5 & & & & & & \\
\hline & Kurtosis/standard error & 11.75 & & & & & & \\
\hline & $\mathrm{Z}$ (test statistic) & 1.345 & & & & & & \\
\hline & Asymptotic significance & 0.178 & & & & & & \\
\hline \multirow{7}{*}{$\begin{array}{l}C C \text { control- } \\
C C \text { test }\end{array}$} & $\begin{array}{l}\text { Median percentage } \\
\text { change (\% of control fill) }\end{array}$ & $\mathbf{0}$ & -12 & 9 & & 1 & 0 & -15 \\
\hline & First Quartile & -26 & -13 & 5 & & -20 & -37 & -52 \\
\hline & Third Quartile & 9 & -28 & 14 & & 15 & 1 & 14 \\
\hline & Skewness/standard error & -8.14 & & & & & & \\
\hline & Kurtosis/standard error & 16.4 & & & & & & \\
\hline & $\mathrm{Z}$ (test statistic) & 0.713 & & & & & & \\
\hline & Asymptotic significance & 0.476 & & & & & & \\
\hline
\end{tabular}

Table 4.2 Results analysis for hyperosmolar fill study 


\section{Figure 4.1}

\section{Histogram of \% FSF difference}

\section{Hyperosmolar study}

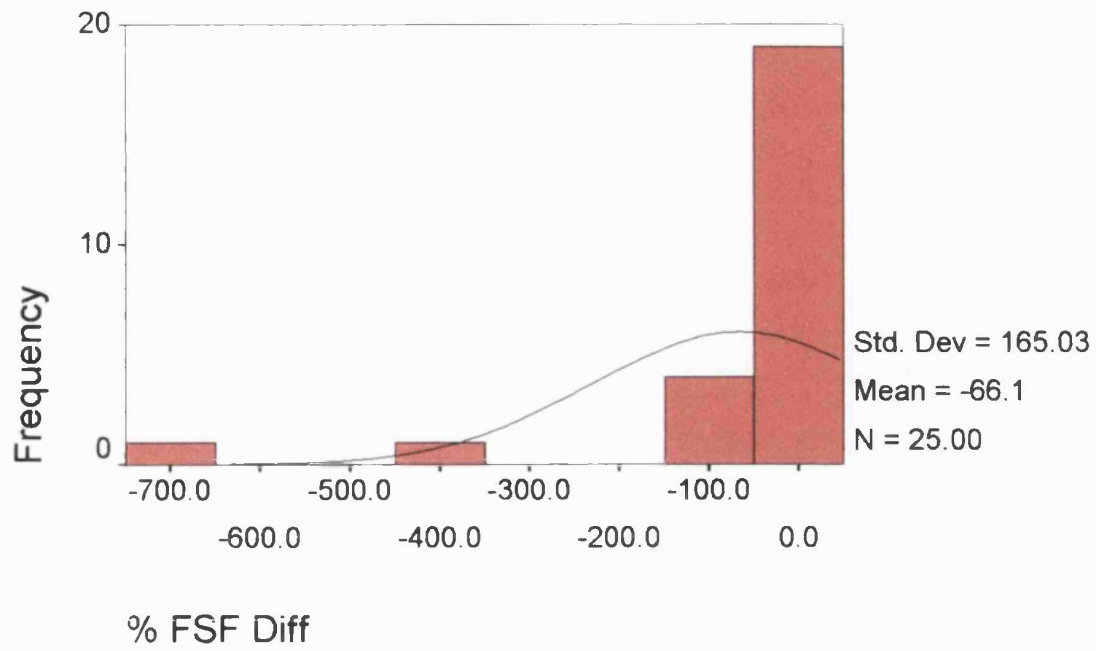

This figure shows the frequencies of $\%$ age change in volume at first sensation of filling between the hyperosmolar test solution and the saline control.

Figure 4.2

\section{Histogram of \% FDV difference}

Hyperosmolar study

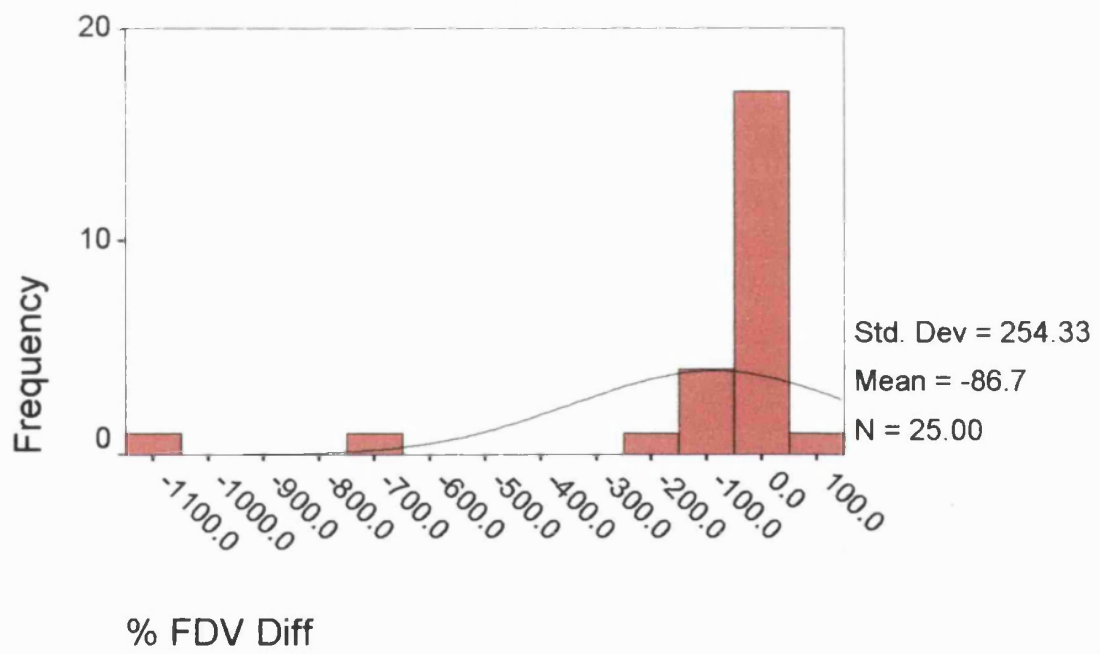

This figure shows the frequencies of \%age change in volume at first desire to void between the hyperosmolar study fill and the saline control fill 


\section{Figure 4.3}

\section{Histogram of \% CC difference}

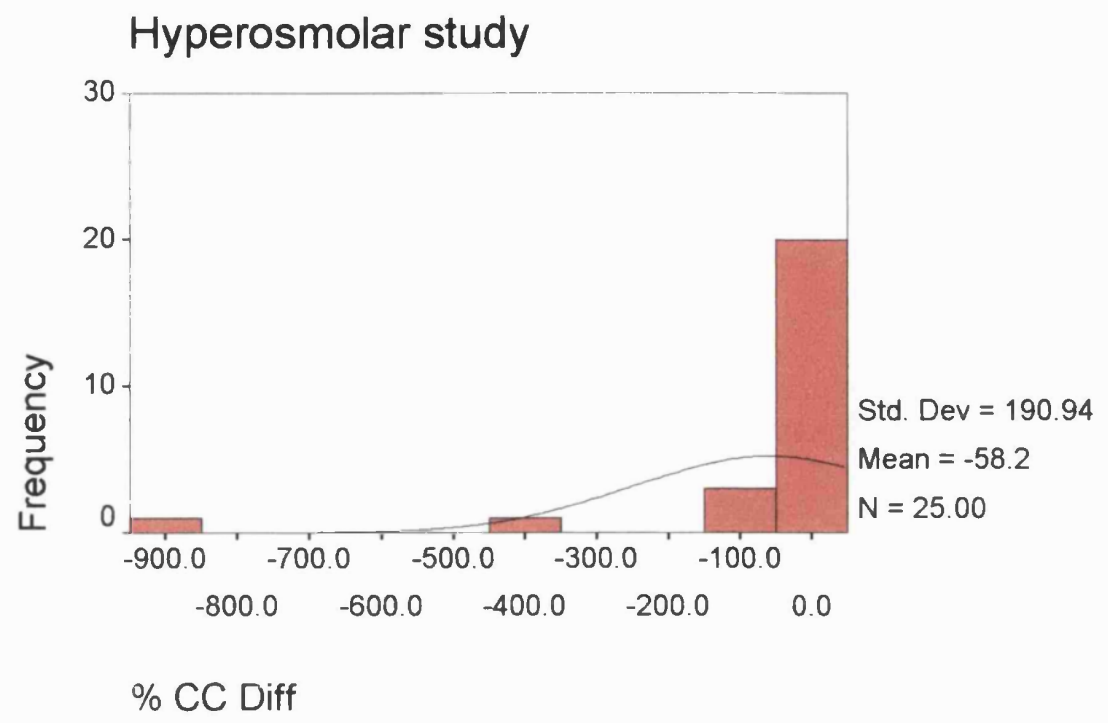

This figure shows the frequencies of \%age change in cystometric capacities between the hyperosmolar study fill and the saline control fill

Figure 4.4

Normal QQ Plot of \% CC difference

Hyperosmolar study

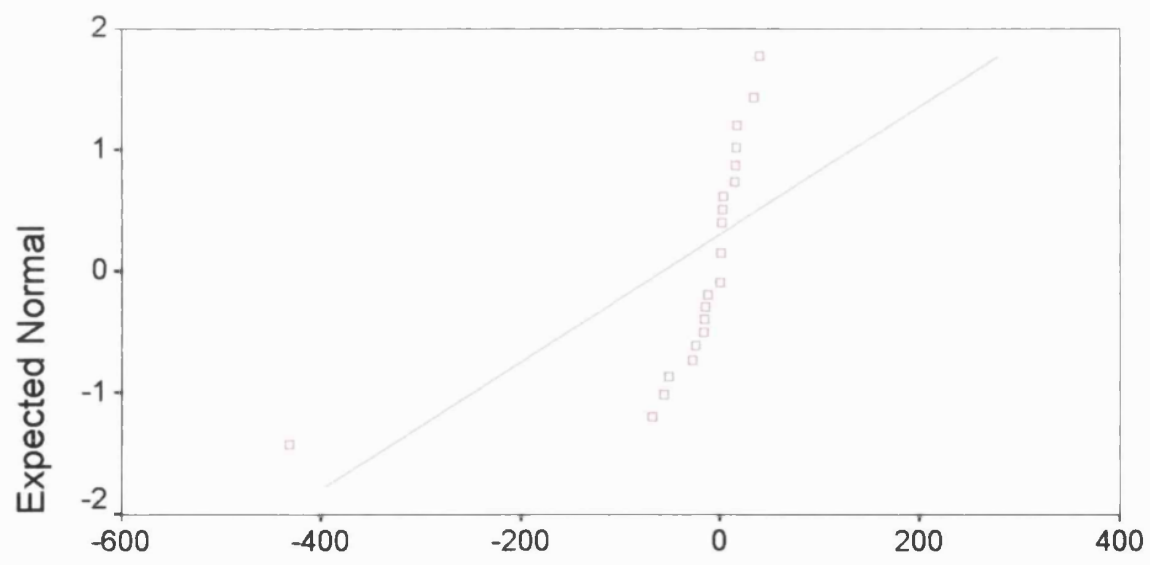

Observed Value

This shows the normal distribution Quantile-Quantile (QQ) plot of the $\%$ age change in cystometric capacity between the hyperosmolar study fill and the saline control fill. The green line shows the best plot of a normal distribution and the red points are the actual data. 
Figure 4.5

\section{Scatter plot of \% CC difference}

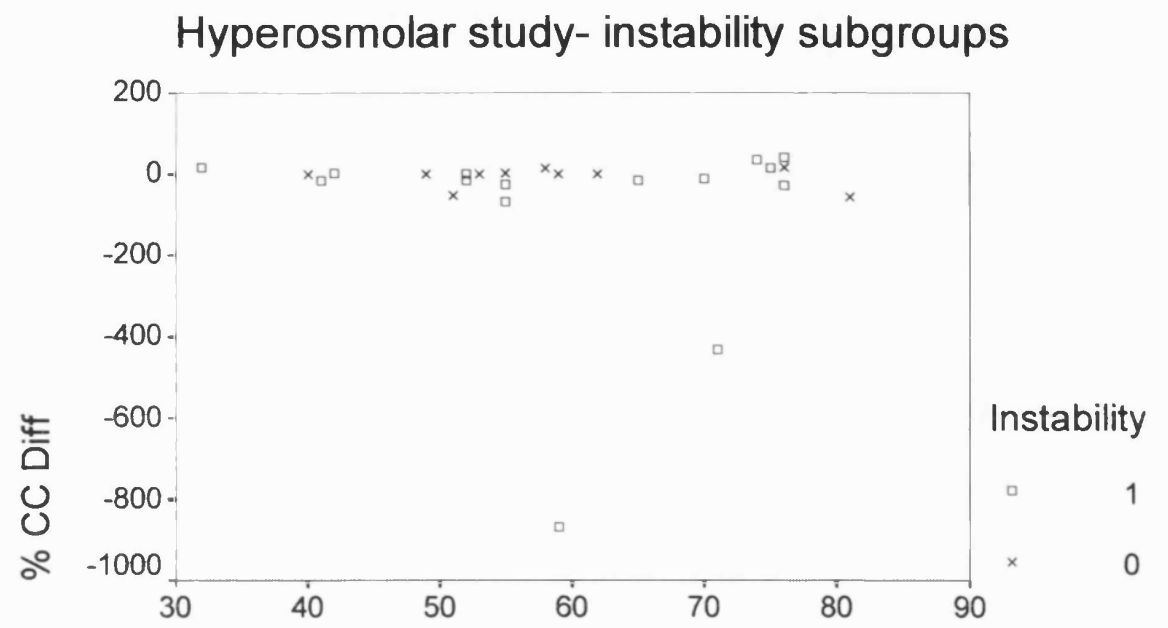

AGE

This shows the data points of \%age change in cystometric capacity between the hyperosmolar study fill and the control fill, plotted against age. Different points are used for those with urodynamic evidence of overactivity (instability)- present- 1 , absent- 0

Figure 4.6

Boxplot of \% FSF difference

Hyperosmolar study- urgency subgroups

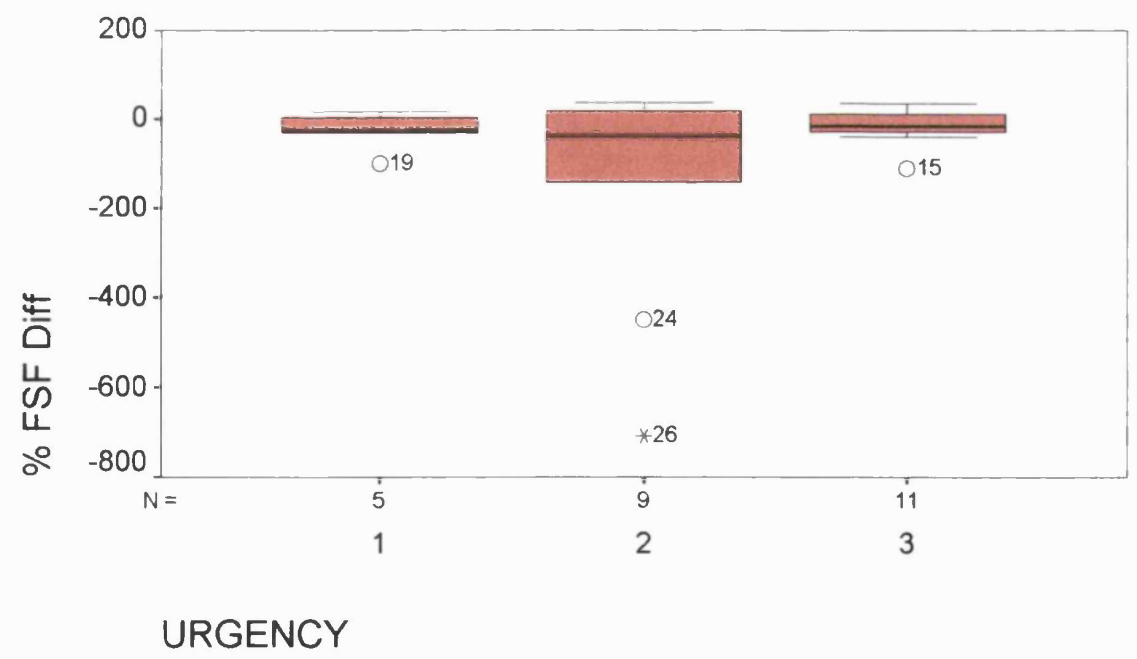

This shows the subgroups of urgency- mild-1, moderate-2, and severe-3, with plotted \% age change in first sensation of filling as a boxplot. 
Figure 4.7

Boxplot of \% FDV Difference

Hyperosmolar study- urgency subgroups

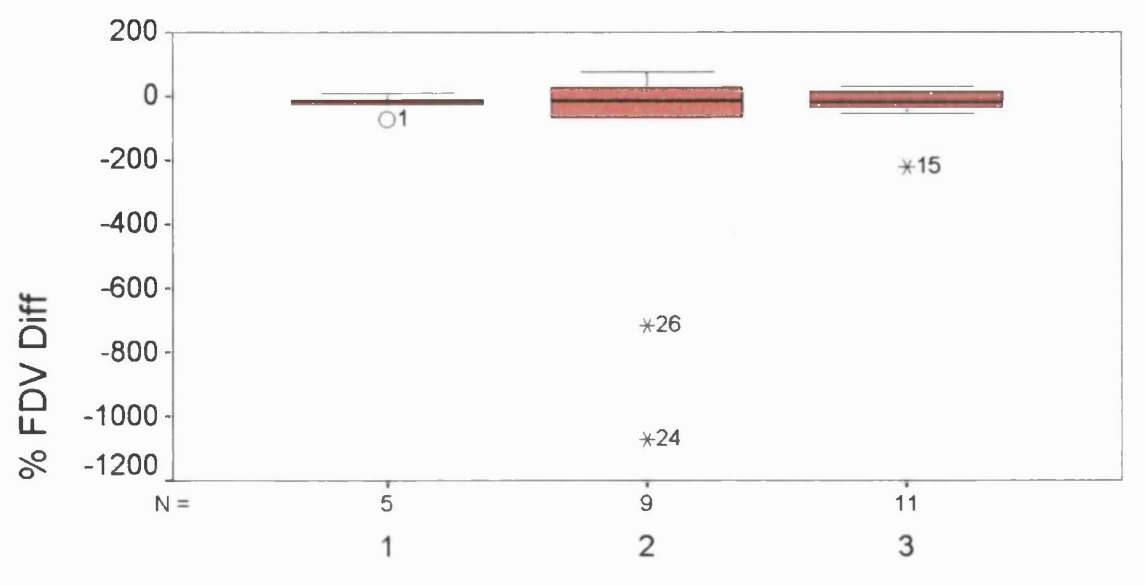

URGENCY

This shows the subgroups of urgency- mild-1, moderate-2, and severe-3, with plotted $\%$ age change in first desire to void as a boxplot

Figure 4.8

Boxplot of \% CC Difference

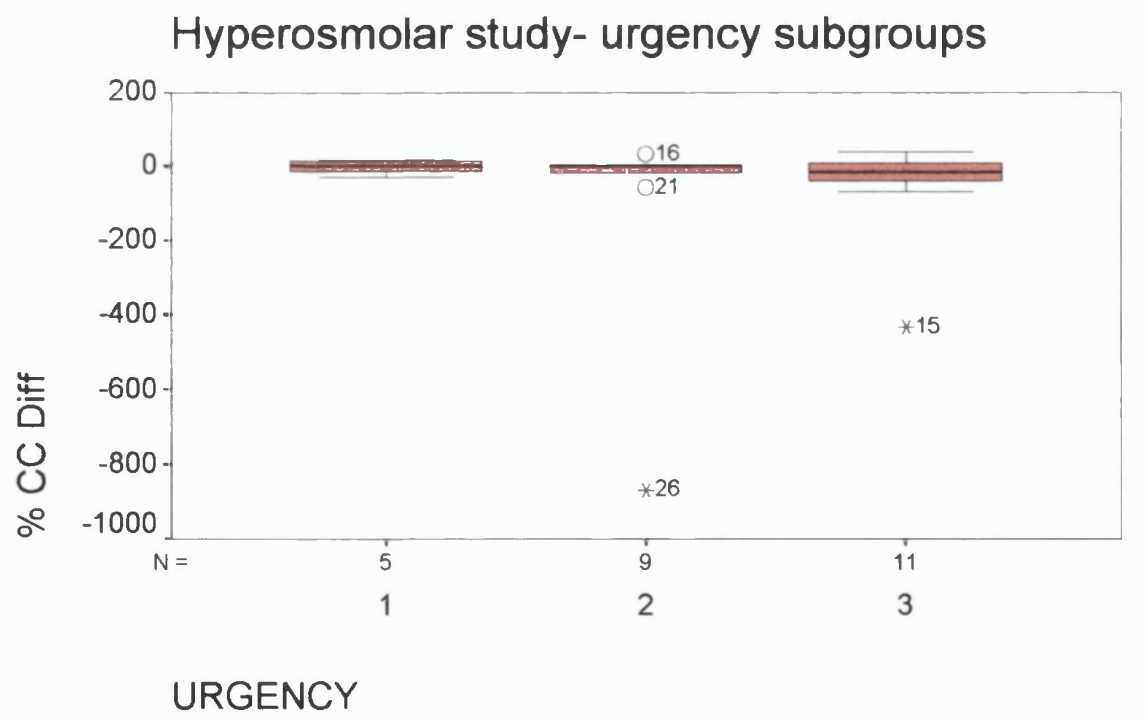

This shows the subgroups of urgency- mild-1, moderate-2, and severe-3, with plotted $\%$ age change in cystometric capacity as a boxplot 


\section{2 'Extracellular' alkalosis study}

The aim of this study was to examine whether instillation of an alkalotic solution with a high bicarbonate content affected urodynamic testing when compared to a normal saline intravesical infusate.

Twenty eight subjects were recruited, median age 53 (range 29-81). Seven had incomplete data, of whom five had urodynamic data which could be analysed (missing history data only). One had data which was lost in a computer failure, and one withdrew from the study after the first fill.

The results for each subject are shown in table 4.3

The numbers with mild urgency were 4 , moderate urgency were 12 , and severe urgency were 5. The diagnoses were as follows- Stress urinary incontinence with normal urodynamics-12, Detrusor overactivity-9, Stress urinary incontinence with detrusor overactivity-1, Normal urodynamics- sensory urgency- 3 .

Of the 9 with urodynamic signs of overactive bladder, 4 had overactivity only on the extracellular alkalosis fill, and 2 only on the saline fill. Five of these showed overactivity on the first fill, but not on the second. None had prior urodynamics, 2 had been previously treated with anticholinergics but weren't on them at the time of the test. The results analysis is shown in table 4.4. All differences between the urodynamic variables (volumes at FSF, FDV and $\mathrm{CC}$ ) of the whole group were small and the interquartile range included zero. No change was statistically significant.

Measurement of $\mathrm{pH}$ values was performed in twenty three cases. These values are displayed in table 4.5. Mean pH of Normal Saline was 5.53 (standard 
deviation 0.68 ) and mean $\mathrm{pH}$ of the study solution was 8.35 (standard deviation $0.18)$.

Histograms are shown of \% change in volumes at FSF, FDV and CC (figures $4.9,4.10$ and 4.11 respectively).

The data were not normally distributed. This is shown in the values for the ratios of skewness to standard error and kurtosis to standard error as well as in the QQ plot (figure 4.12)

A scatter plot of \% difference in cystometric capacity with age is shown in figure 4.13 , with subgroups of stability and instability.

Boxplots of \% difference in FSF, FDV and CC are shown with subgroups of urgency in figures $4.14,4.15$ and 4.16 respectively. The data does show a longer tail to the left on the histograms, which indicates some patients in whom there was a greater test volume at cystometric capacity than the control. The error bars stretch further negatively in the group with higher urgency (2 and 3). However, the numbers in whom this occurred are too small to draw conclusions and the overall change in patients with all subgroups was insignificant. If the data was treated parametrically (appendix 4) all mean values of change would be negative (larger test volumes than control volumes) but all confidence intervals include zero.

On the basis of my data, as the differences are so small, the study had a $14 \%$ power to detect a difference between the groups if there was one, and for an $80 \%$ power a sample size of 1210 patients would be needed. 
Key for Table 4.3

Urgency- $\quad 0$ - None

1- Mild

2- Moderate

3- Severe

Instability $\quad 0 \quad$ Stable urodynamics

1 Unstable urodynamics

FSF Control Volume in mls at first sensation of filling- Saline control fill

FSF Test Volume in mls at first sensation of filling- Intervention study fill

FSF Diff $\quad$ FSF Control- FSF Test

\% FSF Diff FSF Dif expressed as \% of control fill

FDV Control Volume in mls at first desire to void- Saline control fill

FDV Test Volume in mls at first desire to void- Intervention study fill

FDV Diff FDV Control- FDV Test

\% FDV Diff FDV Diff expressed as \% of control fill

CC Control Volume in mls at cystometric capacity- Saline control fill

CC Test Volume in mls at cystometric capacity- Intervention study fill

CC Diff CC Control- CC Test

\% CC Diff CC Diff expressed as \% of control fill

Order test fill Order of the test fill- 1- Test fill followed by control fill

2- Control fill followed by test fill 


\begin{tabular}{|c|c|c|c|c|c|c|c|c|c|c|c|c|c|c|c|c|}
\hline Patient & Age & Urgency & Instability & FSF Control & FSF Test & FSF Diff & $\%$ FSF Diff & FDV Control & FDV Test & FDV Diff & $\%$ FDV Diff & CC Control & CC Test & CC Diff & $\%$ CC Diff & Order Test fill \\
\hline$B 1$ & 43 & & 0 & 19 & 84 & -65 & -342.10526 & 176 & 388 & -212 & -120.4545 & 500 & 500 & 0 & 0 & 1 \\
\hline B3 & 48 & & 0 & 297 & 248 & 49 & 16.498316 & 366 & 294 & 72 & 19.672131 & 499 & 493 & 6 & 1.202405 & 1 \\
\hline B4 & 35 & & 0 & 267 & 132 & 135 & 50.561798 & 342 & 281 & 61 & 17.836257 & 500 & 495 & 5 & 1 & $\overline{1}$ \\
\hline B5 & 39 & & 0 & 219 & 294 & -75 & -34.246575 & 219 & 294 & -75 & -34.24658 & 500 & 501 & -1 & -0.2 & 2 \\
\hline $\bar{B} 6$ & 41 & 2 & 0 & 317 & 343 & -26 & -8.2018927 & 317 & 343 & -26 & -8.201893 & 500 & 501 & -1 & -0.2 & 1 \\
\hline B7 & 59 & 2 & 1 & 264 & 332 & -68 & -25.757576 & 319 & 339 & -20 & -6.269592 & 419 & 500 & -81 & -19.33174 & 2 \\
\hline $\mathrm{B} 8$ & 64 & 2 & 0 & 207 & 134 & 73. & 35.2657 & 207 & 136 & 71 & 34.299517 & 400 & 396 & 4 & 1 & 1 \\
\hline B9 & 45 & 2 & 0 & 92 & 104 & -12 & \begin{tabular}{|l|}
-13.043478 \\
\end{tabular} & 193 & 104 & 89 & 46.11399 & 416 & 344 & 72 & 17.30769 & 1 \\
\hline B10 & 43 & 1 & 0 & 237 & 135 & 102 & 43.037975 & 400 & 261 & 139 & 34.75 & 500 & 498 & 2 & 0.4 & 1 \\
\hline B11 & 55 & 1 & 0 & 335 & 246 & 89 & 26.567164 & 335 & 246 & 89 & 26.567164 & 500 & 500 & 0 & 0 & 1 \\
\hline B13 & 63 & & 0 & 18 & 126 & -108 & -600 & 348 & 234 & 114 & 32.758621 & 435 & 395 & 40 & 9.195402 & 1 \\
\hline$B 16$ & 50 & 2 & 0 & 197 & 267 & -70 & -35.532995 & 230 & 267 & -37 & -16.08696 & 503 & 437 & 66 & 13.12127 & 1 \\
\hline B19 & 59 & 2 & 0 & 137 & 152 & -15 & -10.948905 & 158 & 152 & 6 & 3.7974684 & 500 & 500 & 0 & 0 & 2 \\
\hline B20 & 53 & 2 & 1 & 143 & 113 & 30 & 20.979021 & 271 & 226 & 45 & 16.605166 & 380 & 355 & 25 & 6.578947 & 1 \\
\hline B21 & 54 & 3 & 0 & 219 & 202 & 17 & 7.7625571 & 219 & 281 & -62 & -28.3105 & 500 & 477 & 23 & 4.6 & 1 \\
\hline B22 & 62 & 3 & 1 & 341 & 250 & 91 & 26.686217 & 341 & 250 & 91 & 26.686217 & 500 & 584 & -84 & -16.8 & 1 \\
\hline B25 & 46 & 2 & 0 & 33 & 244 & -211 & -639.39394 & 195 & 245 & -50 & -25.64103 & 488 & 495 & -7 & -1.434426 & 1 \\
\hline B2 & 71 & 1 & 1 & 231 & 349 & -118 & -51.082251 & 349 & 349 & 0 & 0 & 398 & 499 & -101 & -25.37688 & 1 \\
\hline $\mathrm{B} 12$ & 35 & 2 & 1 & 114 & 101 & 13 & 11.403509 & 134 & 147 & \begin{tabular}{|l|}
-13 \\
\end{tabular} & -9.701493 & 249 & 184 & 65 & 26.10442 & 2 \\
\hline B15 & 29 & 1 & 1 & 99 & 168 & -69 & -69.69697 & 100 & 242 & -142 & -142 & 406 & 484 & -78 & -19.21182 & 2 \\
\hline B18 & 81 & 3 & 1 & 88 & 79 & 9 & 10.227273 & 88 & 79 & 9 & 10.227273 & 88 & 79 & 9 & 10.22727 & 2 \\
\hline B26 & 73 & 2 & 1 & 48 & 53 & -5 & -10.416667 & 48 & 53 & -5 & -10.41667 & 48 & 53 & -5 & -10.41667 & 1 \\
\hline B27 & 59 & 3 & 1 & 25 & 50 & -25 & -100 & 25 & 64 & -39 & -156 & 25 & 64 & -39 & -156 & 2 \\
\hline B14 & 53 & & & 114 & & & & 427 & & & & 427 & & & & \\
\hline B28 & 36 & 2 & 0 & 170 & 145 & 25 & 14.705882 & 170 & 145 & 25 & 14.705882 & 279 & 346 & -67 & -24.01434 & 2 \\
\hline B29 & 55 & 3 & 1 & 100 & 80 & 20 & 20 & 103 & 84 & 19 & 18.446602 & 279 & 461 & -182 & -65.23297 & 1 \\
\hline B30 & 42 & 2 & 0 & 127 & 50 & 77 & \begin{tabular}{|l|}
60.629921 \\
\end{tabular} & 127 & 331 & -204 & -160.6299 & 263 & 499 & -236 & -89.73384 & 2 \\
\hline
\end{tabular}




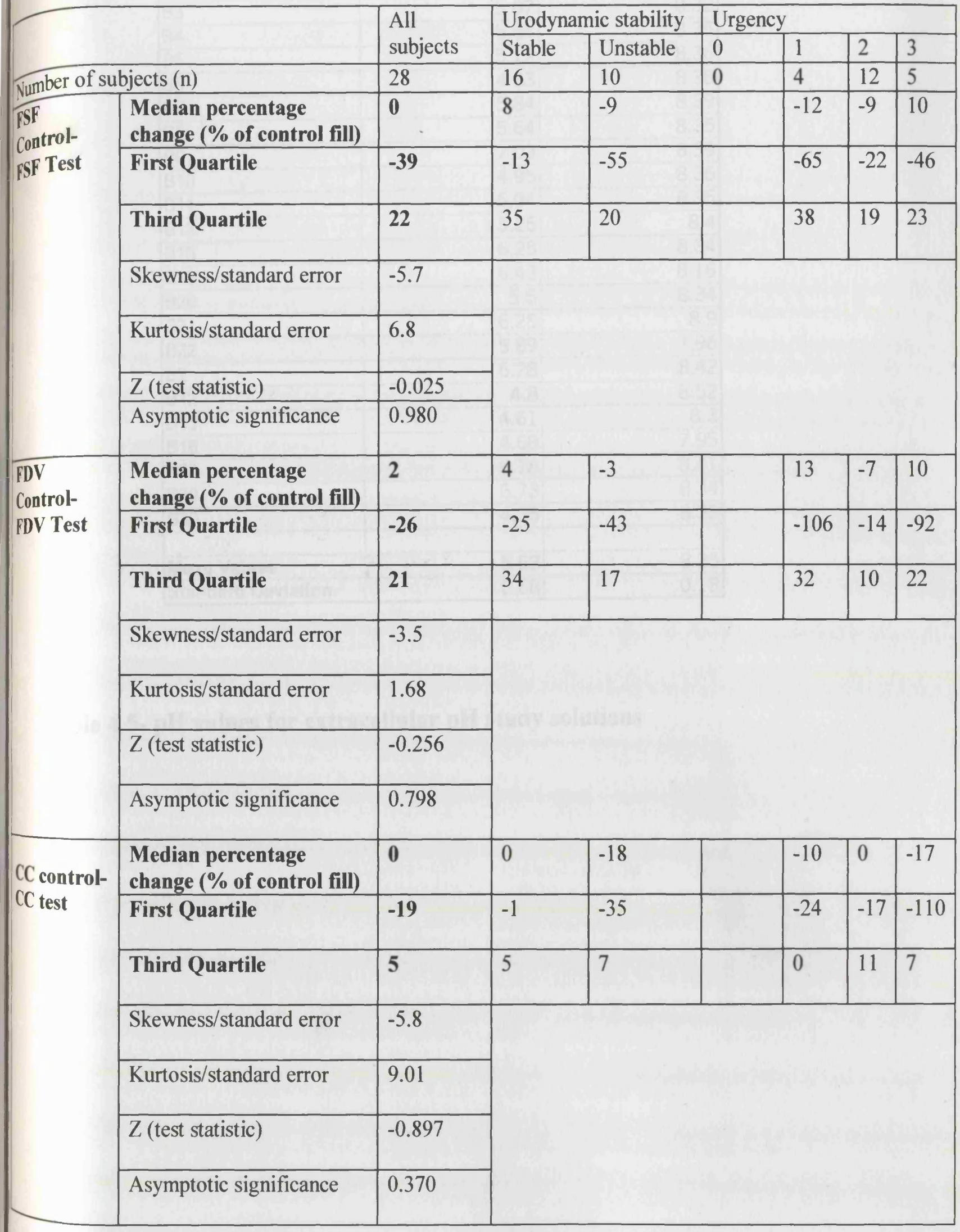

Table 4.4- Results analysis for extracellular alkalosis study 


\begin{tabular}{|l|r|r|}
\hline Patient & pH Normal Saline & pH Study Solution \\
\hline B1 & 5.94 & 8.4 \\
\hline B3 & 5.07 & 8.32 \\
\hline B4 & 5.64 & 8.35 \\
\hline B5 & 5.12 & 8.36 \\
\hline B6 & 4.83 & 8.36 \\
\hline B7 & 5.84 & 8.39 \\
\hline B8 & 5.64 & 8.35 \\
\hline B9 & 7.03 & 8.39 \\
\hline B10 & 4.95 & 8.36 \\
\hline B11 & 5.94 & 8.35 \\
\hline B13 & 5.25 & 8.4 \\
\hline B16 & 6.25 & 8.34 \\
\hline B19 & 6.43 & 8.16 \\
\hline B20 & 5.6 & 8.34 \\
\hline B21 & 6.25 & 8.9 \\
\hline B22 & 5.89 & 7.96 \\
\hline B2 & 6.28 & 8.42 \\
\hline B12 & 4.8 & 8.52 \\
\hline B15 & 4.61 & 8.3 \\
\hline B18 & 4.68 & 7.95 \\
\hline B28 & 5.18 & 8.41 \\
\hline B29 & 5.73 & 8.34 \\
\hline B30 & 4.35 & 8.35 \\
\hline & & 8.35 \\
\hline Mean Values & 5.53 & 0.18 \\
\hline Standard Deviation & 0.68 & \\
\hline
\end{tabular}

Table 4.5- $\mathrm{pH}$ values for extracellular $\mathrm{pH}$ study solutions 


\section{Figure 4.9}

\section{Histogram of \% FSF difference}

\section{Extracellular alkalosis study}

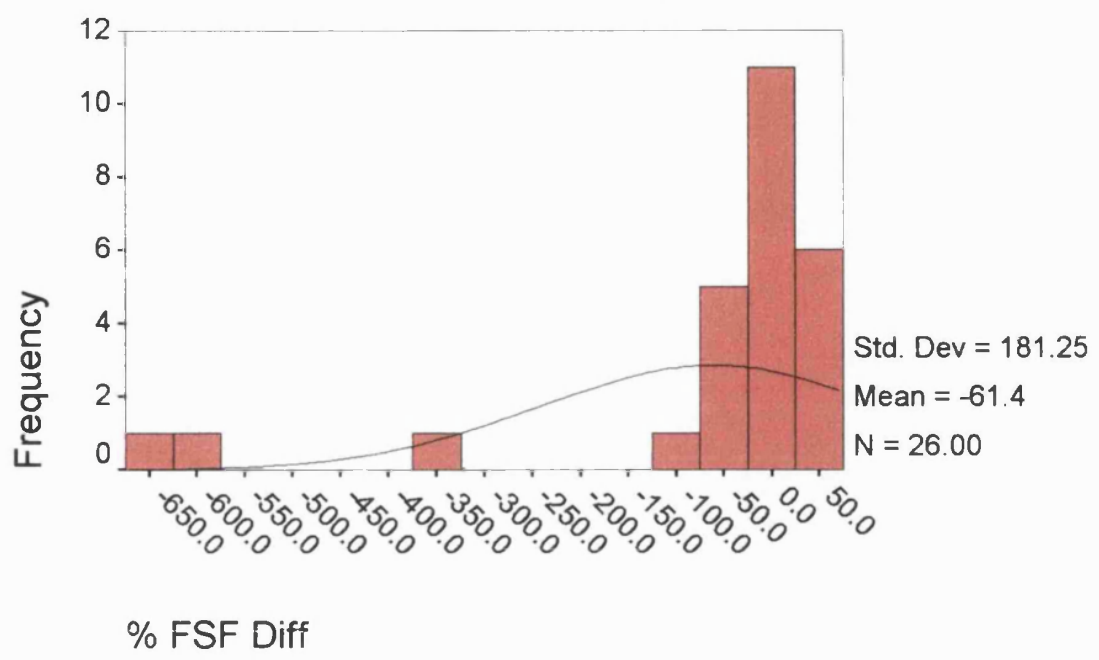

This figure shows the frequencies of $\%$ age change in volume at first sensation of filling between the extracellular alkalosis test solution and the saline control.

Figure 4.10

\section{Histogram of \% FDV Difference}

\section{Extracellular alkalosis study}

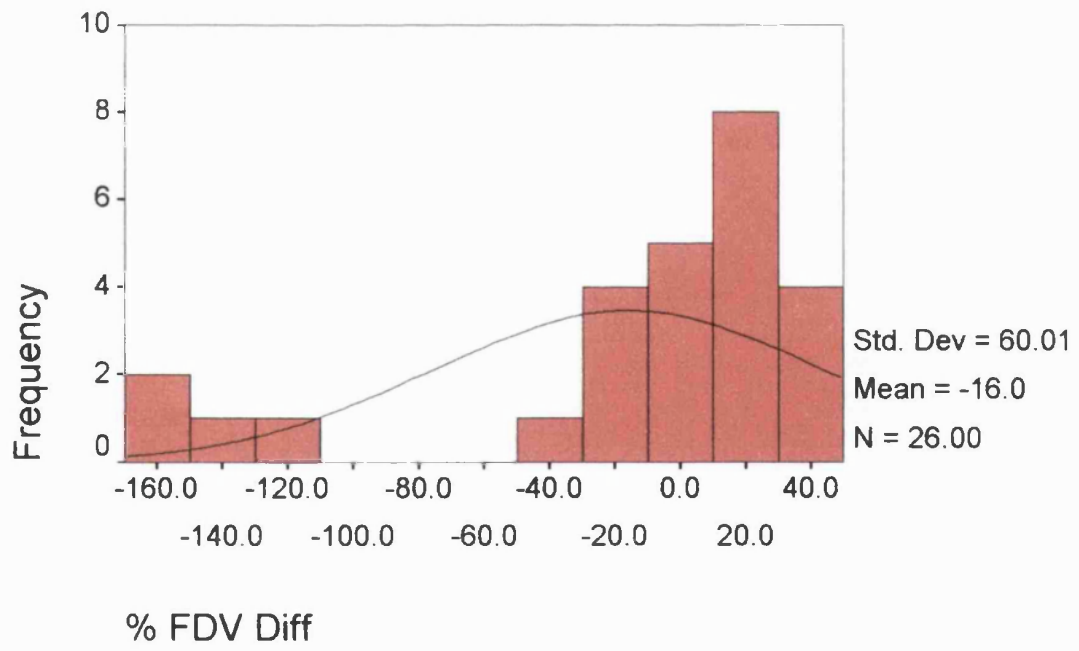

This figure shows the frequencies of $\%$ age change in volume at first desire to void differences between the extracellular alkalosis test solution and the saline control. 
Figure 4.11

\section{Histogram of \% CC Difference}

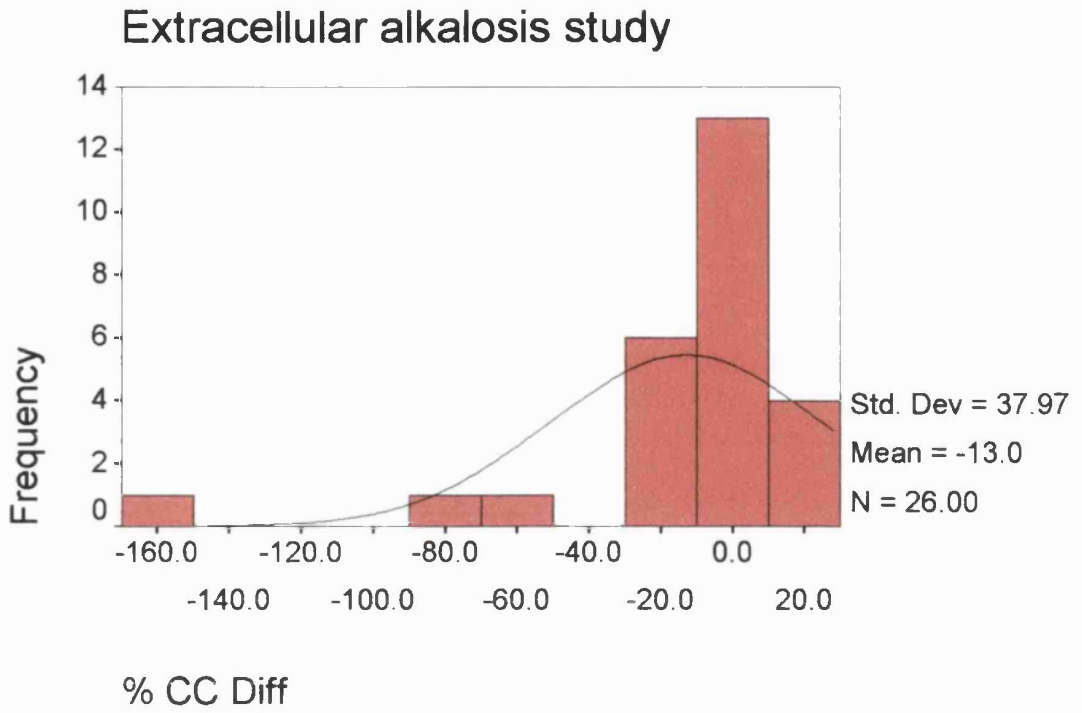

This figure shows the frequencies of \%age change in cystometric capacities between the extracellular alkalosis study fill and the saline control fill

Figure 4.12

Normal QQ plot of \% CC difference

Extracellular alkalosis study

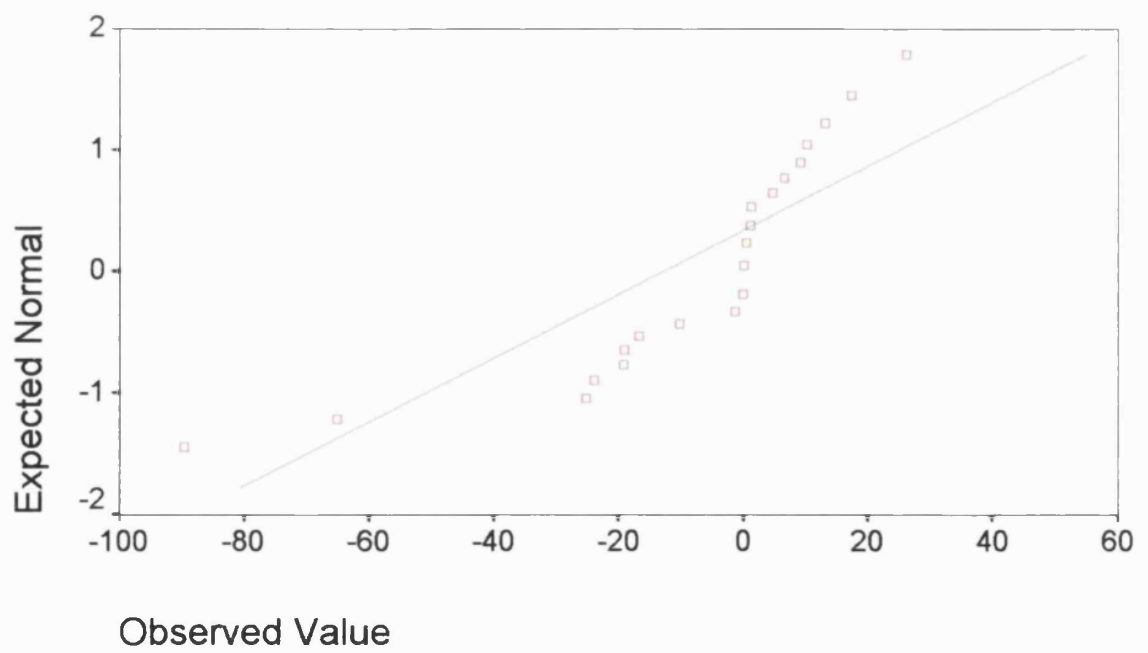

This shows the normal distribution Quantile-Quantile (QQ) plot of the \% age change in cystometric capacity between the extracellular alkalosis study fill and the saline control fill. The green line shows the best plot of a normal distribution and the red points are the actual data. 
Figure 4.13

Scatter plot of \% CC difference

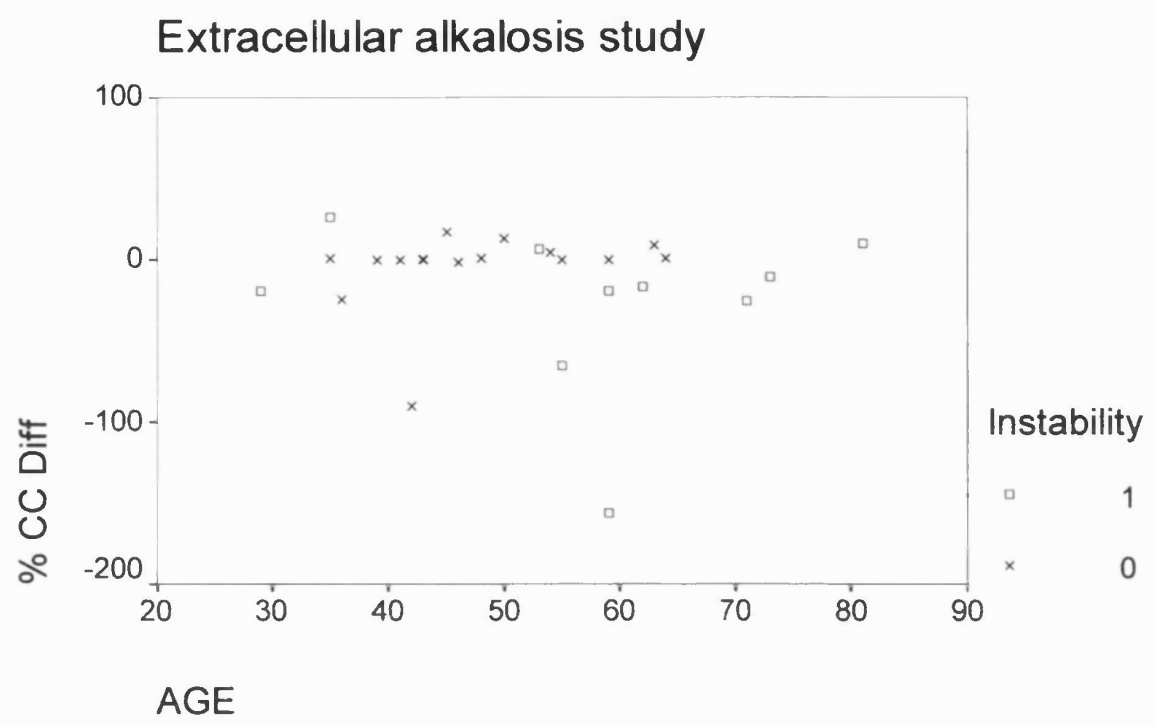

This shows the data points of \%age change in cystometric capacity between the extracellular alkalosis study fill and the control fill, plotted against age.

Different points are used for those with urodynamic evidence of overactivity (instability)present- 1 , absent-0

Figure 4.14

Boxplot of \% FSF difference

Extracellular alkalosis study- urgency subgoups

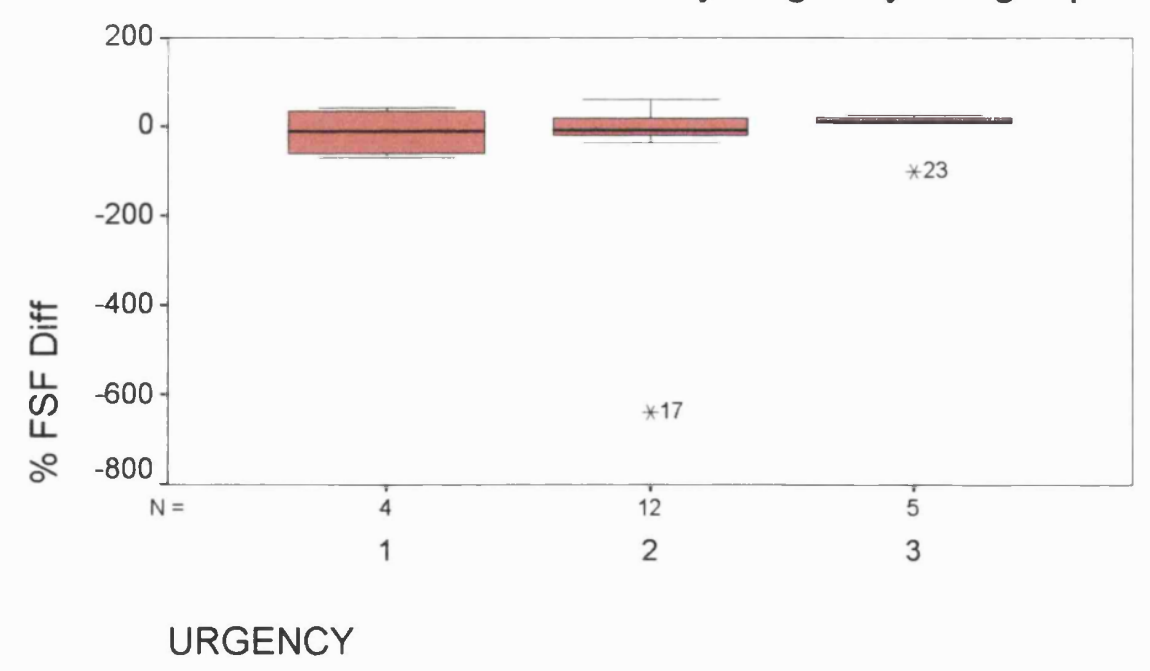

This shows the subgroups of urgency- mild-1, moderate-2, and severe-3, with plotted $\%$ age change in first sensation of filling as a boxplot. 
Figure 4.15

\section{Boxplot of \% FDV difference}

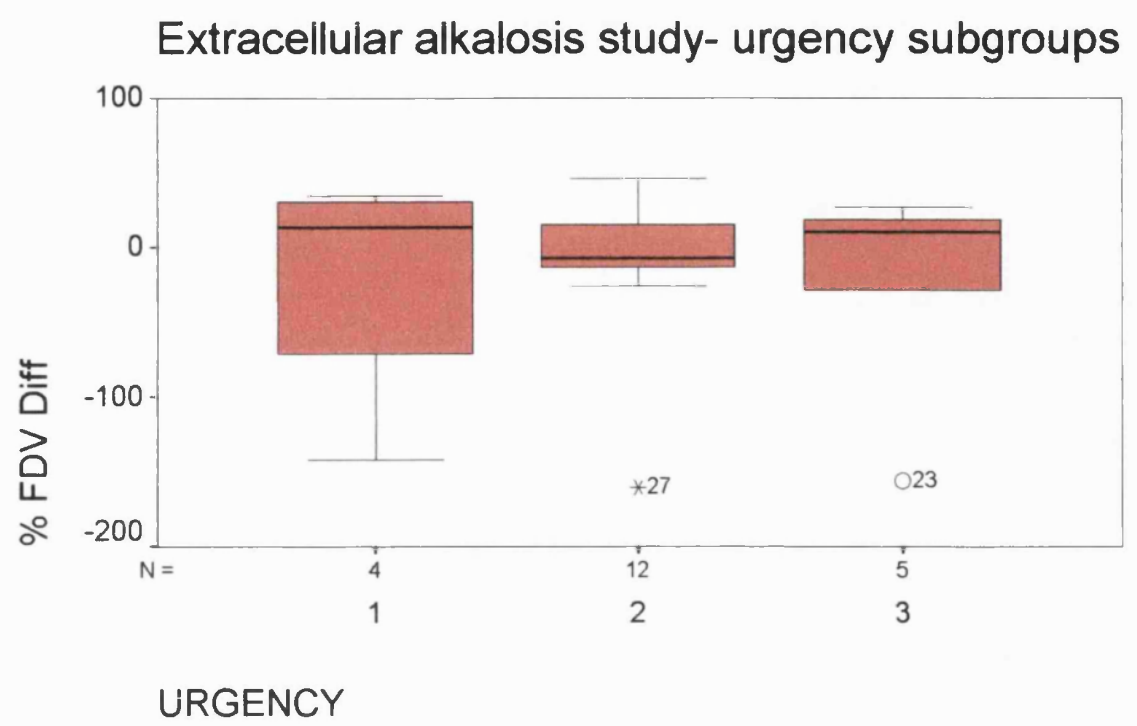

This shows the subgroups of urgency- mild-1, moderate-2, and severe- 3 , with plotted $\%$ age change in first desire to void as a boxplot

Figure 4.16

\section{Boxplot of \% CC difference}

Extracellular alkalosis study- Urgency subgoups

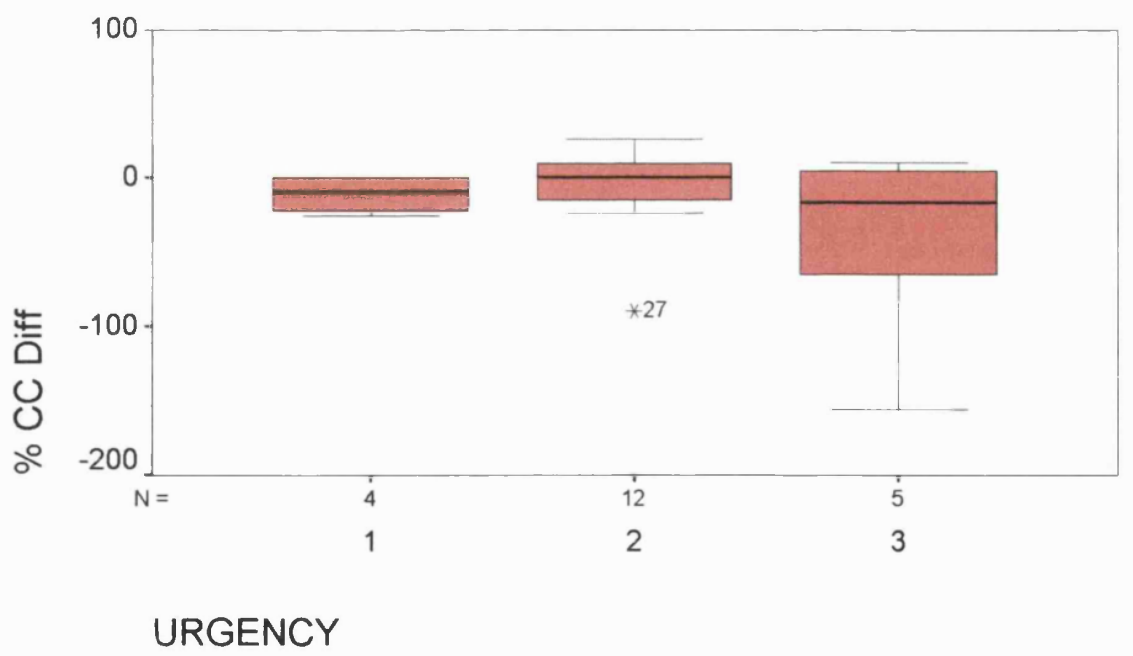

This shows the subgroups of urgency- mild-1, moderate-2, and severe-3, with plotted $\%$ age change in cystometric capacity as a boxplot 


\subsection{Intracellular and extracellular $\mathrm{pH}$ variation study - normocapnic and hypercapnic test solutions}

The aim of this study was to examine whether instillation of an acidotic solution, designed to influence intracellular $\mathrm{pH}$ (by high carbon dioxide concentration), affected urodynamic testing when compared to both a normocapnic control and to a saline intravesical infusate.

Twenty four patients were recruited, median age 57 (range 22-80). Twenty two had stable fills and two unstable fills. Five had incomplete data (one withdrew during test [C19], four computer failures [C1, C2, C6, C20]).

The numbers of subjects with no reported urgency were 7. the numbers with mild, moderate and severe were 7, 6 and 2 respectively. The diagnoses were as follows- Normal urodynamics with stress incontinence 15, Detrusor overactivity-3, Normal urodynamics-5. None had coexistent stress incontinence and unstable bladders on urodynamics.

The results are shown in tables 4.6 and 4.7 for the normocapnic and hypercapnic studies respectively. The results analyses are shown in tables $\mathbf{4 . 8}$ and 4.9. All differences between the urodynamic variables in the whole group were small and the interquartile ranges around the median differences in urodynamic volumes included zero.

These were the first set of patients to be studied and 3 fills were attempted on most of these patients (apart from the first 6 subjects). However, the data are incomplete due to completion of only two fills on some subjects.

The 'intervention' in this study was the hypercapnic study- the normocapnic one was to mimic the control in the in vitro work. The data has therefore also been 
analysed with the normocapnic fill as the control, and the hypercapnic one as the test fill (table 4.10).

The high proportion of stable fills and no or only mild urgencies in these patients is explained by a change in recruitment procedure after this study was complete. This was the first study to be performed and initially, patients were selected for research clinics from the general continence clinics at St Pancras Hospital, which included a lot of patients for preoperative assessment with genuine stress incontinence. It became evident that we were not recruiting many people with overactive bladder, and in view of the previously published literature it was felt to be useful to recruit both those with stable and unstable bladders to compare. The procedure then changed and patients for these research clinics were selected on referral letter to include more with mixed symptoms and symptoms of instability.

It is interesting that of all the studies, these two are closest to normally distributed. The parametric analysis is shown in appendix 4.

The figures accompanying the data show the distribution of data by the histograms (figures 4.17, 4.18, 4.19 for the normocapnic study; 4.25, 4.26, 4.27 for the normocapnic study and 4.33, 4.34, 4.45 for the hypercapnic vs normocapnic control analysis). These along with the QQ plots (Figures 4.20, 4.28, and 4.36) show a very close to normal distribution for the data. The number of patients with urodynamically demonstrated instability was very small and the subgroup results are difficult to interpret. These are shown graphically in boxplots (Figures $4.22,4.23$, and 4.24 for the normocapnic study, $4.30,4.31$, and 4.32 for the hypercapnic study). 
On the basis of the data from the present study, the differences were small and if the two groups were genuinely different from a saline control, the studies would have a $21 \%$ and a $8 \%$ power to detect the difference for normocapnic and hypercapnic studies respectively. The sample size needed to achieve $80 \%$ power at 5\% significance levels would be 120 and 540 patients, for normocapnic and hypercapnic studies respectively. Again, this demonstrates the similarity of the two groups of data to the normal controls. 
Key for Tables 4.6 and 4.7

Urgency- $\quad 0$ - None

1 Mild

2 Moderate

3 Severe

Instability $\quad 0 \quad$ Stable urodynamics

1 Unstable urodynamics

FSF Control Volume in mls at first sensation of filling- Saline control fill

FSF Test Volume in mls at first sensation of filling- Intervention study fill

FSF Diff FSF Control- FSF Test

\% FSF Diff FSF Dif expressed as \% of control fill

FDV Control Volume in mls at first desire to void- Saline control fill

FDV Test Volume in mls at first desire to void- Intervention study fill

FDV Diff $\quad$ FDV Control- FDV Test

$\%$ FDV Diff FDV Diff expressed as \% of control fill

CC Control Volume in mls at cystometric capacity- Saline control fill

CC Test Volume in mls at cystometric capacity- Intervention study fill

CC Diff $\quad$ CC Control- CC Test

\% CC Diff CC Diff expressed as \% of control fill

Order test fill Order of the test fill- 1- Test fill followed by control fill

2- Control fill followed by test fill 


\begin{tabular}{|c|c|c|c|c|c|c|c|c|c|c|c|c|c|c|c|c|c|}
\hline Patient & Age & Urgency & Instability & FSF Contre & FSF Test & FSF Diff & $\%$ FSF Diff & FDV Contry & rfFDV Test & FDV Diff & $\%$ FDV Diff & CC Control & CC Test & CCDiff & $\%$ CC Diff & Order Test $f$ & \\
\hline C1 & 24 & 0 & 0 & 332 & & & & 379 & & & & 379 & & & & & \\
\hline C2 & 37 & 0 & 0 & 159 & & & & & & & & 320 & & & & & \\
\hline C3 & 57 & 0 & 0 & 114 & 54 & 60 & 52.63158 & 176 & 153 & 23 & 13.06818 & 253 & 340 & -87 & $\mid-34.38735$ & 1 & \\
\hline C4 & 53 & 3 & 0 & 214 & 114 & 100 & 46.72897 & 221 & 117 & 104 & 47.05882 & 416 & 473 & -57 & -13.70192 & \begin{tabular}{l|l}
1 \\
\end{tabular} & \\
\hline C5 & 34 & 1 & 0 & 397 & 138 & 259 & 65.23929 & 397 & 138 & 259 & 65.23929 & 471 & 431 & 40 & 8.492569 & 2 & \\
\hline C6 & 55 & 2 & 0 & 152 & & & & 409 & & & & 409 & & & & & \\
\hline C7 & 80 & 0 & 0 & 169 & 55 & 114 & 67.45562 & 211 & 125 & 86 & 40.75829 & 285 & 356 & -71 & -24.91228 & 1 & \\
\hline C8 & 44 & 2 & 0 & 235 & 228 & 7 & 2.978723 & 386 & 318 & 68 & 17.61658 & 484 & 388 & 96 & 19.83471 & 1 & \\
\hline C9 & 67 & 0 & 0 & 281 & 188 & 93 & 33.09609 & 364 & 336 & 28 & 7.692308 & 476 & 336 & 140 & 29.41176 & 2 & \\
\hline C10 & 68 & & 0 & 273 & 220 & 53 & 19.41392 & 273 & 272 & 1 & 0.3663 & 296 & 345 & -49 & -16.55405 & 1 & \\
\hline C11 & 80 & 1 & 0 & 248 & 227 & 21 & 8.467742 & 250 & 250 & 0 & 0 & 297 & 299 & -2 & -0.673401 & 2 & \\
\hline $\mathrm{C} 12$ & 73 & 1 & 0 & 138 & 130 & 8 & 5.797101 & 295 & 136 & 159 & 53.89831 & 295 & 316 & -21 & -7.118644 & 1 & \\
\hline \begin{tabular}{|l|} 
C13 \\
\end{tabular} & 52 & 0 & 0 & 162 & 111 & 51 & 31.48148 & 193 & 193 & 0 & 0 & 320 & 225 & 95 & 29.6875 & 2 & \\
\hline C14 & 24 & 1 & 0 & 147 & 166 & -19 & -12.92517 & 182 & 216 & -34 & -18.68132 & 255 & 258 & -3 & -1.176471 & 1 & \\
\hline C15 & 38 & 2 & 0 & 55 & 60 & -5 & -9.090909 & 79 & 136 & -57 & -72.1519 & 196 & 172 & 24 & 12.2449 & 1 & \\
\hline C16 & 48 & 3 & 1 & 175 & 76 & 99 & 56.57143 & 208 & 165 & 43 & 20.67308 & 431 & 432 & -1 & $\mid-0.232019$ & 2 & \\
\hline C17 & 54 & 1 & 0 & 158 & 95 & 63 & 39.87342 & 413 & 328 & 85 & 20.58111 & 447 & 448 & -1 & -0.223714 & 1 & \\
\hline C18 & 64 & 2 & 1 & 255 & 284 & -29 & \begin{tabular}{|l|}
-11.37255 \\
\end{tabular} & 350 & 407 & -57 & -16.28571 & 434 & 407 & 27 & 6.221198 & 2 & \\
\hline C19 & 85 & 1 & 0 & & & & & & & & & & & & & & \\
\hline $\mathrm{C} 20$ & 22 & & 0 & & & & & & & & & & & & & & \\
\hline C21 & 53 & 2 & 0 & 337 & 240 & 97 & 28.78338 & 340 & 316 & 24 & 7.058824 & 346 & 479 & -133 & -38.43931 & 1 & \\
\hline C22 & 49 & 1 & 0 & 191 & 228 & -37 & \begin{tabular}{|l|}
-19.37173 \\
\end{tabular} & 395 & 458 & -63 & -15.94937 & 464 & 492 & -28 & -6.034483 & 2 & \\
\hline$\overline{\mathrm{C}} 23$ & 39 & 0 & 0 & 234 & 391 & -157 & \begin{tabular}{|l|}
-67.09402 \\
\end{tabular} & 320 & 436 & -116 & -36.25 & 451 & 499 & -48 & -10.64302 & 2 & \\
\hline C24 & 47 & 2 & 0 & 176 & 310 & -134 & \begin{tabular}{|l|}
-76.13636 \\
\end{tabular} & 247 & 373 & -126 & $\mid-51.01215$ & 499 & 499 & 0 & 0 & 2 & \\
\hline
\end{tabular}

Table 4.6 - Results for each subject in the normocapnic study (for key see previous page) 


\begin{tabular}{|c|c|c|c|c|c|c|c|c|c|c|c|c|c|c|c|c|c|}
\hline Patient & Age & Urgency & Instability & FSF Contrd & FSF Test & FSF Diff & $\%$ FSF Diff & FDV Contrif & FDV Test & FDV Diff & \% FDV Diff & CC Control & CC Test & CC Diff & $\%$ CC Diff & Order Test fill & \\
\hline C7 & 80 & 0 & 0 & 169 & 129 & 40 & 23.66864 & 211 & 129 & 82 & 38.86256 & 285 & \begin{tabular}{|r|}
277 \\
\end{tabular} & \begin{tabular}{|r|}
8 \\
\end{tabular} & \begin{tabular}{|c|}
2.807018 \\
\end{tabular} & 1 & \\
\hline $\mathrm{C} 8$ & 44 & 2 & 0 & 235 & 295 & -60 & \begin{tabular}{|l|}
-25.53191 \\
\end{tabular} & 386 & 295 & 91 & 23.57513 & 484 & 381 & 103 & 21.28099 & 2 & \\
\hline $\mathrm{Cg}$ & 67 & 0 & 0 & 281 & 207 & 74 & 26.33452 & 364 & & 364 & 100 & 476 & 324 & 152 & 31.93277 & 2 & \\
\hline C10 & 68 & & 0 & 273 & 250 & 23 & 8.424908 & 273 & 272 & 1 & 0.3663 & 296 & 328 & -32 & -10.81081 & 1 & \\
\hline C11 & 80 & 1 & 0 & 248 & 244 & 4 & 1.612903 & 250 & 295 & -45 & -18 & 297 & 333 & -36 & -12.12121 & 2 & \\
\hline C12 & 73 & 1 & 0 & 138 & 205 & -67 & -48.55072 & 295 & 263 & 32 & 10.84746 & 295 & 281 & 14 & 4.745763 & 2 & \\
\hline C13 & 52 & 0 & 0 & 162 & 108 & 54 & 33.33333 & 193 & 159 & 34 & 17.61658 & 320 & 185 & 135 & 42.1875 & 2 & \\
\hline C14 & 24 & 1 & 0 & 147 & 204 & -57 & -38.77551 & 182 & 227 & -45 & -24.72527 & 255 & 332 & -77 & -30.19608 & 1 & \\
\hline C15 & 38 & 2 & 0 & 55 & 95 & -40 & \begin{tabular}{|l|}
-72.72727 \\
\end{tabular} & 79 & 182 & -103 & \begin{tabular}{|l|}
-130.3797 \\
\end{tabular} & 196 & 219 & -23 & \begin{tabular}{|c|}
-11.73469 \\
\end{tabular} & 1 & \\
\hline C16 & 48 & 3 & 1 & 175 & 64 & 111 & 63.42857 & 208 & 229 & -21 & -10.09615 & 431 & 442 & -11 & -2.552204 & 2 & \\
\hline C17 & 54 & 1 & 0 & 158 & 333 & -175 & -110.7595 & 413 & 350 & 63 & 15.25424 & 447 & 432 & 15 & 3.355705 & 1 & \\
\hline C18 & 64 & 2 & 1 & 255 & 174 & 81 & 31.76471 & 350 & 189 & 161 & 46 & 434 & 416 & 18 & 4.147465 & 1 & \\
\hline C19 & 85 & 1 & 0 & & & & & & & & & & & & & & \\
\hline $\mathrm{C} 20$ & 22 & & 0 & & 114 & & & & 294 & & & & 364 & & & 1 & \\
\hline C21 & 53 & 2 & 0 & 337 & 384 & -47 & \begin{tabular}{|l|}
-13.94659 \\
\end{tabular} & 340 & 390 & -50 & -14.70588 & 346 & 396 & -50 & -14.45087 & 2 & \\
\hline C22 & 49 & 1 & 0 & 191 & 103 & 88 & 46.0733 & 395 & 469 & -74 & -18.73418 & 464 & 469 & -5 & -1.077586 & 1 & \\
\hline $\mathrm{C23}$ & 39 & 0 & 0 & 234 & 245 & -11 & \begin{tabular}{|l|}
-4.700855 \\
\end{tabular} & 320 & 322 & -2 & -0.625 & 451 & 454 & -3 & $\mid-0.665188$ & 1 & \\
\hline C24 & 47 & 2 & 0 & 176 & 211 & -35 & \begin{tabular}{|c|}
-19.88636 \\
\end{tabular} & 247 & 312 & -65 & -26.31579 & 499 & 505 & -6 & -1.202405 & 2 & \\
\hline
\end{tabular}

Table 4.7- Results for each subject in the hypercapnic study 


\begin{tabular}{|c|c|c|c|c|c|c|c|c|}
\hline & \multirow{2}{*}{$\begin{array}{l}\text { All } \\
\text { subjects }\end{array}$} & \multicolumn{2}{|c|}{ Urodynamic stability } & \multicolumn{4}{|c|}{ Urgency } \\
\hline & & & Stable & Unstable & 0 & 1 & 2 & 3 \\
\hline \multicolumn{2}{|c|}{ Number of subjects (n) } & 16 & 13 & 2 & 4 & 5 & 5 & 1 \\
\hline \multirow{7}{*}{$\begin{array}{l}\text { FSF } \\
\text { Control- } \\
\text { FSF Test }\end{array}$} & $\begin{array}{l}\text { Median percentage } \\
\text { change (\% of control fill) }\end{array}$ & -2 & -14 & 47 & 25 & -39 & -20 & \\
\hline & First Quartile & -35 & -43 & & 2 & -80 & -49 & \\
\hline & Third Quartile & 30 & 25 & & 31 & 23 & 8 & \\
\hline & Skewness/standard error & 1.24 & & & & & & \\
\hline & Kurtosis/standard error & 0.202 & & & & & & \\
\hline & $\mathrm{Z}$ (test statistic) & -0.181 & & & & & & \\
\hline & Asymptotic significance & 0.856 & & & & & & \\
\hline \multirow{7}{*}{$\begin{array}{l}\text { FDV } \\
\text { Control- } \\
\text { FDV Test }\end{array}$} & $\begin{array}{l}\text { Median percentage } \\
\text { change ( } \% \text { of control fill) }\end{array}$ & 0 & -1 & 18 & 28 & -18 & -14 & \\
\hline & First Quartile & -18 & -22 & & 4 & -21 & -78 & \\
\hline & Third Quartile & 22 & 20 & & 84 & 13 & 34 & \\
\hline & Skewness/standard error & 1.424 & & & & & & \\
\hline & Kurtosis/standard error & 3.65 & & & & & & \\
\hline & $\mathrm{Z}$ (test statistic) & -0.056 & & & & & & \\
\hline & Asymptotic significance & 0.955 & & & & & & \\
\hline \multirow{7}{*}{$\begin{array}{l}\text { CC control- } \\
C C \text { test }\end{array}$} & $\begin{array}{l}\text { Median percentage } \\
\text { change ( } \% \text { of control fill) }\end{array}$ & -1 & -1 & 1 & 17 & -1 & -1 & \\
\hline & First Quartile & -12 & -12 & & 0 & -21 & -13 & \\
\hline & Third Quartile & 4 & 13 & & 39 & 4 & 12 & \\
\hline & Skewness/standard error & 1.39 & & & & & & \\
\hline & Kurtosis/standard error & 0.957 & & & & & & \\
\hline & $\mathrm{Z}$ (test statistic) & -0.103 & & & & & & \\
\hline & Asymptotic significance & 0.918 & & & & & & \\
\hline
\end{tabular}

Table 4.9 Hypercapnic study results analysis 


\begin{tabular}{|c|c|c|}
\hline & & $\begin{array}{l}\text { All } \\
\text { subjects }\end{array}$ \\
\hline Number of $s$ & bjects (n) & 14 \\
\hline $\begin{array}{l}\text { FSF } \\
\text { Control- }\end{array}$ & $\begin{array}{l}\text { Median percentage } \\
\text { change (\% of control fill) }\end{array}$ & -14 \\
\hline FSF Test & First Quartile & -59 \\
\hline & Third Quartile & 32 \\
\hline & Skewness/standard error & 3.012 \\
\hline & Kurtosis/standard error & 3.325 \\
\hline & $\mathrm{Z}$ (test statistic) & -0.7 \\
\hline & Asymptotic significance & 0.469 \\
\hline $\begin{array}{l}\text { FDV } \\
\text { Control- }\end{array}$ & $\begin{array}{l}\text { Median percentage } \\
\text { change ( } \% \text { of control fill) }\end{array}$ & -3 \\
\hline FDV Test & First Quartile & -23 \\
\hline & Third Quartile & 16 \\
\hline & Skewness/standard error & 1.558 \\
\hline & Kurtosis/standard error & 2.247 \\
\hline & $\mathrm{Z}$ (test statistic) & -0.408 \\
\hline & Asymptotic significance & 0.683 \\
\hline CC control- & $\begin{array}{l}\text { Median percentage } \\
\text { change (\% of control fill) }\end{array}$ & 4 \\
\hline CC test & First Quartile & -2.3 \\
\hline & Third Quartile & 11 \\
\hline & Skewness/standard error & -1.46 \\
\hline & Kurtosis/standard error & 0.425 \\
\hline & $\mathrm{Z}$ (test statistic) & -1.241 \\
\hline & Asymptotic significance & 0.215 \\
\hline
\end{tabular}

Table 4.10 Hypercapnic (test) vs normocapnic (control)- results analysis 


\begin{tabular}{|c|c|c|c|c|}
\hline \multirow{2}{*}{$\begin{array}{l}\text { Patient Number } \\
\text { C1 }\end{array}$} & \multirow[t]{2}{*}{ pH Normal Saline } & \multirow[t]{2}{*}{ pH Normocapnic solution } & \multicolumn{2}{|l|}{ pH Hypercapnic solution } \\
\hline & & & & \\
\hline \multicolumn{5}{|l|}{$\mathrm{C} 2$} \\
\hline \multicolumn{5}{|l|}{ C3 } \\
\hline C4 & 5.71 & 7.61 & & \\
\hline C5 & 5.78 & 7.6 & & \\
\hline C6 & 5.89 & 7.72 & & \\
\hline $\mathrm{C7}$ & 5.85 & 7.6 & 7.1 & \\
\hline C8 & 4.36 & 7.3 & 6.91 & \\
\hline C9 & 4.79 & 7.6 & 7.08 & \\
\hline C10 & 5.51 & 7.62 & 7.1 & \\
\hline C11 & 5.85 & 7.6 & 7.15 & \\
\hline C12 & 5.38 & 7.71 & 7.14 & \\
\hline C13 & 5.28 & 7.62 & 7.24 & \\
\hline C14 & 5.85 & 7.64 & 6.91 & \\
\hline \multicolumn{5}{|l|}{ C15 } \\
\hline$\overline{C 16}$ & 5.1 & 7.66 & 7.08 & \\
\hline C17 & & 7.7 & 7 & \\
\hline C18 & 5 & 7.68 & 7.08 & \\
\hline \multicolumn{5}{|l|}{ C19 } \\
\hline $\mathrm{C} 20$ & 4.9 & & 7.13 & \\
\hline $\mathrm{C} 21$ & 6.27 & 7.71 & 7.09 & \\
\hline C22 & 4.61 & 7.89 & 7.17 & \\
\hline C23 & 6.03 & 7.69 & 7.21 & \\
\hline C24 & 4.65 & 7.61 & 7.06 & \\
\hline Mean values & 5.38 & 7.64 & 7.09 & \\
\hline Standard deviation & 0.56 & 0.11 & 0.09 & \\
\hline
\end{tabular}

Table 4.11- pH values for the test solutions in intracellular and extracellular pH studies 
Figure 4.17

\section{Histogram of \% FSF difference}

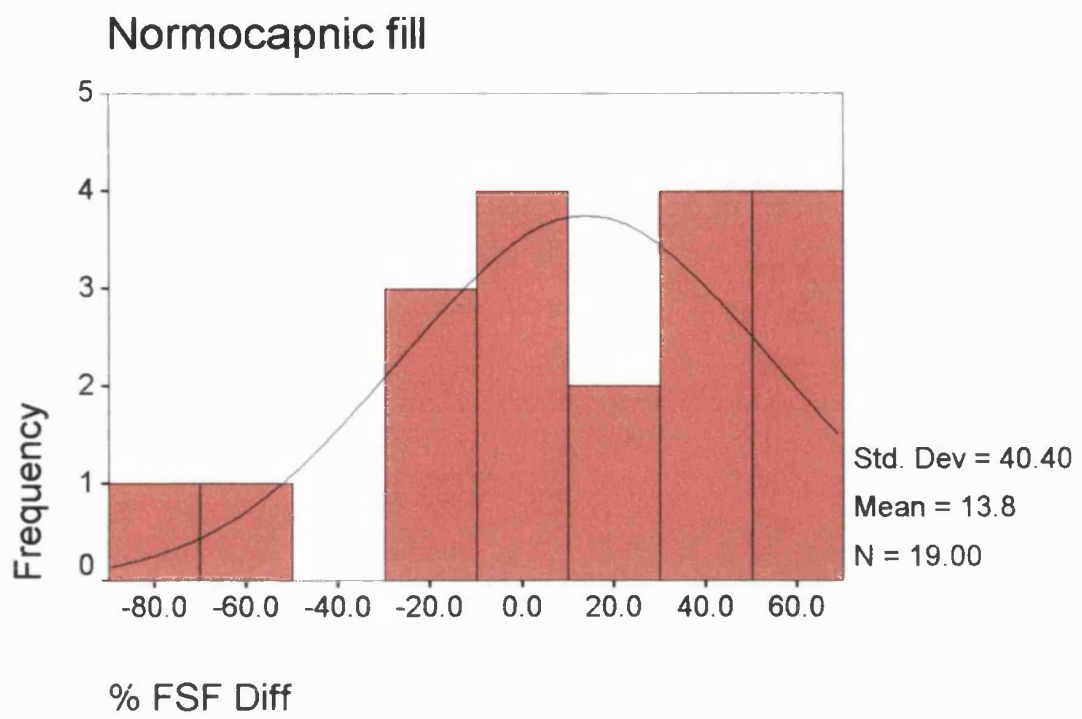

This figure shows the frequencies of $\%$ age change in volume at first sensation of filling between the normocapnic solution and the saline control.

Figure 4.18

Histogram of \% FDV difference

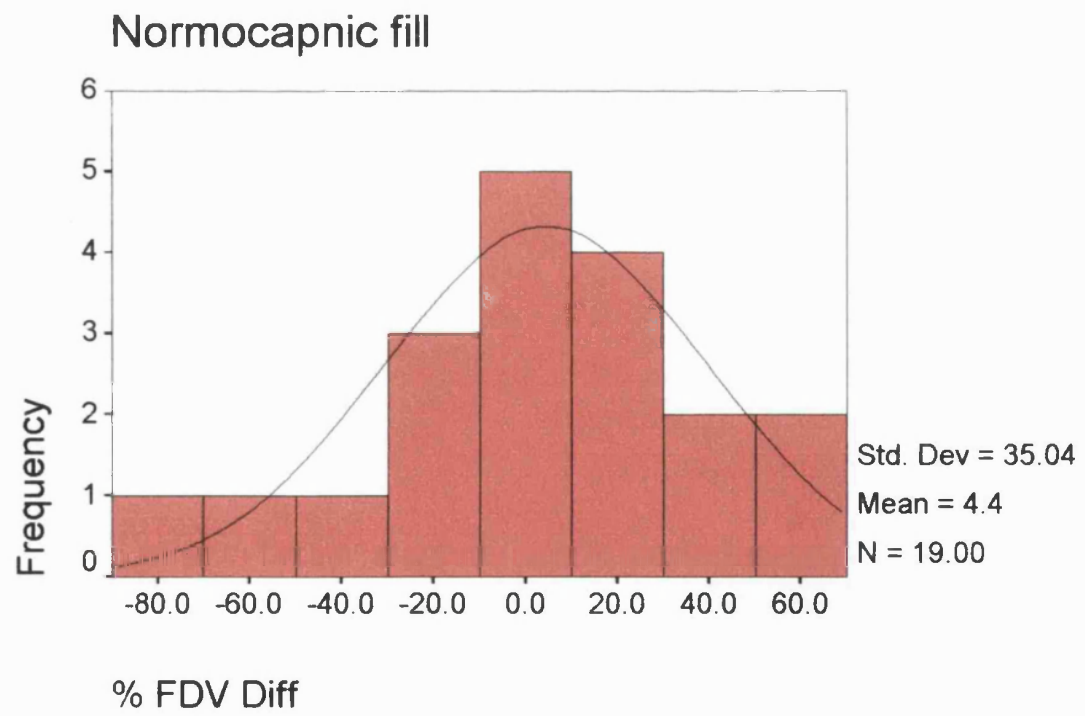

This figure shows the frequencies of $\%$ age change in volume at first desire to void differences between the normocapnic solution and the saline control. 
Figure 4.19

\section{Histogram of \% CC difference}

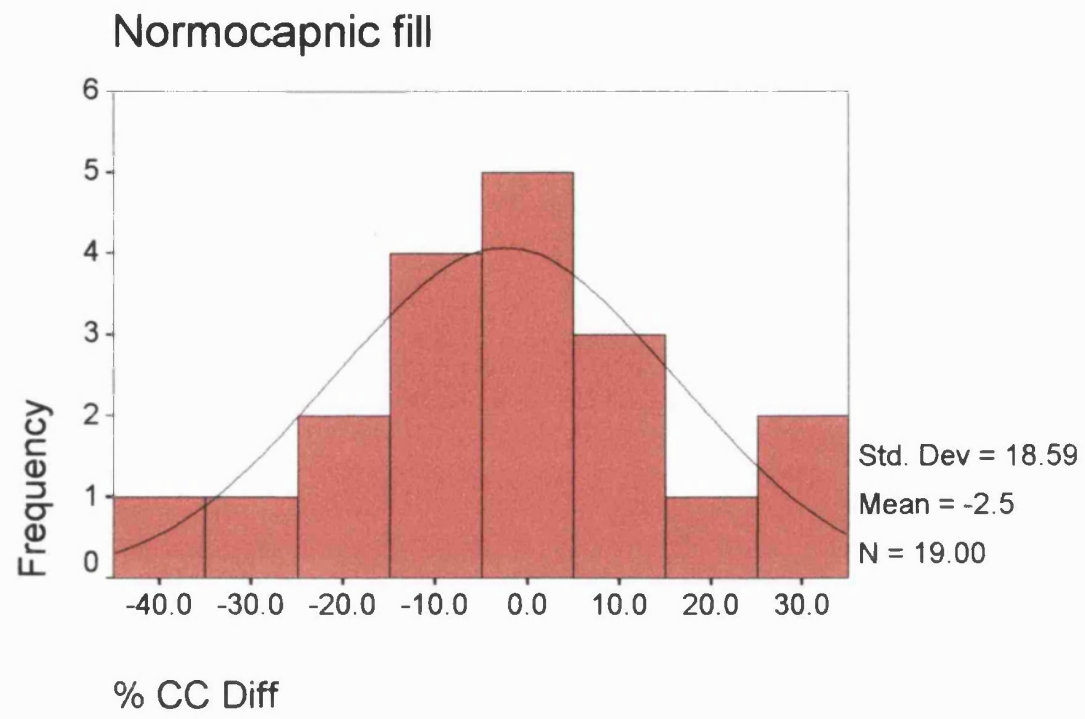

This figure shows the frequencies of \%age change in cystometric capacities between the normocapnic fill and the saline control fill

Figure 4.20

Normal QQ plot of \% CC difference

Normocapnic fill

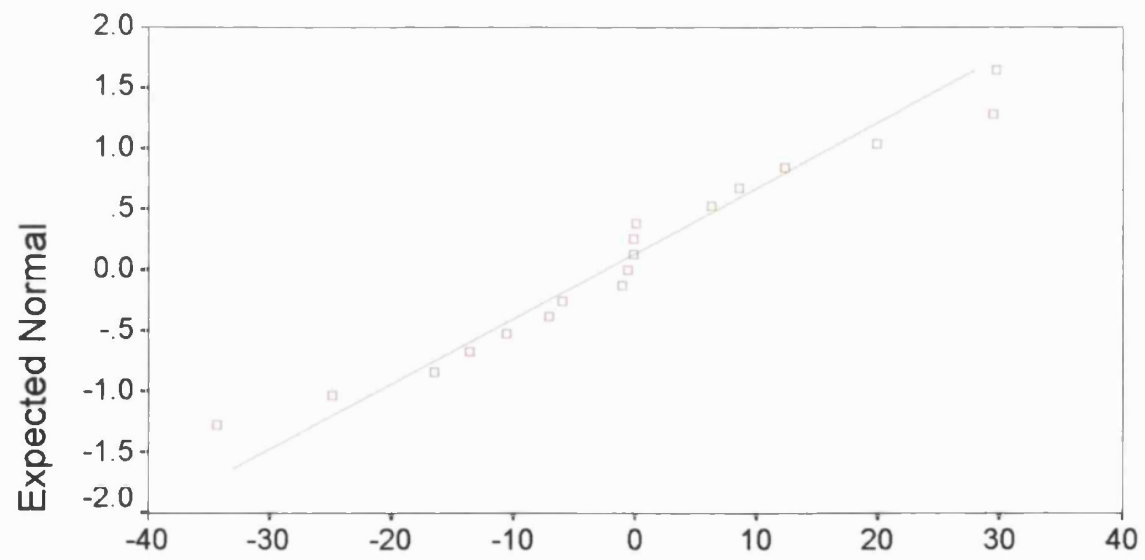

Observed Value

This shows the normal distribution Quantile-Quantile (QQ) plot of the \% age change in cystometric capacity between the normocapnic fill and the saline control fill. The green line shows the best plot of a normal distribution and the red points are the actual data 
Figure 4.21

Scatter plot of \% CC difference

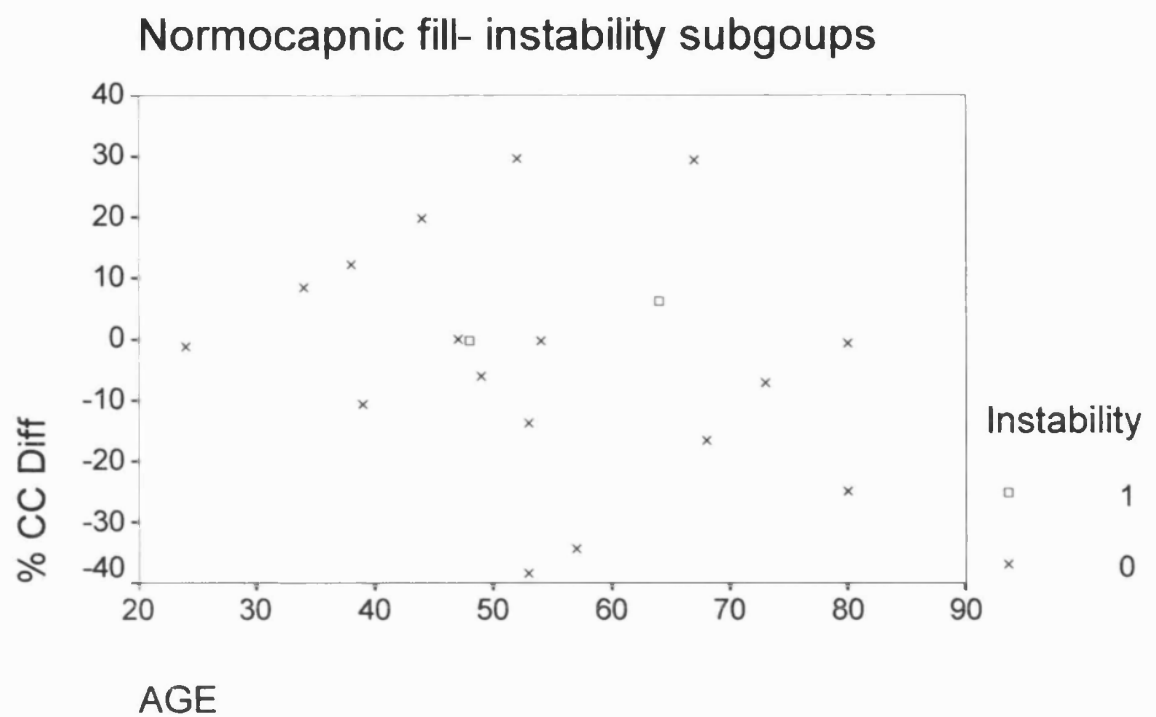

This shows the data points of \%age change in cystometric capacity between the normocapnic fill and the control fill, plotted against age. Different points are used for those with urodynamic evidence of overactivity (instability)- present- 1 , absent- 0

Figure 4.22

Boxplot of \% FSF difference

Normocapnic fill- urgency subgroups

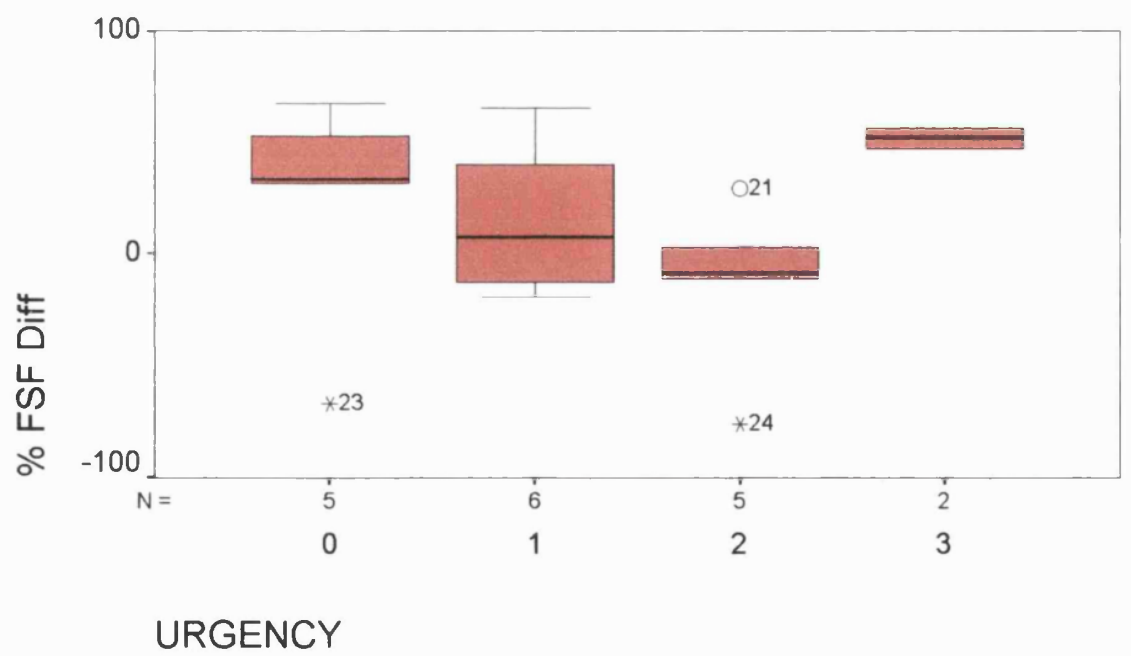

This shows the subgroups of urgency- mild-1, moderate-2, and severe-3, with plotted $\%$ age change in first sensation of filling as a boxplot. 
Figure 4.23

\section{Boxplot of \% FDV difference}

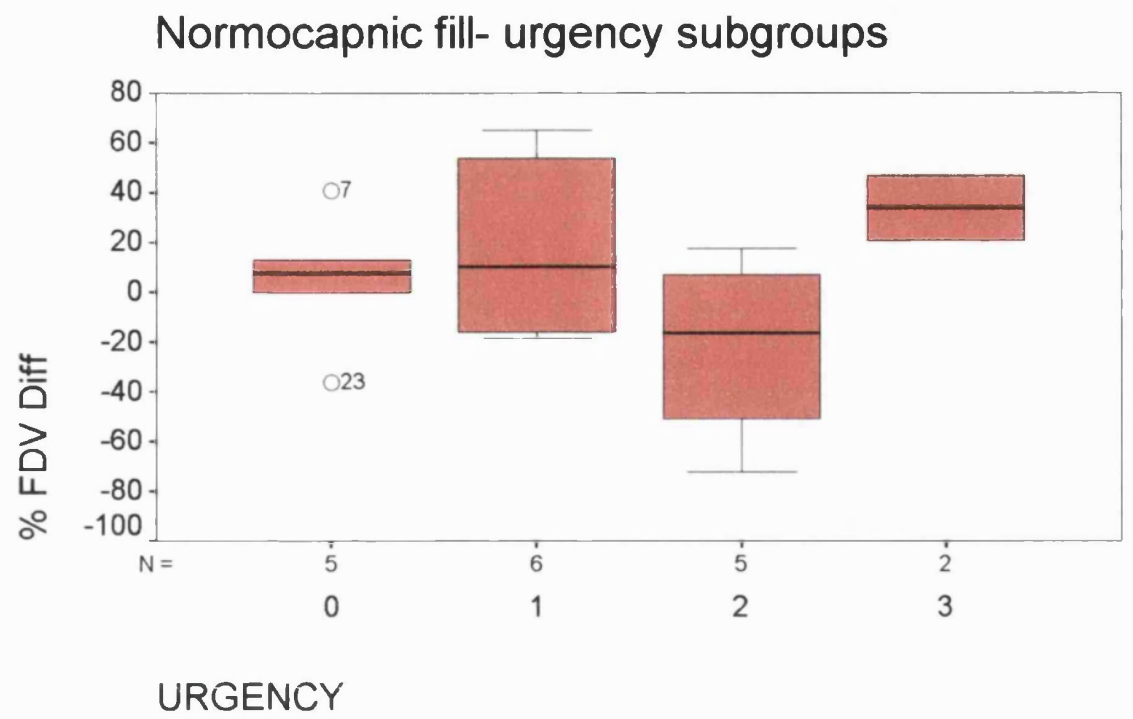

This shows the subgroups of urgency- mild-1, moderate- 2 , and severe- 3 , with plotted $\%$ age change in first desire to void as a boxplot

Figure 4.24

Boxplot of \% CC difference

Normocapnic fill- urgency subgroups

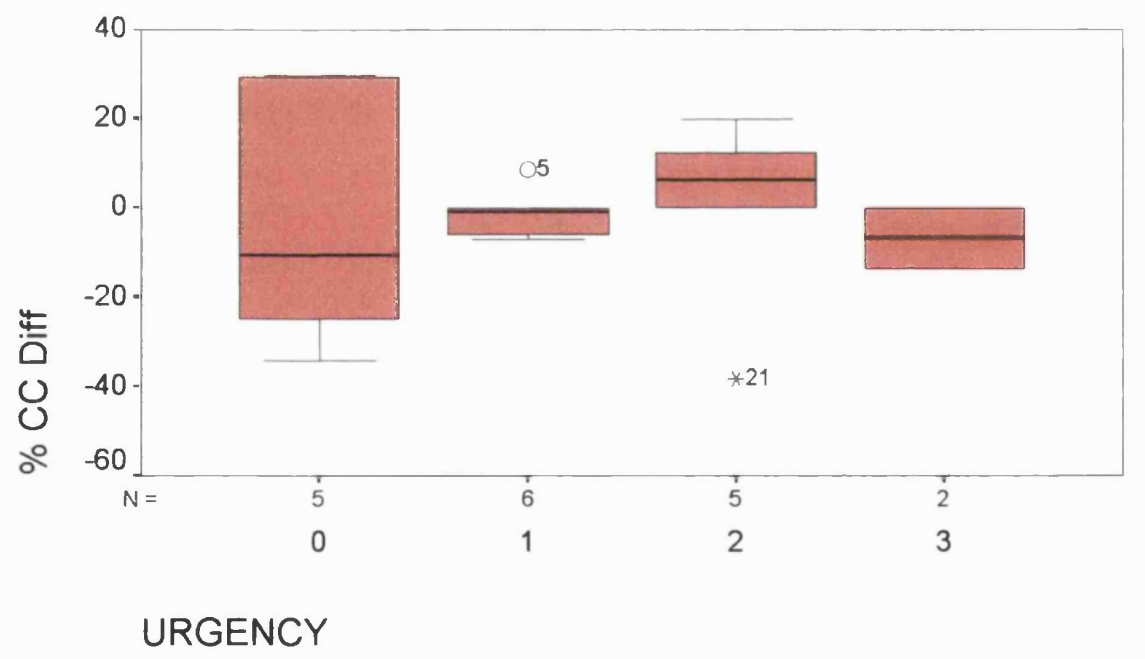

This shows the subgroups of urgency- mild-1, moderate-2, and severe-3, with plotted $\%$ age change in cystometric capacity as a boxplot 


\section{Figure 4.25}

\section{Histogram of \% FSF difference}

\section{Hypercapnic study}

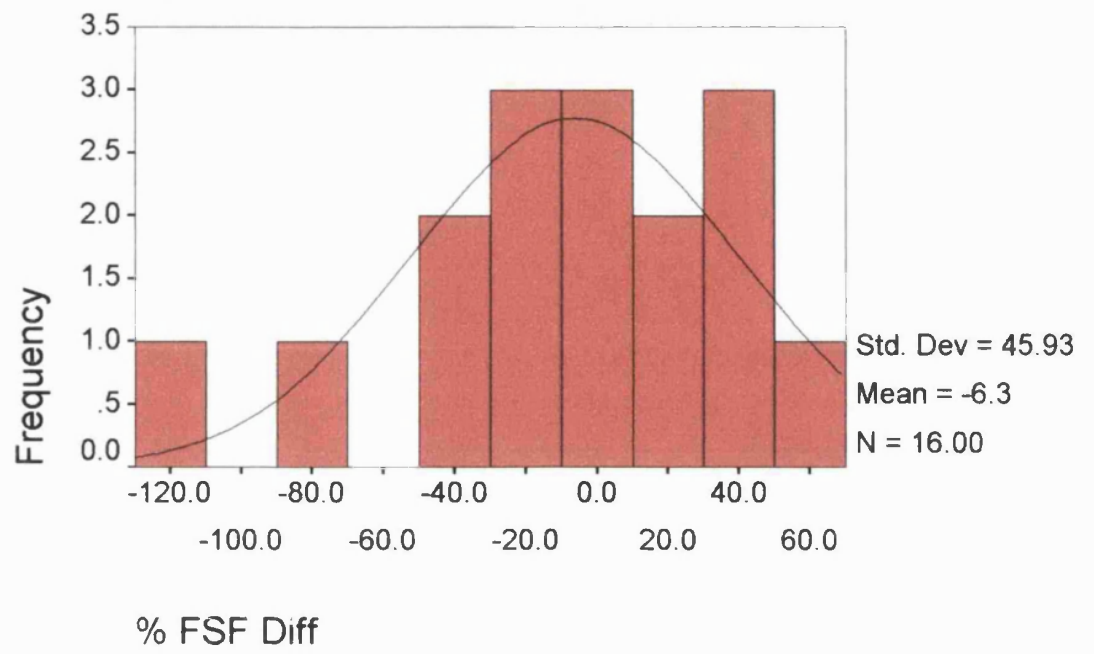

This figure shows the frequencies of $\%$ age change in volume at first sensation of filling between the hypercapnic study solution and the saline control.

Figure 4.26

Histogram of \% FDV difference

Hypercapnic study

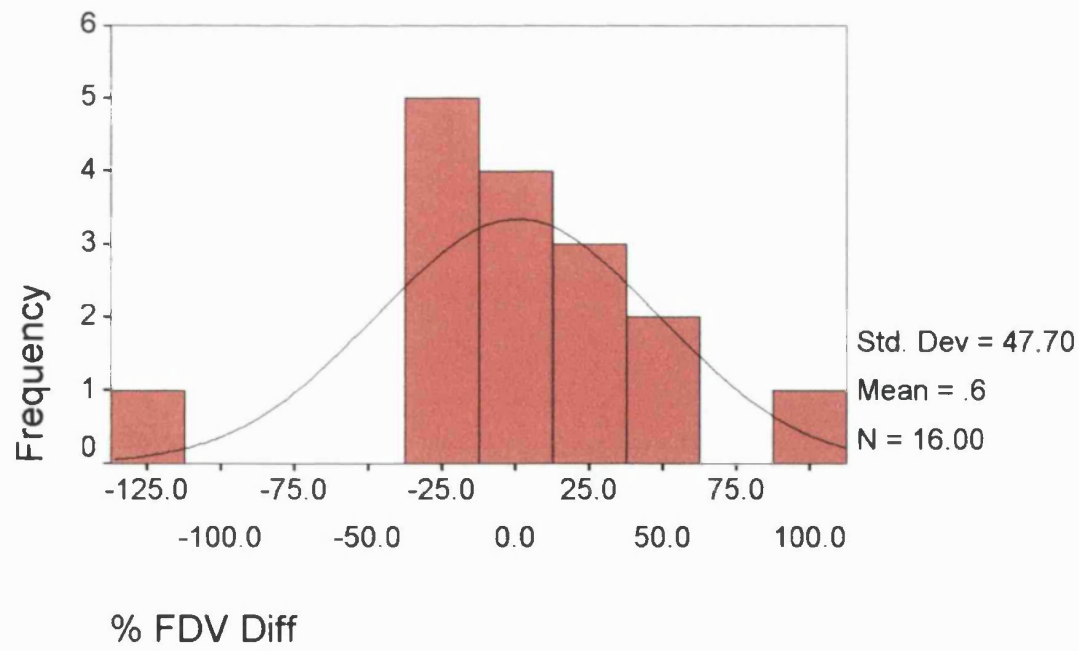

This figure shows the frequencies of $\%$ age change in volume at first desire to void differences between the hypercapnic study solution and the saline control. 
Figure 4.27

Histogram of \% CC difference

Hypercapnic study

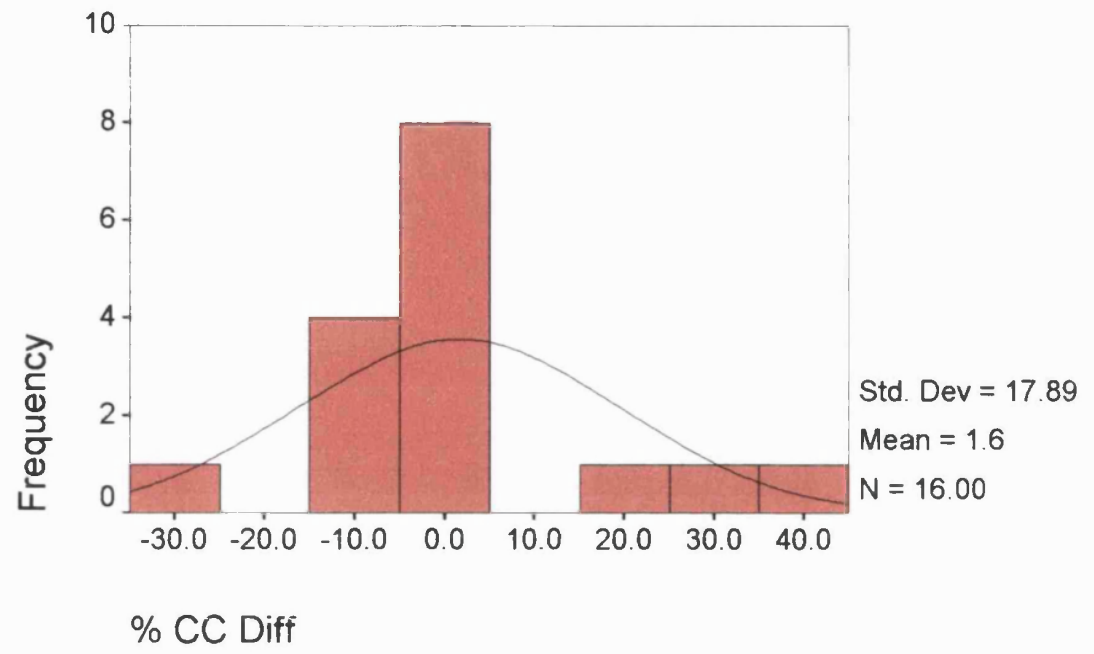

This figure shows the frequencies of \%age change in cystometric capacities between the hypercapnic study fill and the saline control fill

Figure 4.28

Normal QQ plot of \% CC difference

Hypercapnic study

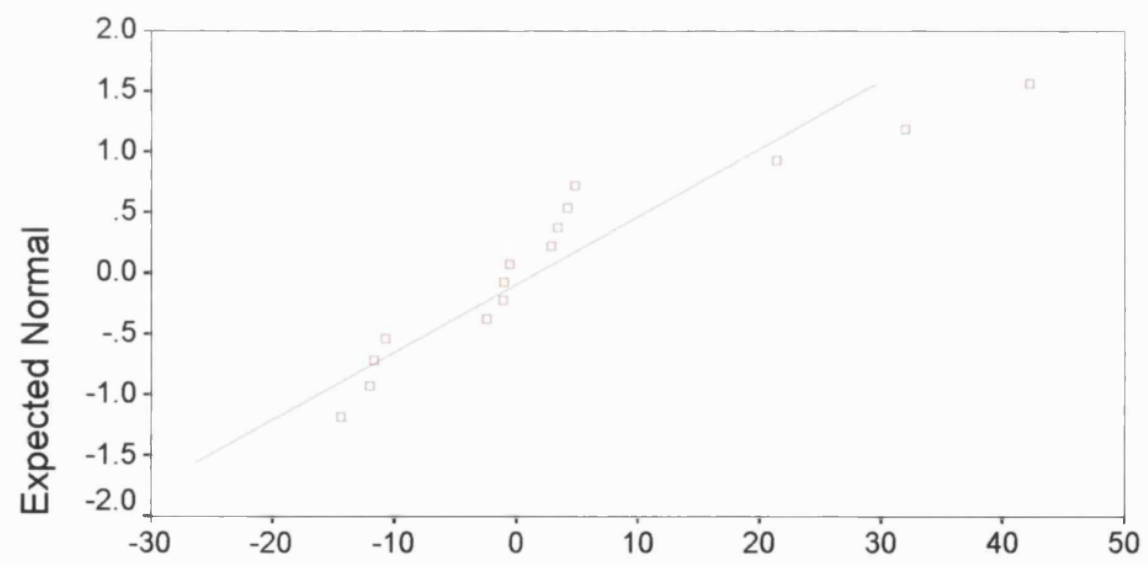

Observed Value

This shows the normal distribution Quantile-Quantile (QQ) plot of the $\%$ age change in cystometric capacity between the hypercapnic study fill and the saline control fill. The green line shows the best plot of a normal distribution and the red points are the actual data. 
Figure 4.29

Scatter plot of \% CC difference

Hypercapnic study- instability subgroups

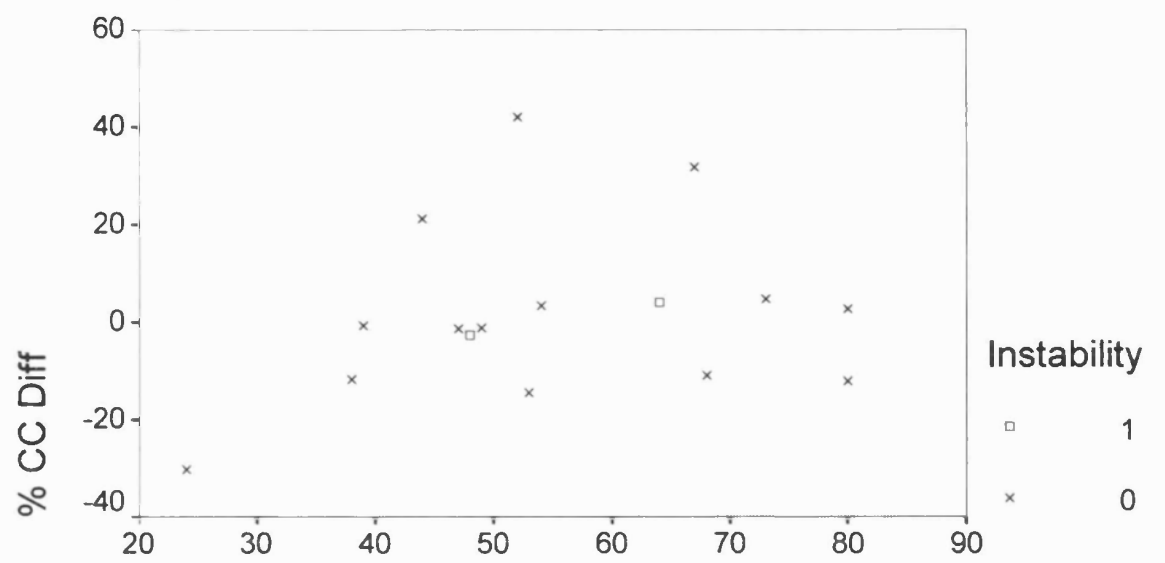

AGE

This shows the data points of \%age change in cystometric capacity between the hypercapnic study fill and the control fill, plotted against age. Different points are used for those with urodynamic evidence of overactivity (instability)- present-1, absent-0

Figure 4.30

Boxplot of \% FSF difference

Hypercapnic study- urgency subgroups

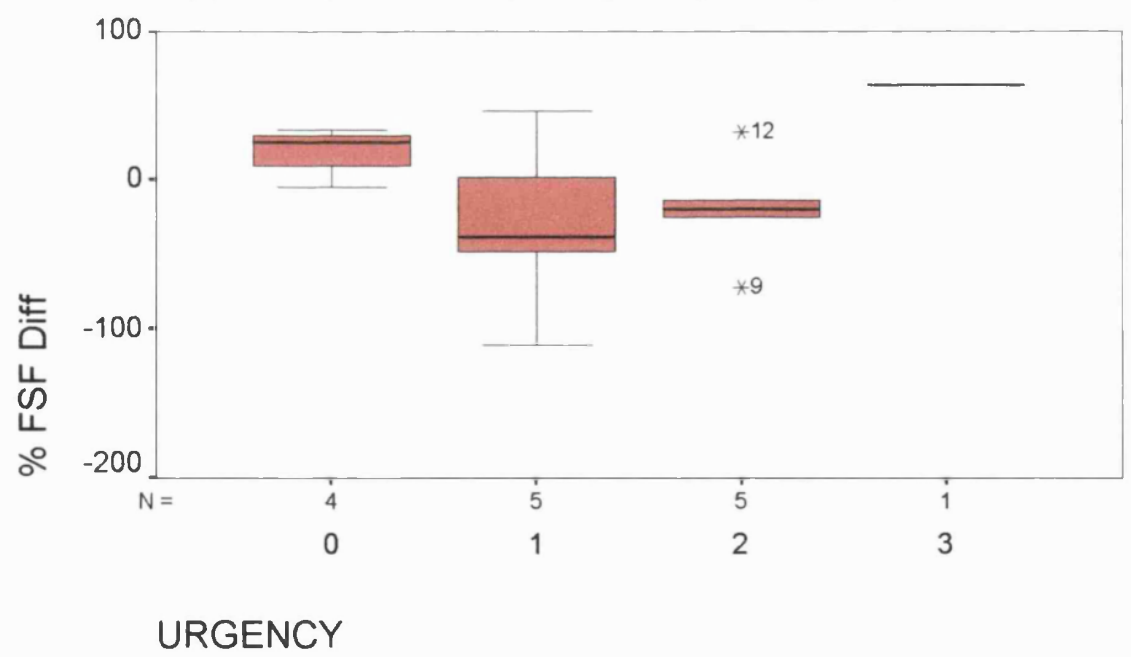

This shows the subgroups of urgency- mild-1, moderate-2, and severe-3, with plotted $\%$ age change in first sensation of filling as a boxplot. 
Figure 4.31

Boxplot of \% FDV difference

Hypercapnic study- urgency subgroups

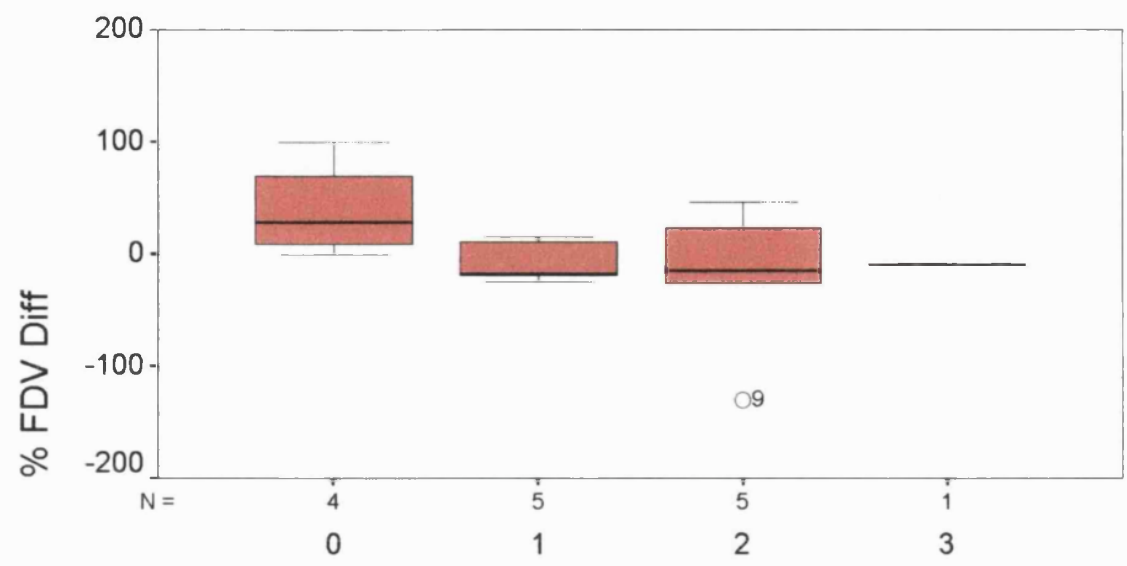

URGENCY

This shows the subgroups of urgency- mild-1, moderate-2, and severe-3, with plotted \% age change in first desire to void as a boxplot

Figure 4.32

Boxplot of \% CC difference

Hypercapnic study- urgency subgroups

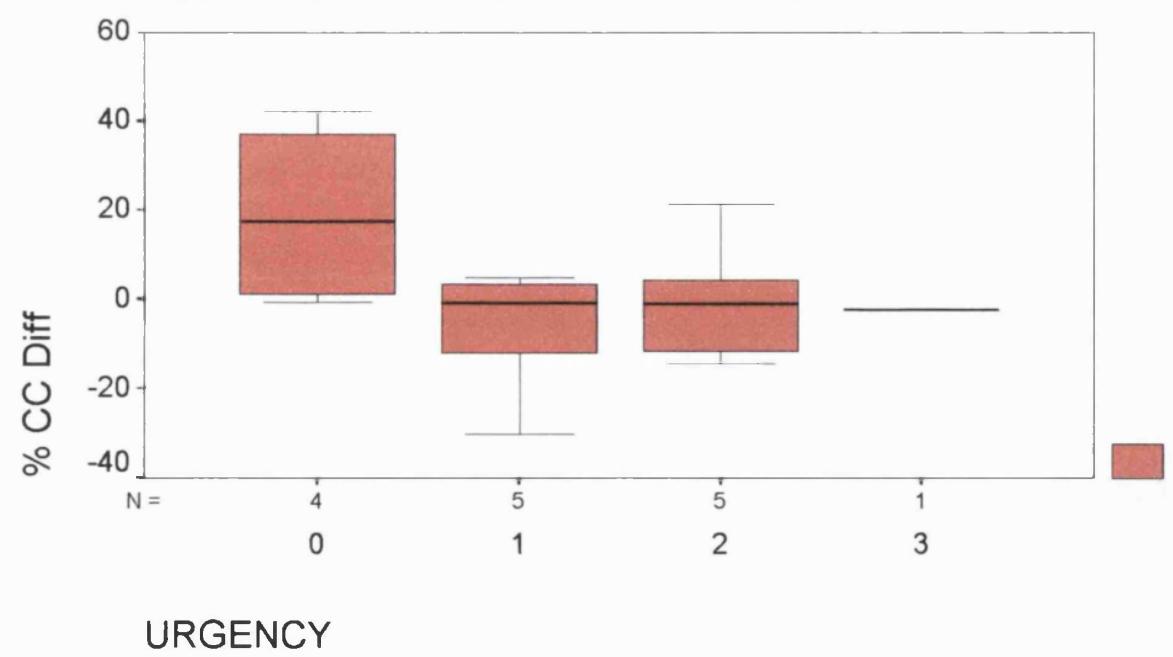

This shows the subgroups of urgency- mild-1, moderate-2, and severe-3, with plotted $\%$ age change in cystometric capacity as a boxplot 
Figure 4.33

Histogram of \% FSF difference

Hypercapnic (test) vs normocapnic (control)

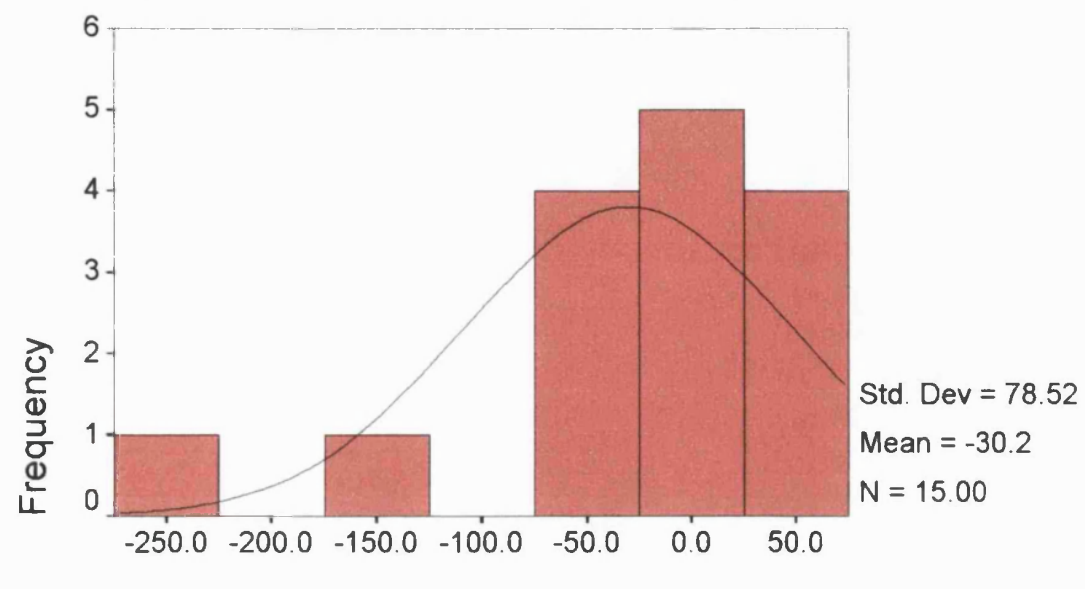

$\%$ FSF Diff

This figure shows the frequencies of $\%$ age change in volume at first sensation of filling between the hypercapnic study solution and the normocapnic study, treated as a control

Figure 4.34

\section{Histogram of \% FDV difference}

Hypercapnic (test) vs normocapnic (control)

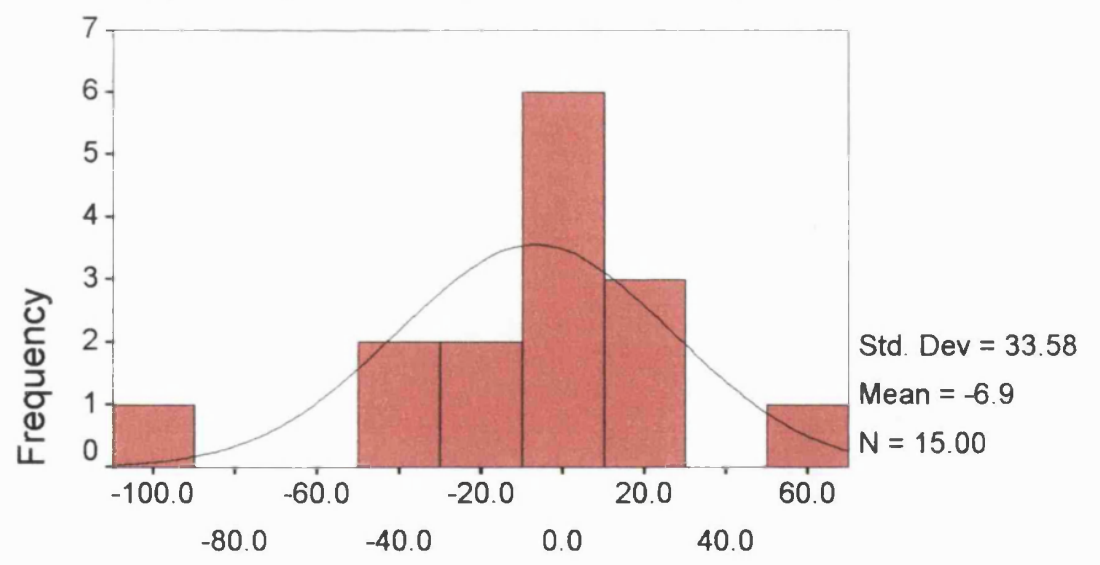

$\%$ FDV Diff

This figure shows the frequencies of $\%$ age change in volume at first desire to void differences between the hypercapnic study solution and the normocapnic study, treated as a control. 
Figure 4.35

Histogram of \% CC difference

Hypercapnic (test) vs normocapnic (control)

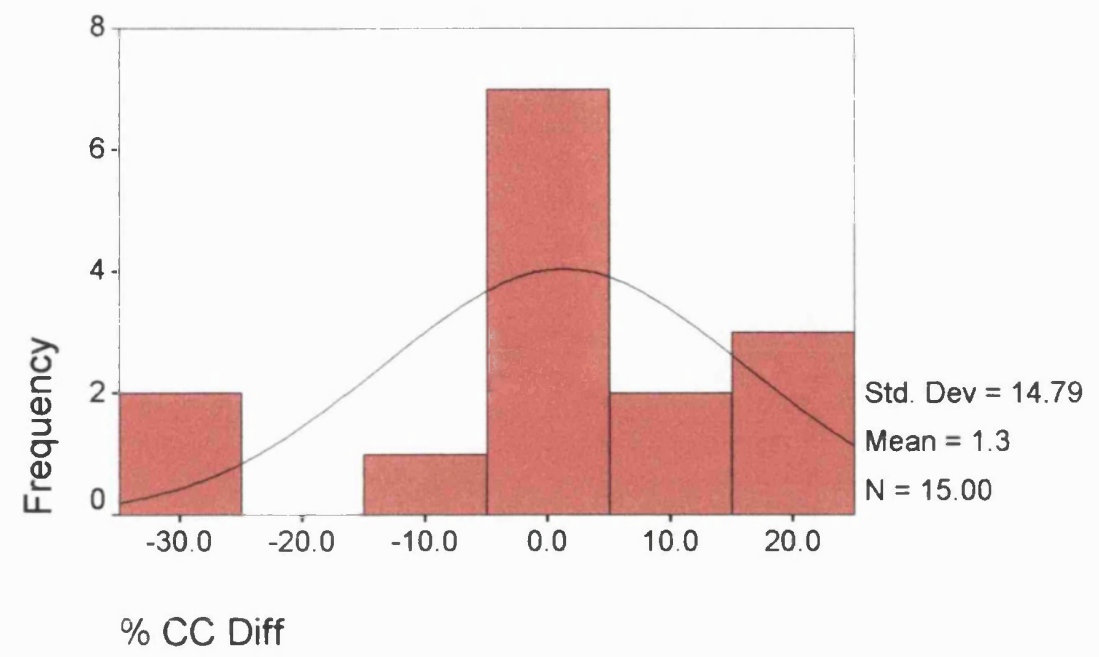

This figure shows the frequencies of \%age change in cystometric capacities between the hypercapnic study fill and the and the normocapnic study, treated as a control

Figure 4.36

Normal QQ plot of \% CC difference

Hypercapnic (test) vs normocapnic (control)

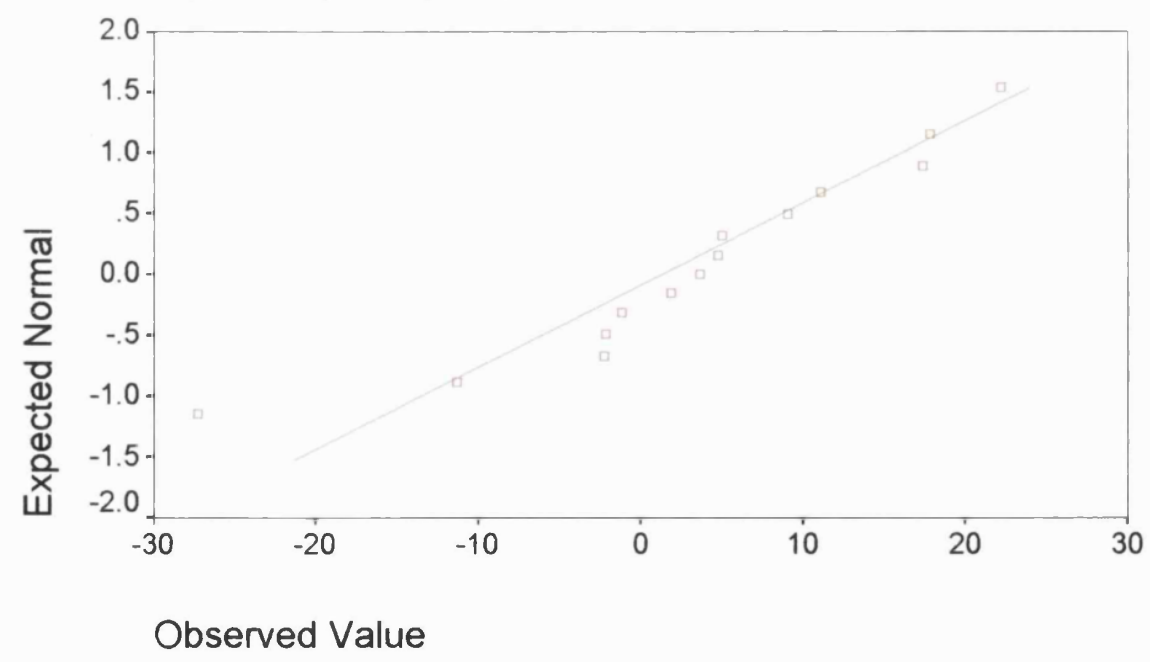

This shows the normal distribution Quantile-Quantile (QQ) plot of the \% age change in cystometric capacity between the hypercapnic study fill and the normocapnic study, treated as a control. The green line shows the best plot of a normal distribution and the red points are the actual data. 


\subsection{Potassium study}

The aim of this study was to examine whether instillation of a solution high in potassium affected urodynamic testing when compared to a normal saline intravesical infusate.

Thirteen subjects were recruited, mean age 59. Six patients had stable fills and six unstable fills. One withdrew after the first fill (patient D1). Three had urgency graded by themselves to be 'none' or 'mild', ten had urgency graded as moderate or severe. The results are shown in table 4.12 , and the results analysis in table 4.13 .

The diagnoses were as follows- Stress urinary incontinence with stable urodynamics-4, Detrusor overactivity-4, Mixed stress incontinence with detrusor overactivity-1, Normal urodynamics-4. No subjects had taken prior anticholinergics. All tests showed the same diagnosis urodynamically on each fill.

All differences between the urodynamic variables in the whole group were small and the interquartile ranges around the median differences in the urodynamic variables included zero.

In one patient (D5) the FSF rose from $10 \mathrm{ml}$ in the control fill to $274 \mathrm{ml}$ in the test fill (she felt the first sensation o filling and the first desire to void at the same time). This outlier influenced the statistical data for \% FSF difference to some degree. Similar changes were not seen in the FDV or CC for the same patient, so this may well have been a one off result with little significance. The histograms for the \% differences in urodynamic variables are shown in figures 4.37, 4.38, and 4.39. The normal QQ plot for \% CC difference is shown in figure 4.40, and demonstrates near normal distribution, although most of the 
values for the ratios of skewness and kurtosis to their standard errors fall above 2 or below- 2 , suggesting that the non parametric analysis is more appropriate.

The subgroups of urgency and instability do not reveal any significant differences, and the outlier already described skews the data for severe urgency (3) \% FSF difference. The scatter plot and boxplots for the instability and urgency subgroups are shown in figures $4.41,4.42,4.43$, and 4.44 .

The groups are very similar, and on this data, the study had a $20 \%$ power to detect a difference between the fills (control and potassium) if one is present. This suggests that for an $80 \%$ power and a significance level of $5 \%$ the study would have needed 80 patients. 
Key for Table 4.11

Urgency- $\quad 0$ - None

1 Mild

2 Moderate

3 Severe

Instability $\quad 0 \quad$ Stable urodynamics

1 Unstable urodynamics

FSF Control Volume in mls at first sensation of filling- Saline control fill

FSF Test Volume in mls at first sensation of filling- Intervention study fill

FSF Diff $\quad$ FSF Control- FSF Test

\% FSF Diff FSF Dif expressed as \% of control fill

FDV Control Volume in mls at first desire to void- Saline control fill

FDV Test Volume in mls at first desire to void- Intervention study fill

FDV Diff FDV Control- FDV Test

$\%$ FDV Diff FDV Diff expressed as \% of control fill

CC Control Volume in mls at cystometric capacity- Saline control fill

CC Test Volume in mls at cystometric capacity- Intervention study fill

CC Diff CC Control- CC Test

\% CC Diff CC Diff expressed as \% of control fill

Order test fill Order of the test fill- 1- Test fill followed by control fill

2- Control fill followed by test fill 


\begin{tabular}{|c|c|c|c|c|c|c|c|c|c|c|c|c|c|c|c|c|}
\hline Patient & Age & Urgency & Instability & FSF Contre & FSF Test & FSF Diff & $\%$ FSF Diff & FDV Contro & FDV Test & FDV Diff & \% FDV Diff & CC Control & $\sqrt{1 \text { CC Test }}$ & CC Diff & $\%$ CC Diff & Order Test fill \\
\hline $\mathrm{D} 1$ & 29 & 2 & 0 & & 74 & & & & 293 & & & & 497 & & & 1 \\
\hline $\mathrm{D} 2$ & 79 & 2 & 1 & 235 & 150 & 85 & 36.17021 & 235 & 150 & 85 & 36.17021 & 235 & 165 & 70 & 29.78723 & 1 \\
\hline D3 & 43 & 2 & 1 & 22 & 45 & -23 & -104.5455 & 85 & 84 & 1 & 1.176471 & 485 & 468 & 17 & 3.505155 & 2 \\
\hline D4 & 75 & 3 & 1 & 82 & 122 & -40 & -48.78049 & 104 & 125 & -21 & -20.19231 & 213 & 136 & 77 & 36.15023 & 2 \\
\hline D5 & 45 & 3 & 1 & 10 & 274 & -264 & -2640 & 408 & 274 & 134 & 32.84314 & 499 & 483 & 16 & 3.206413 & 1 \\
\hline D6 & 64 & 1 & 0 & 185 & 151 & 34 & 18.37838 & 185 & 151 & 34 & 18.37838 & 300 & 190 & 110 & 36.66667 & 2 \\
\hline D7 & 45 & 1 & 0 & 51 & 9 & 42 & 82.35294 & 500 & 501 & -1 & -0.2 & 500 & 501 & -1 & -0.2 & 1 \\
\hline D8 & 66 & 1 & 0 & 240 & 369 & -129 & -53.75 & 350 & 392 & -42 & -12 & 350 & 392 & -42 & -12 & 1 \\
\hline D9 & 59 & 3 & 1 & 150 & 267 & -117 & -78 & 179 & 267 & -88 & -49.16201 & 431 & 374 & 57 & 13.22506 & 2 \\
\hline D10 & 84 & 2 & 0 & 333 & 95 & 238 & 71.47147 & 337 & 98 & 239 & 70.91988 & 501 & 500 & 1 & 0.199601 & 1 \\
\hline D11 & 71 & 2 & 0 & 233 & 293 & -60 & \begin{tabular}{|l|}
-25.75107 \\
\end{tabular} & 240 & 304 & -64 & -26.66667 & 395 & 498 & -103 & -26.07595 & 1 \\
\hline $\mathrm{D} 12$ & 38 & 2 & 0 & 81 & 75 & 6 & \begin{tabular}{|l|l|}
7.407407 \\
\end{tabular} & 123 & 76 & 47 & 38.21138 & 234 & 414 & -180 & -76.92308 & 1 \\
\hline D13 & 56 & 2 & 1 & 178 & 184 & -6 & \begin{tabular}{|l|}
-3.370787 \\
\end{tabular} & 186 & 186 & 0 & 0 & 257 & 243 & 14 & 5.447471 & 2 \\
\hline
\end{tabular}

Table 4.12- results for each subject in potassium study (see previous page for key)

$\Xi$ 


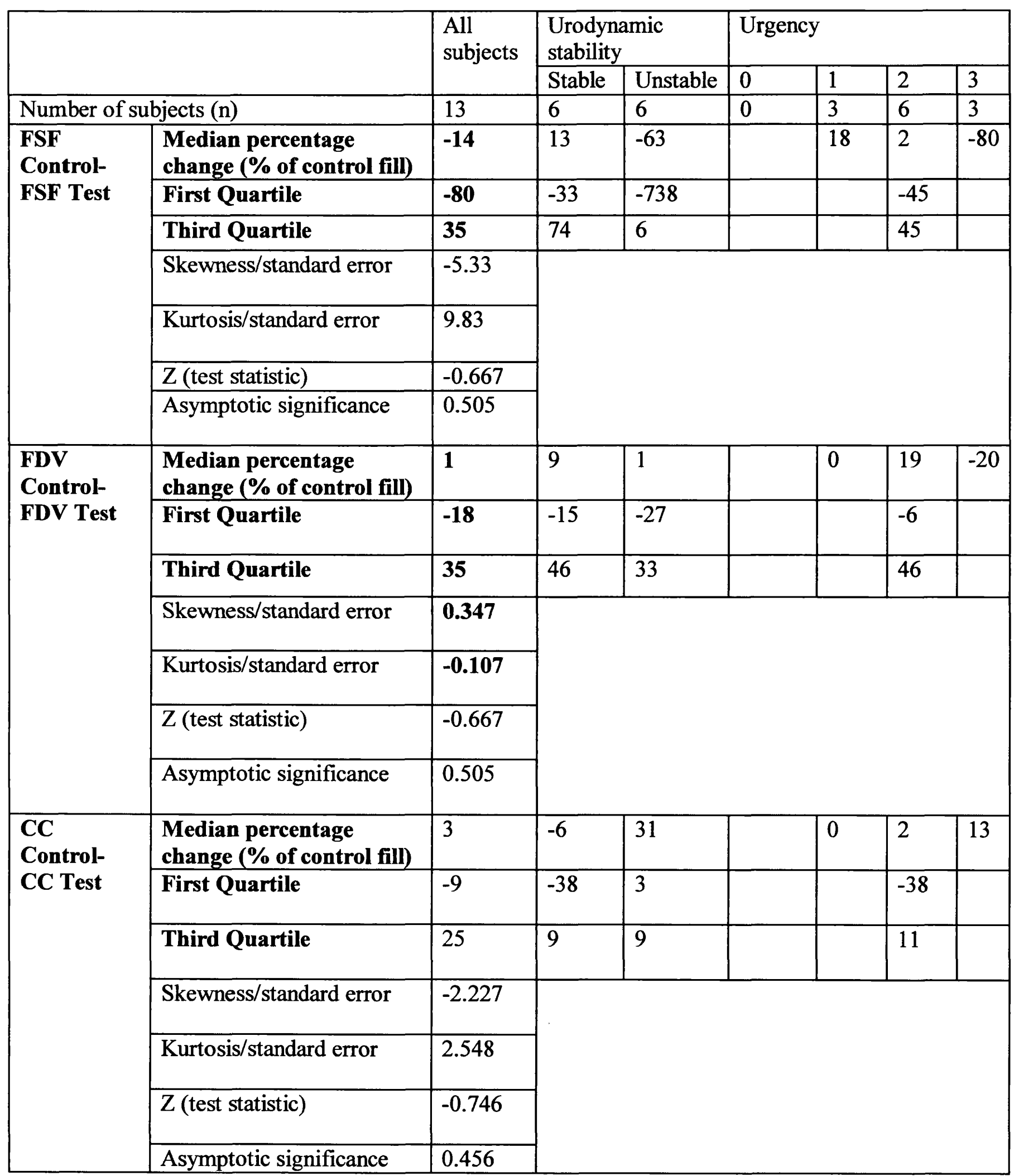

Figure 4.13- Results analysis for potassium study 
Figure 4.37

Histogram of \% FSF difference

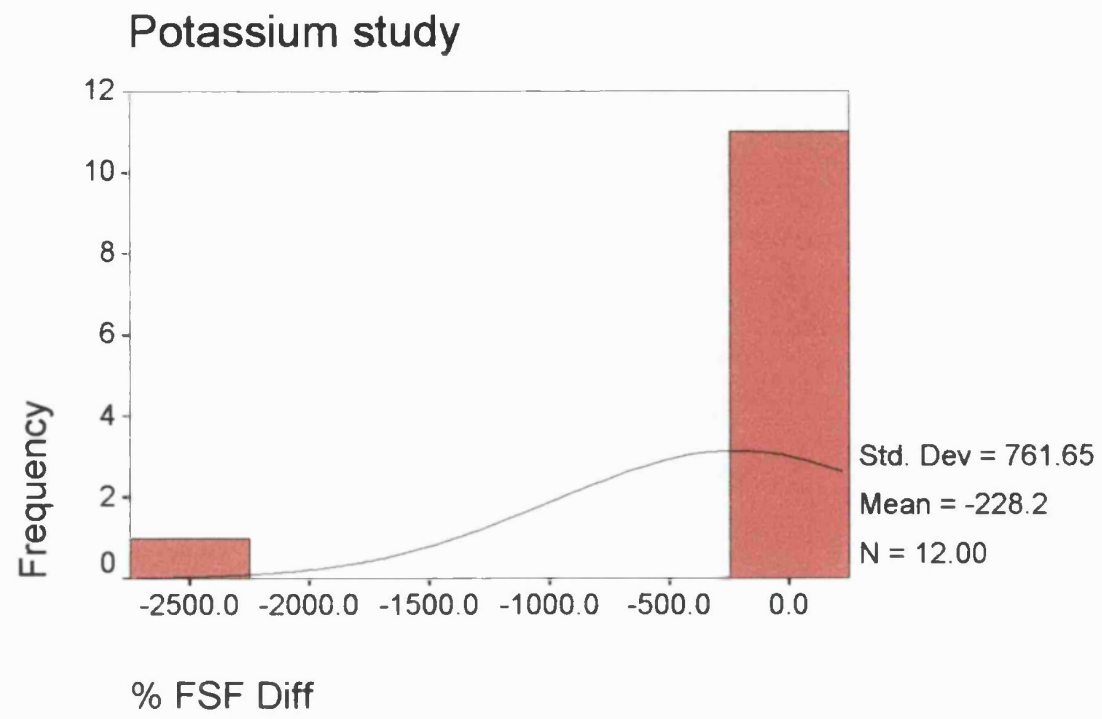

This figure shows the frequencies of $\%$ age change in volume at first sensation of filling between the high potassium study solution and the saline control.

Figure 4.38

\section{Histogram of \% FDV difference}

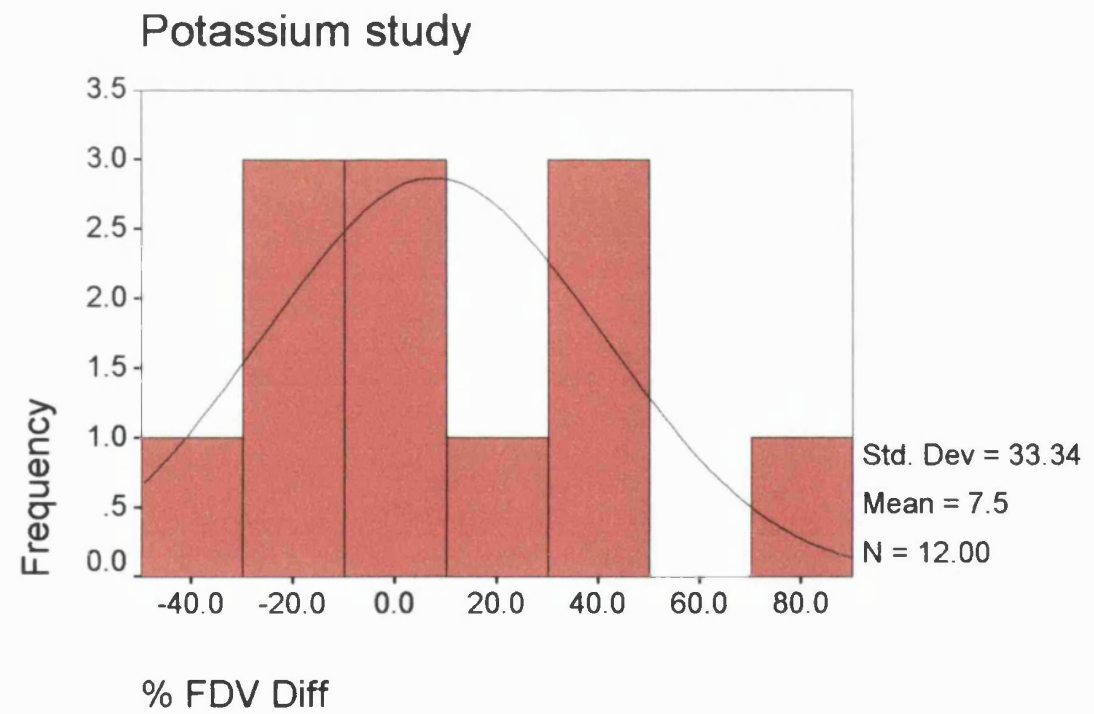

This figure shows the frequencies of $\%$ age change in volume at first desire to void differences between the high potassium study solution and the saline control 
Figure 4.39

\section{Histogram of \% CC difference}

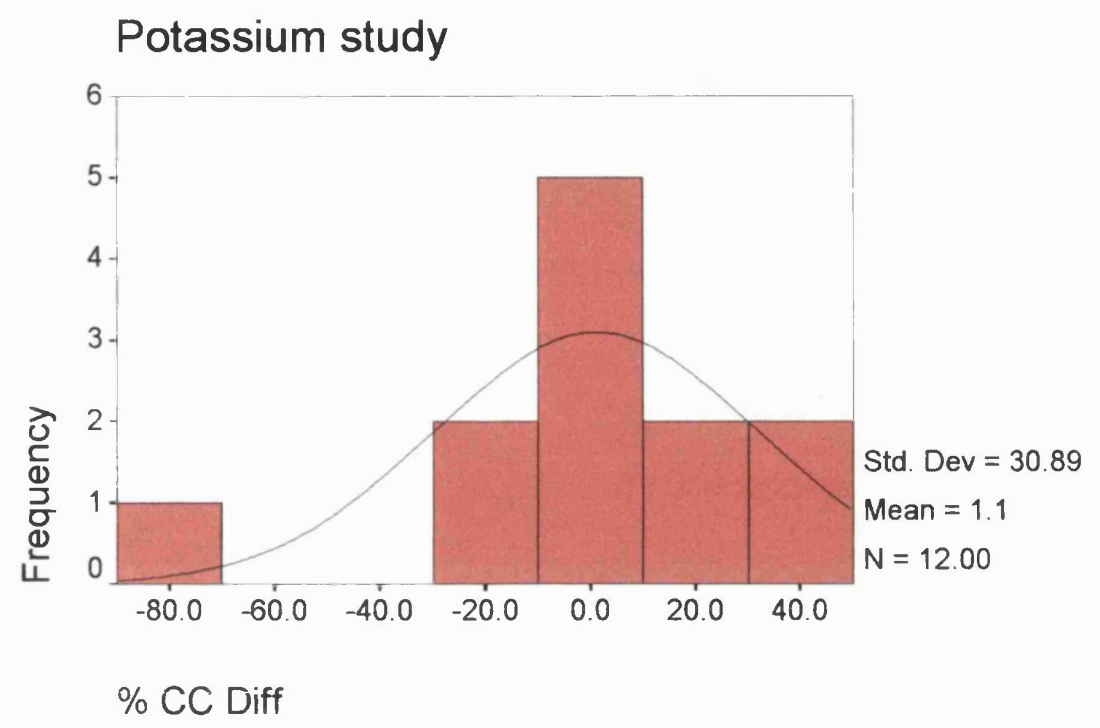

This figure shows the frequencies of \%age change in cystometric capacities between the high potassium study solution and the saline control

Figure 4.40

\section{Normal QQ plot of \% CC difference}

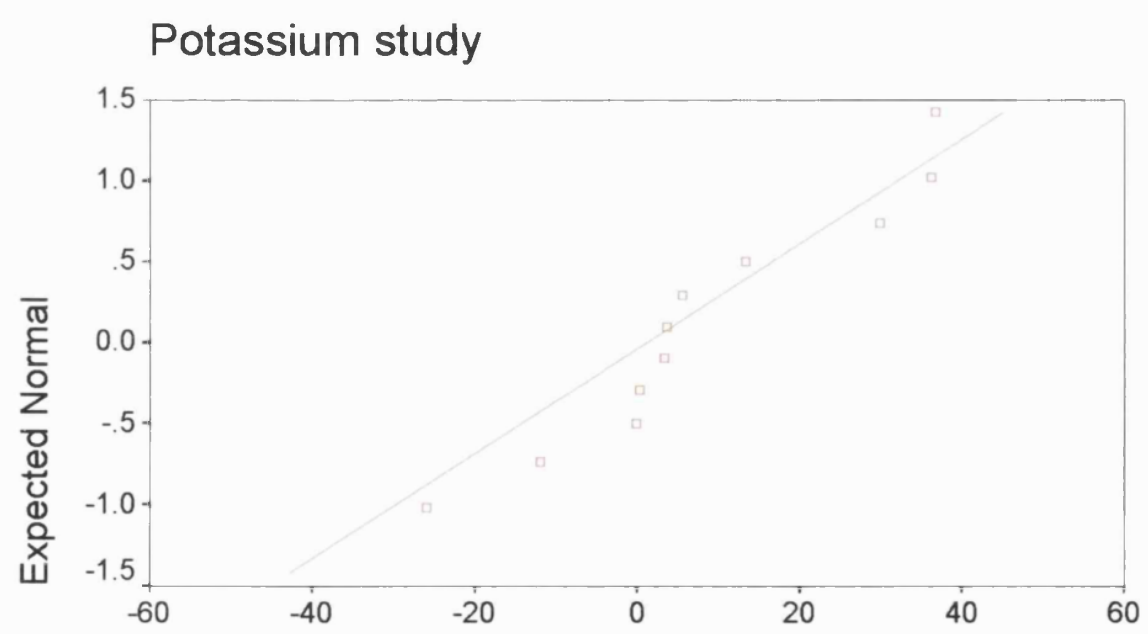

Observed Value

This shows the normal distribution Quantile-Quantile (QQ) plot of the $\%$ age change in cystometric capacity between the high potassium study solution and the saline control. The green line shows the best plot of a normal distribution and the red points are the actual data. 
Figure 4.41

\section{Scatter plot of \% CC difference}

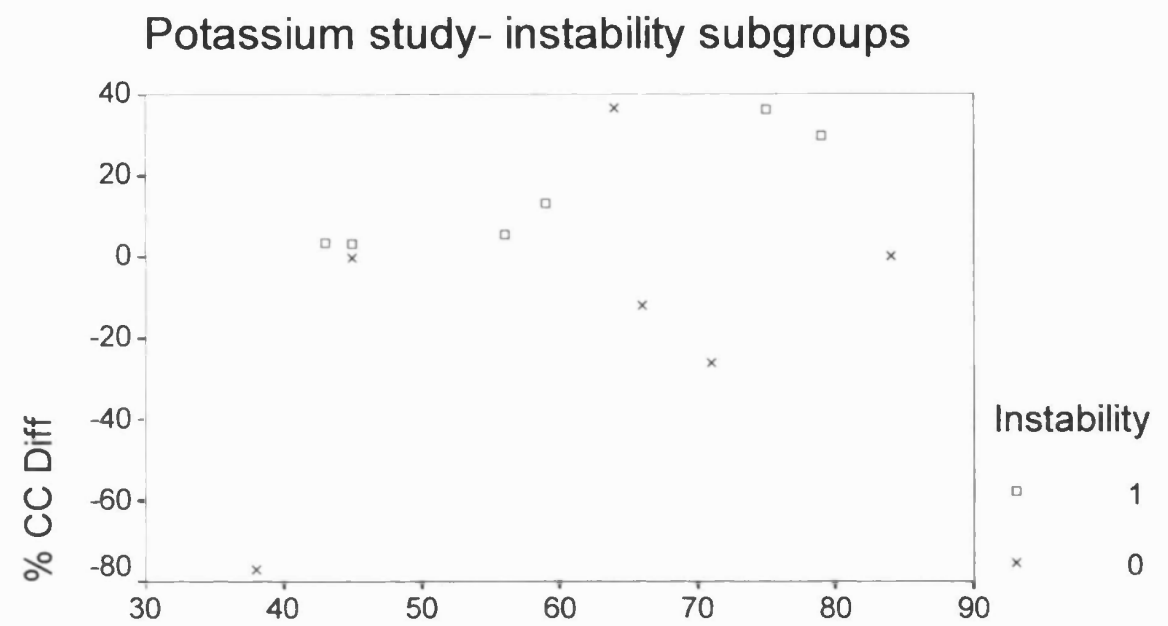

AGE

This shows the data points of \%age change in cystometric capacity between the high potassium study solution and the saline control, plotted against age. Different points are used for those with urodynamic evidence of overactivity (instability)- present- 1 , absent -0

Figure 4.42

Boxplot of \% FSF difference

Potassium study- urgency subgroups

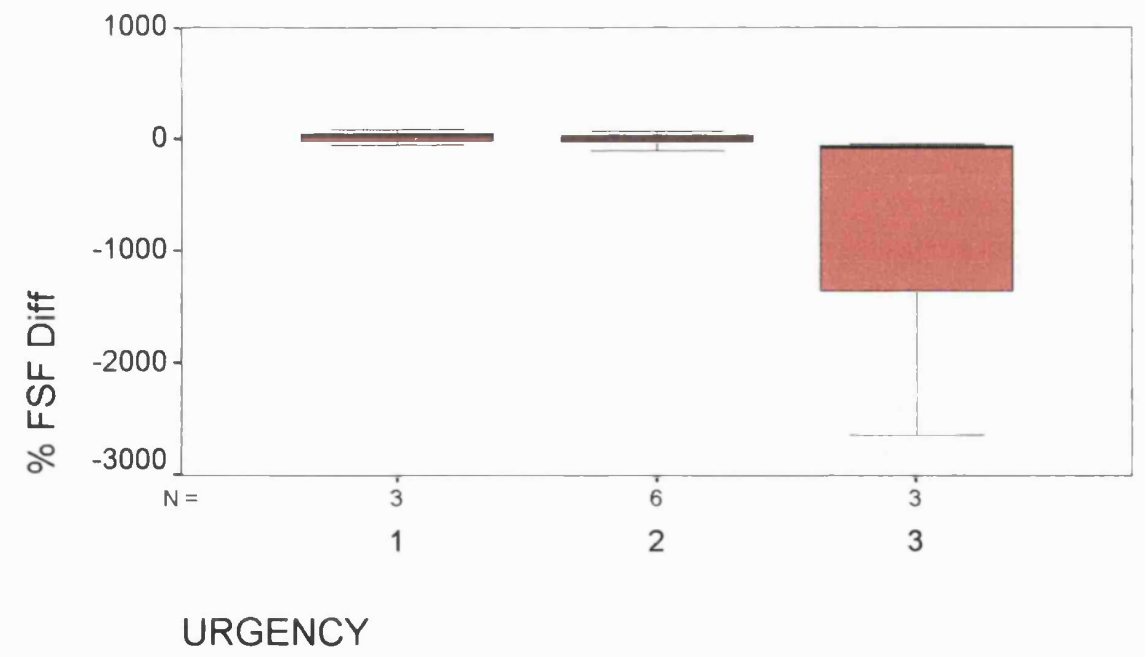

This shows the subgroups of urgency- mild-1, moderate-2, and severe-3, with plotted $\%$ age change in first sensation of filling as a boxplot. 
Figure 4.43

Boxplot of \% FDV difference

Potassium study- urgency subgroups

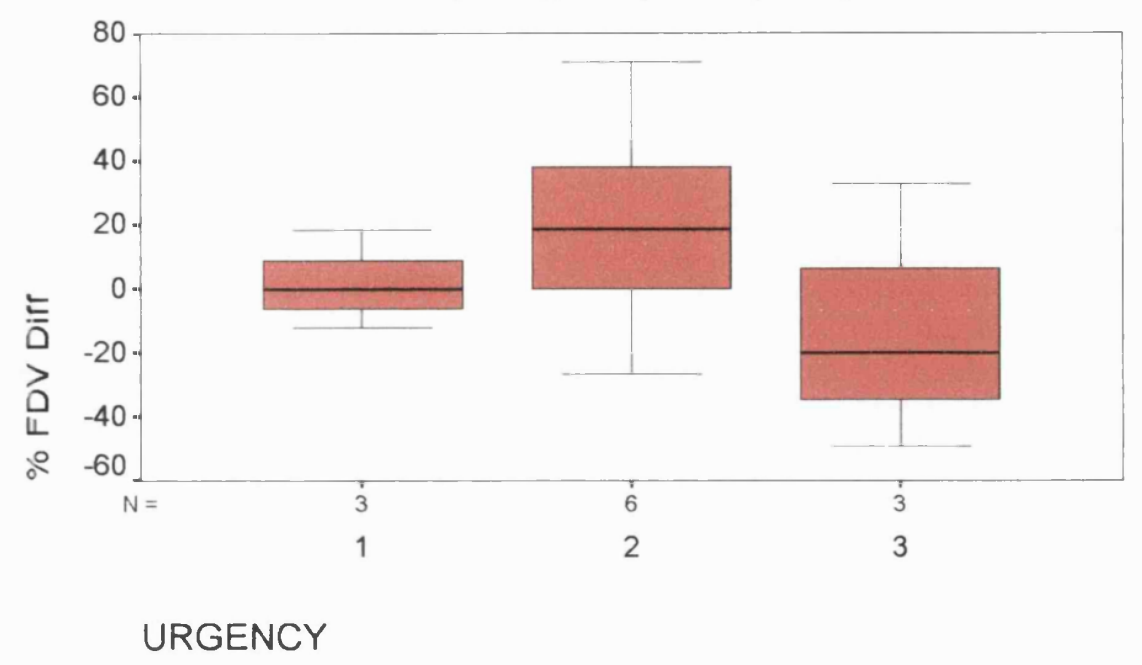

This shows the subgroups of urgency- mild-1, moderate-2, and severe-3, with plotted $\%$ age change in first desire to void as a boxplot

Figure 4.44

Boxplot of \% CC difference

Potassium study- urgency subgroups

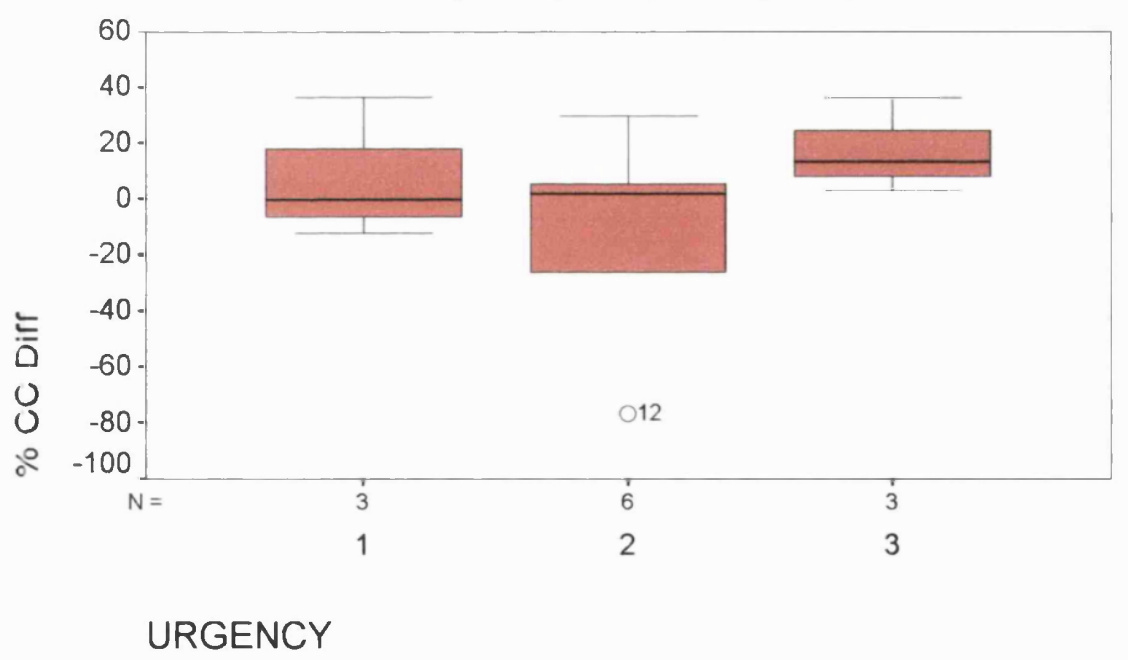

This shows the subgroups of urgency- mild-1, moderate-2, and severe-3, with plotted $\%$ age change in cystometric capacity as a boxplot 


\subsection{Order of fill data}

The order of the fills was randomised throughout the study. Thus the study gave the opportunity to analyse the cystometric variables between order of fills. As there was no significant influence of filling solution on cystometric variables, these could be analysed for all studies together ( 94 patients). The null hypothesis of this analysis is therefore that repeat filling has no influence on urodynamic variables.

This analysis showed that there was no significant difference between variablesvolumes at FSF, FDV and CC on first and subsequent fills (as shown in table 4.14). In the cases where three fills were completed, they were all analysed, but first against second were treated in the same way as first against third fills. All the differences are small and the interquartile ranges include zero. The levels of significance on the Wilcoxon test are all $>0.05$. The histograms of the repeat fill data are shown in figures $4.45,4.46$, and 4.47. The normal QQ plot is shown in figure 4.48. These show that the data are clustered tightly around zero but there is a negative 'tail'- suggesting that in a group of patients, the second fill produces smaller volumes at FSF, FDV and CC than in the first fill. This group cannot be identified by their stability or instability or by their symptoms of urgency. Nor does age identify this group (scatter plot against age with instability subgroups figure 4.49).

The boxplots (figures 4.50, 4.51 and 4.52) show the data divided into urgency subgroups.

The data are not normally distributed- the ratios of skewness and kurtosis to their standard errors are greater than 2 or less than -2 . Non-parametric treatment is therefore the most appropriate. The parametric treatment of data (appendix 4) 
suggests a larger capacity in the first fill than the second, (mean difference of capacity $-20 \%[95 \% \mathrm{CI}-40 \%,-6 \%])$. The non-parametric treatment shows a median change in capacity of zero, with the interquartile range from -17 to 3 which reflects the tight clustering with a negative tail referred to above.

If the differences between the first and second fills were significant, at $p<0.05$, and at a power of $80 \%$, this study would have needed 540 patients. Again, this demonstrates the closeness of the groups rather than the lack of power of the study. 


\begin{tabular}{|c|c|c|c|c|c|c|c|c|}
\hline & \multirow[t]{2}{*}{$\begin{array}{l}\text { All } \\
\text { subjects }\end{array}$} & \multicolumn{2}{|c|}{$\begin{array}{l}\text { Urodynamic } \\
\text { stability }\end{array}$} & \multicolumn{4}{|c|}{ Urgency } \\
\hline & & & Stable & Unstable & 0 & 1 & 2 & 3 \\
\hline \multicolumn{2}{|c|}{ Number of subjects (n) } & 94 & 55 & 35 & 8 & 23 & 37 & 22 \\
\hline \multirow[t]{7}{*}{ FSF 2-FSF 1} & $\begin{array}{l}\text { Median percentage } \\
\text { change (\% of control fill) }\end{array}$ & 6 & 6 & -3 & 9 & -5 & 3 & 11 \\
\hline & First Quartile & -30 & -35 & -25 & -49 & -39 & -25 & -33 \\
\hline & Third Quartile & 27 & 28 & 26 & 49 & 33 & 25 & 27 \\
\hline & Skewness/standard error & -30.4 & & & & & & \\
\hline & Kurtosis/standard error & 129.9 & & & & & & \\
\hline & $\mathrm{Z}$ (test statistic) & -0.303 & & & & & & \\
\hline & Asymptotic significance & 0.762 & & & & & & \\
\hline \multirow[t]{7}{*}{ FDV 2- FDV 1} & $\begin{array}{l}\text { Median percentage } \\
\text { change }(\% \text { of control fill) }\end{array}$ & 9 & 7 & 9 & 7 & 9 & 7 & 12 \\
\hline & First Quartile & -18 & -18 & -23 & -6 & -19 & -20 & -27 \\
\hline & Third Quartile & 27 & 33 & 26 & 36 & 21 & 35 & 28 \\
\hline & Skewness/standard error & -24.767 & & & & & & \\
\hline & Kurtosis/standard error & 97.344 & & & & & & \\
\hline & $\mathrm{Z}$ (test statistic) & -1.231 & & & & & & \\
\hline & Asymptotic significance & 0.218 & & & & & & \\
\hline \multirow[t]{7}{*}{ CC 2- CC 1} & $\begin{array}{l}\text { Median percentage } \\
\text { change ( } \% \text { of control fill) }\end{array}$ & $\mathbf{0}$ & 0 & -7 & -30 & -1 & 0 & -7 \\
\hline & First Quartile & -17 & -17 & -25 & -42 & -18 & -11 & -17 \\
\hline & Third Quartile & 3 & 3 & 7 & 2 & 0 & 12 & 7 \\
\hline & Skewness/standard error & -29.363 & & & & & & \\
\hline & Kurtosis/standard error & 118.041 & & & & & & \\
\hline & $\mathrm{Z}$ (test statistic) & -1.468 & & & & & & \\
\hline & Asymptotic significance & 0.142 & & & & & & \\
\hline
\end{tabular}

Table 4.14- Order of fill data results analysis 
Figure 4.45

\section{Histogram of \% FSF difference}

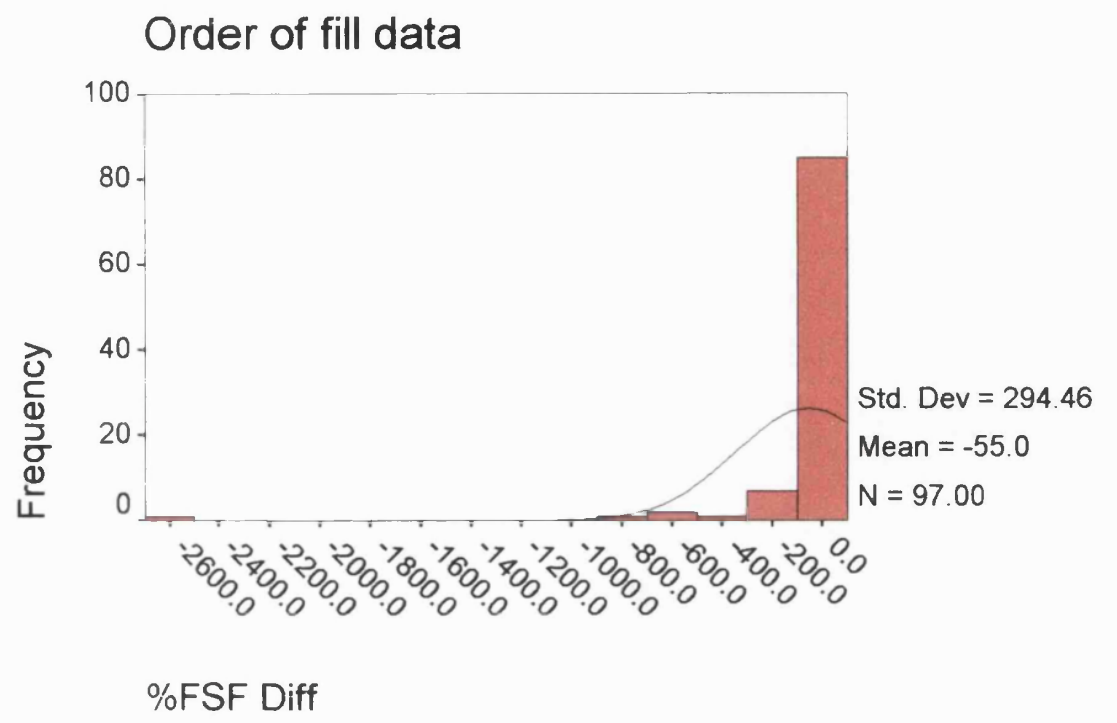

This figure shows the frequencies of \%age change in volume at first sensation of filling between first and second fills

Figure 4.46

\section{Histogram of \% FDV difference}

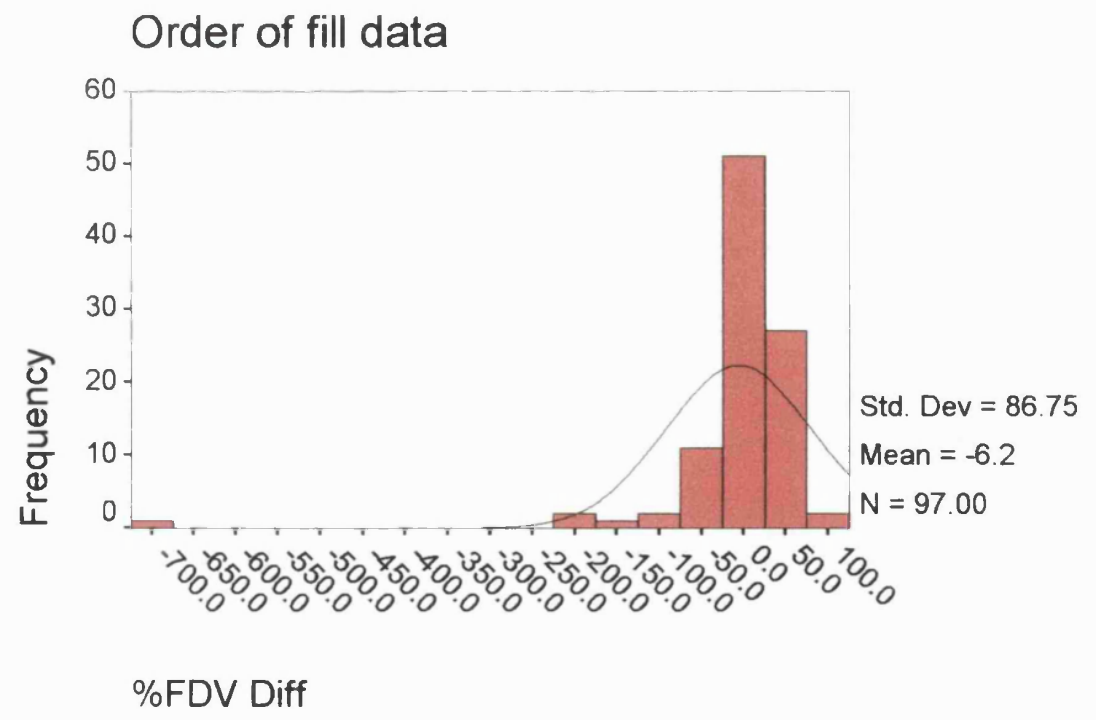

This figure shows the frequencies of \%age change in volume at first desire to void between first and second fills 
Figure 4.47

Histogram of \% CC difference

Order of fill data

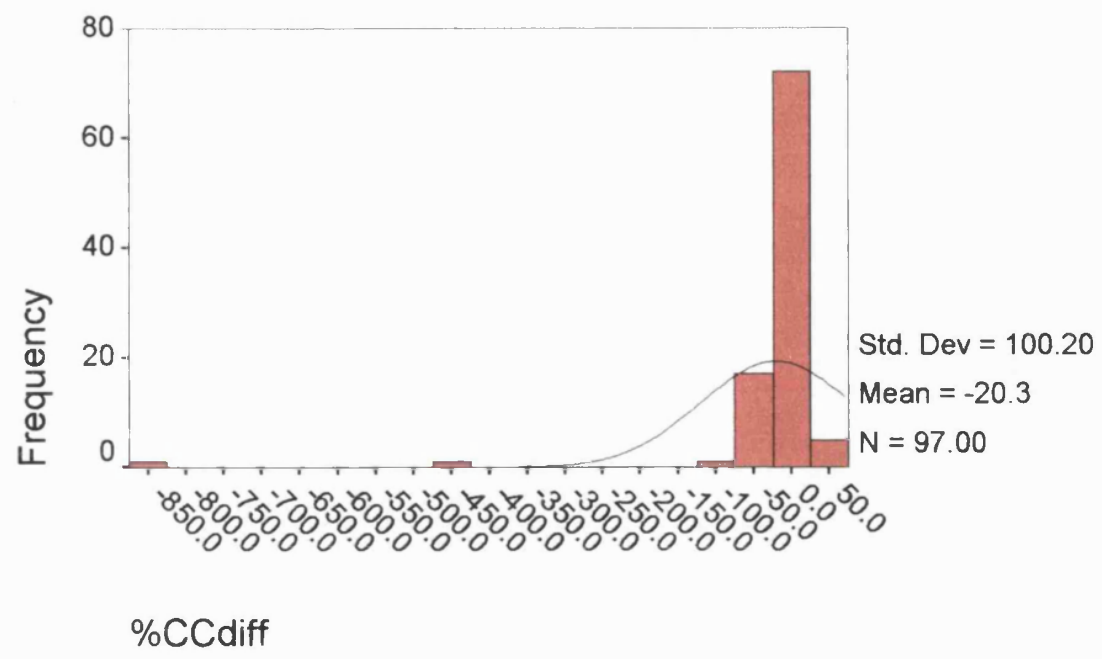

This figure shows the frequencies of \%age change in volume at cystometric capacity between first and second fills

Figure 4.48

Normal QQ plot of \% CC difference

Order of fill data

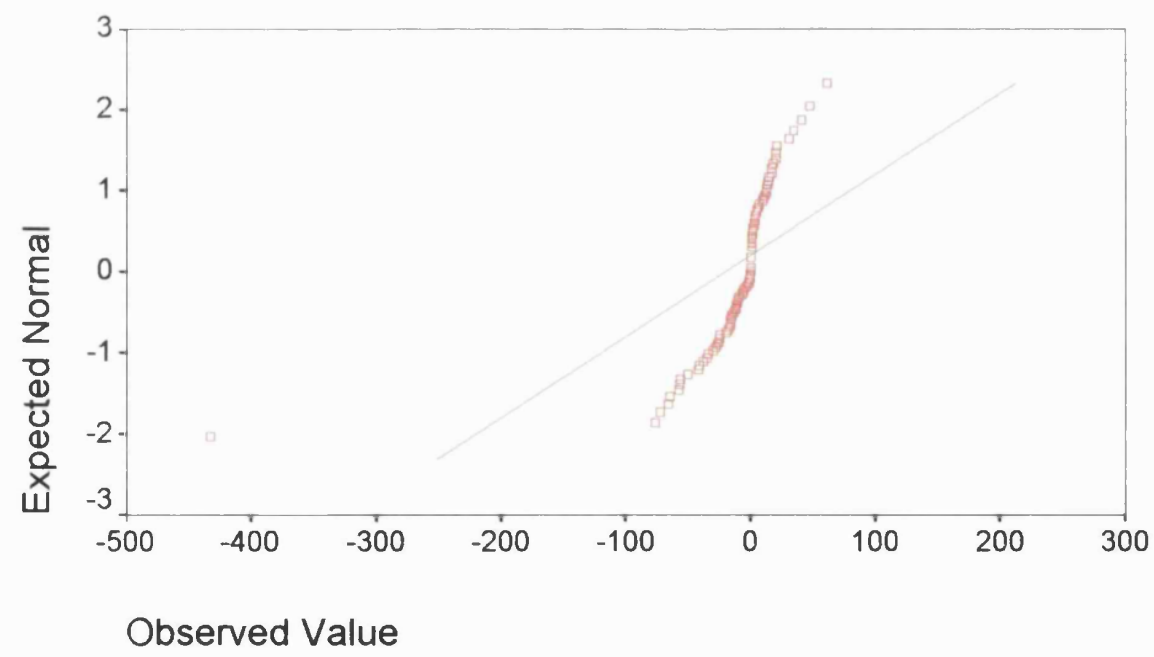

This shows the normal distribution quantile-quantile plot (QQ plot) of the \%age change in cystometric capcity between the first and second fills. The green line shows the best plot of a normal distribution and the red points are the actual data 
Figure 4.49

\section{Scatter plot of \% CC difference}

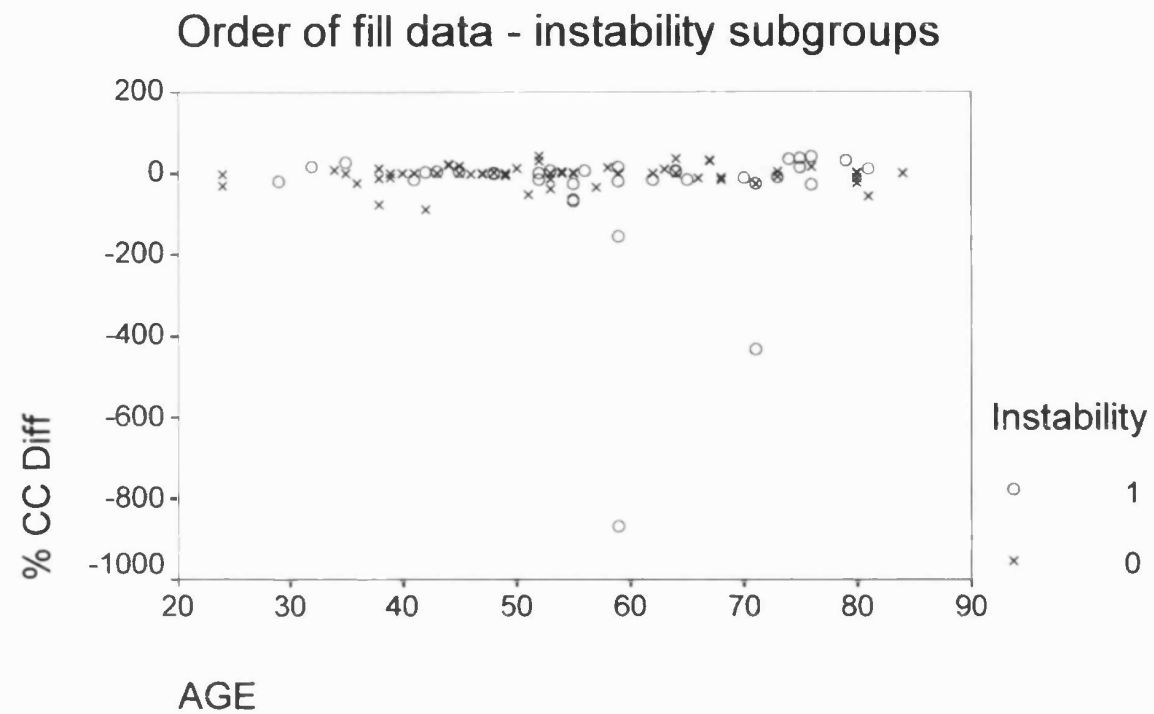

This shows the data points of \%age change in cystometric capacity between the first and second fills, plotted against age. Different points are used for those with instability- present-1, absent- 0 .

Figure 4.50

Boxplot of \% FSF difference

Order of fill data- urgency subgroups

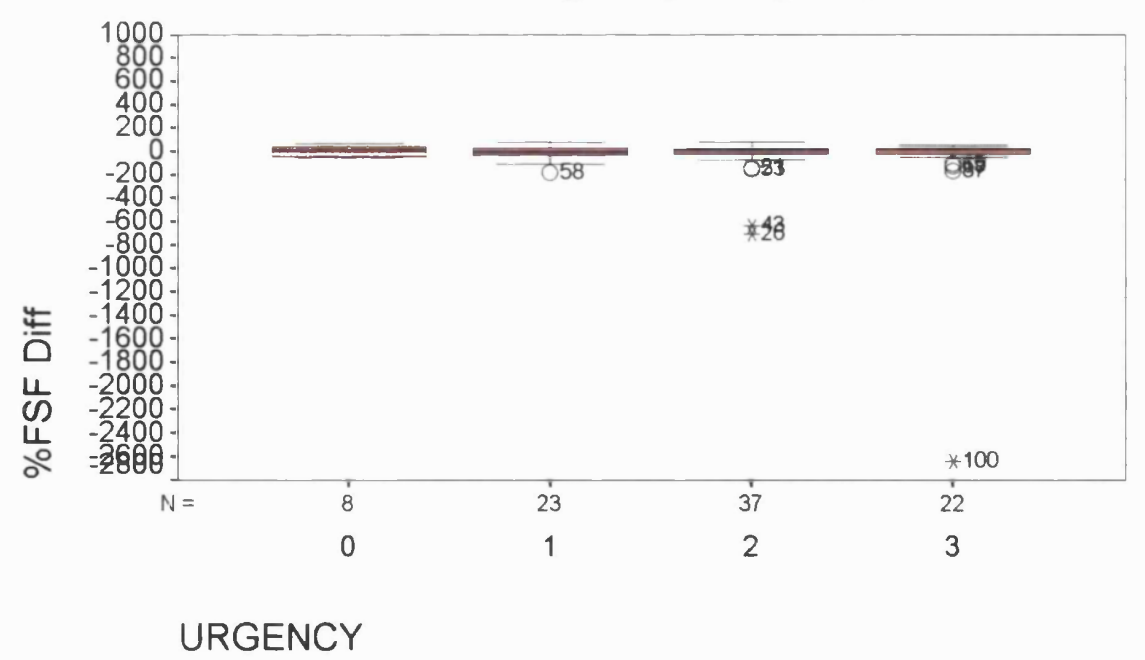

This shows the subgroups of urgency- mild-1, moderate-2, and severe-3, with plotted \%age change in volume at first sensation of filling between first and second fills as a boxplot 
Figure 4.51

Boxplot of \% FDV difference

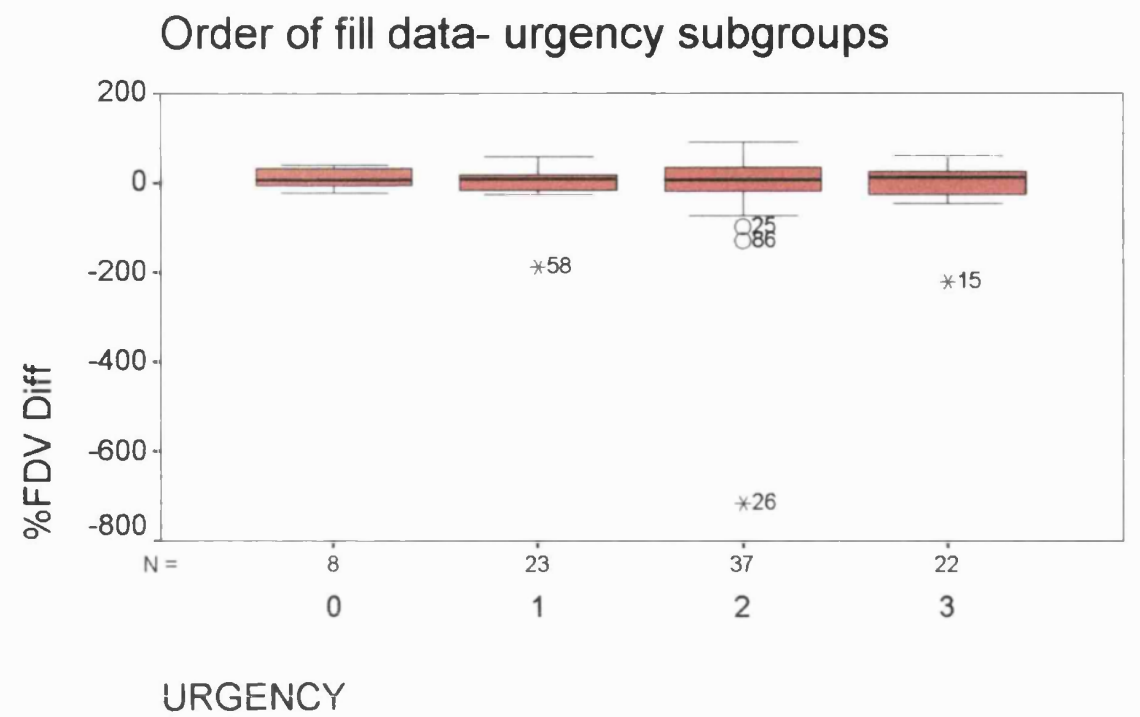

This shows the subgroups of urgency- mild-1, moderate-2, and severe-3, with plotted \%age change in volume at first desire to void between first and second fills as a boxplot

Figure 4.52

Boxplot of \% CC difference

Order of fill data- urgency subgroups

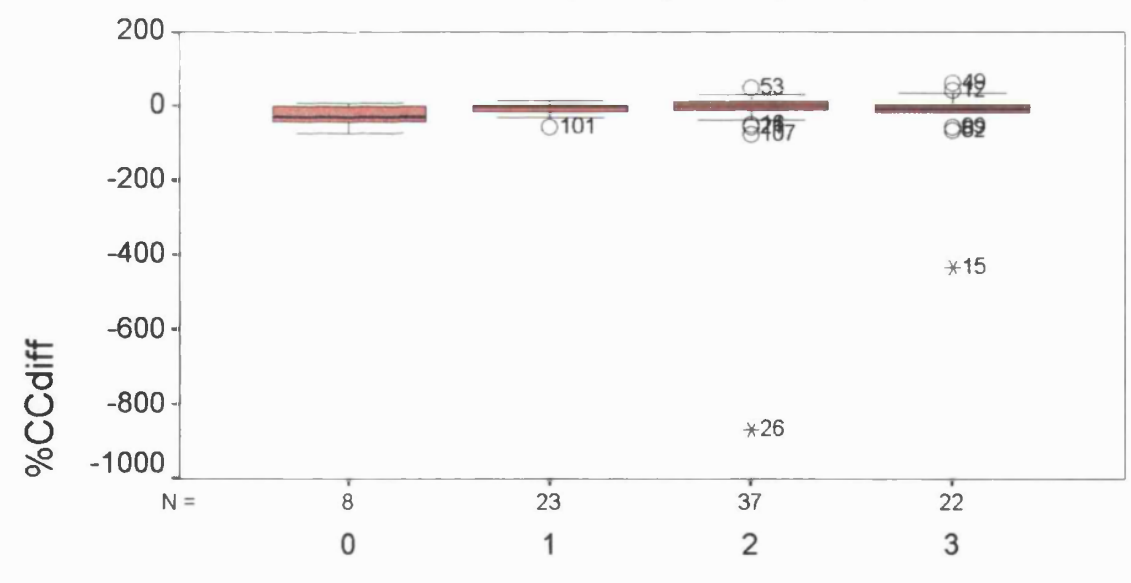

URGENCY

This shows the subgroups of urgency- mild-1, moderate-2, and severe-3, with plotted \%age change in volume at cystometric capacity between first and second fills as a boxplot 


\subsection{Urgency and instability}

The correlation of urgency with urodynamically demonstrated instability was analysed and is shown in table 4.15

\begin{tabular}{|l|l|l|l|l|}
\hline & & Instability & & \\
\hline Urgency & & 0 (stable) & 1 (Unstable) & Total \\
\hline & 0 (none) & 11 & 0 & 11 \\
\hline & 1 (Mild) & 19 & 6 & 25 \\
\hline & 2 (Moderate) & 27 & 12 & 39 \\
\hline & 3 (Severe) & 6 & 17 & 23 \\
\hline & Total & 63 & 35 & 98 \\
\hline
\end{tabular}

Table 4.15 Cross-tabulation of urgency with instability

This shows that of the eleven with no urgency, all had stable bladders urodynamically. However, beyond that, only the broadest correlation exists. Six of the twenty three with severe urgency had stable bladders, as did twenty seven of the thirty nine with moderate urgency.

No patients had neurological findings suggestive of a cause for overactive (neurogenic) bladder. These, it is assumed were adequately screened out prior to attendance by the selection procedure for research clinic. 


\subsection{Interaction of variables}

The interaction of variables was checked for using SPSS multivariate analysis.

The results are shown in table 4.16. The $\mathrm{F}$ value represents the ratio of the two mean squares. the $P$ value represents significance. If the $F$ value is high and the $\mathrm{P}$ value is small $(<0.05)$, then the null hypothesis can be rejected, ie the two variables compared are related, and potentially interacting with each other. The only two data sets which are see to interact are urgency and instability- F value of 23.652 with a $P$ value of $<0.0005$. As discussed in the previous section, this is as expected. The other variables, including the urodynamic variables and age, do not interact significantly- their $\mathrm{F}$ values are all low and $\mathrm{P}$ values high.

\begin{tabular}{|c|c|c|c|}
\hline Source & $\begin{array}{l}\text { Dependant } \\
\text { variable }\end{array}$ & F value & P value \\
\hline \multirow[t]{8}{*}{ Instability } & Age & 2.038 & 0.157 \\
\hline & Urgency & 23.652 & 0.000 \\
\hline & FSF difference & 1.584 & 0.211 \\
\hline & FDV difference & 0.375 & 0.542 \\
\hline & CC difference & 3.514 & 0.064 \\
\hline & $\begin{array}{l}\text { FSF order } \\
\text { difference }\end{array}$ & 1.480 & 0.227 \\
\hline & $\begin{array}{l}\text { FDV order } \\
\text { difference }\end{array}$ & 1.149 & 0.286 \\
\hline & $\begin{array}{l}\text { CC order } \\
\text { difference }\end{array}$ & 3.133 & 0.080 \\
\hline \multirow[t]{6}{*}{ Urgency } & FSF difference & 0.778 & 0.510 \\
\hline & FDV difference & 0.807 & 0.494 \\
\hline & CC difference & 0.526 & 0.665 \\
\hline & $\begin{array}{l}\text { FSF order } \\
\text { difference }\end{array}$ & 0.743 & 0.529 \\
\hline & $\begin{array}{l}\text { FDV order } \\
\text { difference }\end{array}$ & 0.246 & 0.864 \\
\hline & $\begin{array}{l}\text { CC order } \\
\text { difference }\end{array}$ & 0.166 & 0.919 \\
\hline
\end{tabular}

Table 4.16- The multivariate analysis of the interactions of variables against urgency and instability. 
Key to Table 4.16-

FSF difference- \% age change in first sensation filling between test fill and control fill

FDV difference- $\%$ age change in first desire to void between test fill and control fill

$\mathrm{CC}$ difference- \% age change in cystometric capacity between test fill and control fill

FSF order difference- \% age change in first sensation filling between first fill and second fill

FDV order difference- $\%$ age change in first desire to void between first fill and second fill

$\mathrm{CC}$ order difference- \% age change in cystometric capacity between first fill and second fill 


\section{DISCUSSION}

I will discuss each study separately and then the shared conclusions.

\subsection{Hyperosmolar study.}

The published work in animal studies (Hohlbrugger and Lentsch 1985 and Uvelius 1985) suggested that in the presence of a hyperosmolar solution, bladder muscle becomes more 'active' (nerve induced contractions increased in amplitude). The whole animal preparation (Hohlbrugger and Lentsch 1985) showed a decreased bladder capacity with the hypertonic solution. The magnitude of the mean change with hypertonic solution in their study was $15 \%$, with all values showing change in the same direction. The present study, however, showed no significant change, and a trend in the volumes at FSF and FDV to the reverse of that expected, ie that the volumes were larger in the hyperosmolar fill than the control.

There are several possible explanations for this. One could argue that bladder capacity in an anaesthetised whole animal preparation represents something different to that in a human urodynamic test. In the human test, values beyond $500 \mathrm{mls}$ are not achieved, and the capacity is reached when the subject becomes uncomfortable. In an anaesthetised animal preparation, the capacity is determined by a sudden increase in pressure, and as such may be argued to represent a more 'scientific' end point. There may also be differences in permeability mechanisms and muscle susceptibility to the intervention between the rat and human.

The symptoms during filling are also an important factor, which the human model can include. Some valuable information could be gained from volumes at 
sensations of filling and first desire to void, rather than just the end point of bladder capacity.

The buffering of the hyperosmolar solution with bicarbonate may have affected the outcome. The buffered solutions was used to mimic the superfusates used in the in vitro work. This could have been a confounding variable in the analysis of the results.

It could be postulated that the osmolality change in the present study was not enough to produce a response. Hohlbrugger and Lentsch (1985) used an osmolality of $700 \mathrm{mmol} / \mathrm{l}$ as the hypertonic test solution .The present study used a solution with a calculated osmolality of $552 \mathrm{mosm} / \mathrm{l}$. 


\section{2 'Extracellular' alkalosis study}

This study also showed no effect of the intervention on volumes of urodynamic variables. The result predicted by published work would have been an increase in bladder capacities, particularly in overactive bladders. For the group of patients with stable bladders, all the median differences are positive (designating test fill smaller than control fill). For the group of patients with unstable bladders the median differences are negative (designating test fill larger than control). Had the differences been significant this would support the previous published findings, however the differences are small and the confidence intervals include zero. The parametric analysis (appendix 4) shows negative mean changes in all groups (signifying test fill larger than control fill values) but all $95 \%$ confidence intervals include zero. If the raw data are analysed it can be seen that the mean negativity reflects a few very high negative outliers. The possible explanations for such marked negative values could be that some individuals are particularly susceptible to the intervention by reason of individual pathophysiological changes in permeability or muscle physiology. The alternative explanation is that the outliers are experimental 'noise', and that parametric treatment is not appropriate- only non parametric analysis rules this out.

The analysis of the results of Sethia and Smith (1987) is not directly comparable to the present study. In their analysis the bladder capacity is averaged then the differences between the means for the different fills is calculated. In the present study, the statistical analysis is done on the differences in each individual patient. This controls for the original bladder capacity in individual patients. This has more clinical weighting, and also would represent an important change 
in the muscle physiology were it affected. The magnitude of change in the Sethia and Smith study was $145 \mathrm{mls}$ capacity in the saline group versus $197 \mathrm{mls}$ capacity in the alkali group. Expressed as a percentage of control, this represents a $26 \%$ change in the unstable group (standard error $4 \%$ ). Despite a similar $\mathrm{pH}$ of the alkali solution (theirs was $\mathrm{pH} 8.5$ ), the present study was unable to replicate this result. Their study did not control for osmolality, or order of fill, which may have been confounding factors, and were controlled for in the present study. However, they did use a larger total number of patients than in the present study, in particular a larger group of patients with unstable bladders (42), although their group with stable bladders was smaller than in the present study (8). 


\subsection{Intracellular and extracellular pH variation study}

The published data to which this study can be compared is largely in vitro work. Liston et al (1991) examined ferret muscle cells in vitro, and varied the superfusate. They used a superfusate controlled for osmolality and as a normocapnic control, gassed $5 \% \mathrm{CO}_{2}$ and $20 \% \mathrm{O}_{2}$ through it and the mean $\mathrm{pH}$ of this was 7.33. They also used a superfusate with $20 \% \mathrm{CO}_{2}$ and $80 \% \mathrm{O}_{2}$ which had a mean $\mathrm{pH}$ of 6.86 . This was the hypercapnic study solution, designed to achieve intracellular acidosis (as $\mathrm{CO}_{2}$ crossed the membrane). They found that this solution led to a reduction in intracellular $\mathrm{pH}$ of the order of 0.2 units. This led to an increase in tension generated by the muscle of $20 \%$ above the controls. The present study used a similar intervention, with the addition of a normal saline control (as the study was designed to compare with standard urodynamic technique).

In the present study, no trends emerge from the data and there are no significant changes in volumes at sensations or capacity in the test solutions, compared to a normal saline control. The $\mathrm{pH}$ achieved in the test solutions were 7.64 (standard deviation 0.11) for the normocapnic control and 7.09 (standard deviation 0.09 ) for the hypercapnic solution, whilst the normal saline had a mean $\mathrm{pH}$ of 5.38 (standard deviation 0.56 ). These values are not fully comparable to those of the in vitro studies. The standard deviations of the $\mathrm{pH}$ for the test solutions are small, which is reassuring and the standard deviation for $\mathrm{pH}$ of normal saline is larger, as would be expected. Both values for $\mathrm{pH}$ of the test solutions are slightly higher than the equivalent in vitro solution. The reasons for this are not entirely clear. One possibility is an error of measurement or sampling. The $\mathrm{pH}$ was measured at the end of the study on the fluid left after 
the fill was complete. This was done because the $\mathrm{pH}$ meter did not have a sterile or sterilisable electrode. Therefore, the volume of filling solution tested at the end was often very small. This could have led to errors of sampling. The present study used $\mathrm{NaCl}(118 \mathrm{mM})$ and $\mathrm{NaHCO}_{3}(24 \mathrm{mM})$ (with a calculated osmolarity of $284 \mathrm{mosm} / \mathrm{l}$ ), and the in vitro study (Liston et al 1991) used first a Tyrodes then a modified Tyrodes solution which contain $\mathrm{CaCl}_{2}, \mathrm{MgCl}_{2}$, sodium pyruvate, $\mathrm{NaHPO}_{4}$ and glucose. These may influence the $\mathrm{pH}$ to a small degree. The lack of influence of the present study's solutions on urodynamic variables, may however, have less to do with the solutions and more to do with the experimental set up. Whilst $\mathrm{CO}_{2}$ crosses the stripped detrusor cell membrane in the in vitro solution, it may well not cross the bladder wall and get straight to the muscle with as much ease in our study. The solution does not stay in the bladder for long (10 minutes maximum during filling), and the gas bubbling cannot continue while the solution is in the bladder. The homeostatic mechanisms of the detrusor seem likely to control the microenvironment, and reduce the impact of solutions such as these, on the bladder muscle itself. 


\subsection{Potassium study}

Again, no significant effect was seen on any urodynamic volumes by filling the bladder with a solution with high potassium concentration. This does not support the findings of Hohlbrugger and Lentsch (1985) that intravesical potassium decreased bladder capacity (in an animal model). The Hohlbruger and Lentsch study used isotonic KCL, ie with a concentration of $150 \mathrm{mM}$, whereas the present study used $54 \mathrm{mM} \mathrm{KCl}$ in a solution which was made isotonic and buffered by the combination of $\mathrm{KCL}, \mathrm{NaCl}$ and $\mathrm{NaHCO}$. Thus, the potassium concentration was considerably higher in the animal study than in the present one. the buffering could have been a confounding variable- the $\mathrm{pH}$ could have been considerably lower in the Hohlbrugger and Lentsch study than in the present one- unfortunately this was not measured in the present study nor documented in Hohlbrugger and Lentsch (1985).

It could be that the concentrations used in the present study are not high enough to have an effect on the bladder function or sensations. It should also be pointed out that in the Hohlbrugger and Lentsch study the difference was more pronounced after experimental cystitis by DMSO. Parsons et al (1998) used intravesical $\mathrm{KCl}$ to differentiate between normal bladders and those with interstitial cystitis. None of the patients in the present study had symptoms of discomfort with potassium containing solution, nor did any have a working diagnosis of interstitial cystitis or other intrinsic bladder disease likely to increase permeability. However, Hohlbrugger suggested in his review (Hohlbrugger 1999) that patients with urge frequency syndrome should be abnormally sensitive to the effects of urinary potassium, which has increased access to the detrusor and therefore a tendency to depolarise it. Thus, one would 
expect smaller bladder capacities and volumes at first sensations of filling and first desire to void in patients with instability or urgency. This difference between groups of instability and stability or urgency and no urgency is not seen in the present study. 


\subsection{Order of fill data}

The combination of the data from all the above studies was used to study the effect of order of fill on urodynamic studies in repeat fills. This was a treatment of data which was possible because of the lack of effect of the interventions performed. Thus, we are able to draw conclusions about ninety four patients studied with repeat fills, a larger number of patients than previously published. Had there been significant differences between the intervention parts of the study, these may have acted as confounding factors.

The finding in the present study of tight clustering of the data for $\%$ difference of variables around zero with negative 'tail' of the distribution suggests a group of patients in whom the second fill results in smaller volumes than the first. It is not clear whether this is a genuine physiological phenomenon or not. One could speculate about a psychological element to this- some patients may be more expectant during the second fill than the first, and anticipate symptoms earlier the second time, when they know what to expect.

The absence of influence of the filling order found in the present study supports the previous work by Wyndaele (1992) suggesting the bladder volumes and sensations are highly reproducible in repeat filling. As no gap was left in the present study between the successive fills, it also suggests that repeat filling gives relatively consistent results even when 20 minutes does not need to be left, unlike the recommendations of Jensen (1982). Amongst the repeat fill studies previously published, data are treated in a variety of ways. Jensen (1982) expresses the differences as a percentage, but averages the first fill and then the second fill, rather than the differences. This would seem to increase the possible confounding factors- ie the variation of 
absolute values of capacity. Sorensen et al (1983) used a variety of different filling protocols, and again expressed mean values at different fills (up to 4 fills per patient). Ramsden et al (1977) studied the effect of filling rate and position on urodynamic testing, and expressed the differences in absolute values and also in terms of the numbers showing urodynamically proven instability.

Poulsen et al (1989) also expressed the results as differences in the averaged mean values of the two fills. 


\subsection{Limitations and criticisms of the study}

Although the total number of subjects studied was large, the subgroups were small and in some cases difficult to interpret. In particular, the groups with or without overactivity or differing degrees of urgency were small and it was in many cases difficult to draw conclusions from these subgroups.

The study was not blinded. The logistics of preparing the bottles and the different gas permeations meant that blinding could not be accommodated. The investigator could have biased the results by prompting for sensations or stopping the studies early. It could, however be speculated that had systematic bias been present then a positive result might have been expected.

There were technical considerations in measuring $\mathrm{pH}$ - the electrodes used were not sterile. Therefore the $\mathrm{pH}$ measurements were made on the residual amount in the bottle after filling. This may not have accurately represented the intravesical $\mathrm{pH}$. It could also be that the buffering of those test solutions not involved in $\mathrm{pH}$ studies (potassium and hyperosmolar) could have added a confounding variable to the results analysis, particularly when compared to other unbufferred studies in the literature.

The voided solutions were not analysed- this could have added information about the contribution of urea and other urinary constituents to the intravesical biochemistry which may have aided interpretation of the essentially negative results.

The individual intervention studies could be criticised for not having made the interventions more extreme, and thus more likely to render a positive result. The interventions were, however, designed to mimic possible physiological changes which might pertain in urine, and their influence on urodynamics. There were 
also ethical issues about the potential risks of using higher concentrations of potassium, or greater extremes on $\mathrm{pH}$, which would have limited the study. Voiding urodynamics were not studied, so it is not possible to draw any conclusions about the effects on isometric function, nor on urethral physiology. This was a deliberate decision based on some earlier studies of pressure/flow urodynamics. The dispersion of data from pressure/flow studies is such that it was thought unlikely that differences would be detected on the pressure flow plot as a result of different biochemical environments. It was therefore considered an unnecessary extra procedure.

This does however, mean that all the variables studied were related to filling, and sensations during filling. It has been argued that these are likely to represent physiological phenomena (Wyndaele 1998). However, the basic animal and in vitro physiological work which the present study attempts to translate are ones in which detrusor motor function observations are the outcomes. The present study could therefore be criticised as motor function was not studied. The test solutions were not left in the bladder for more than in the standard urodynamic practise- the fill was at $50 \mathrm{mls} /$ minute (ie 10 minutes for a fill of $500 \mathrm{mls}$, then emptied immediately.) An interesting variation may have been to leave the solutions in the bladder for longer, giving more likelihood of an influence on the detrusor muscle and a 'positive response'. In particular, sensation may have been more influenced by a longer time of exposure to the test solutions.

Only women were investigated in the study. The majority of patients attending the unit for investigation at the time were women, and thus this was the most practical approach. There is no evidence in the literature that there is a gender 
difference in the reactions of detrusor muscle to these interventions, however, these results may not be generalisable to men. 


\subsection{Future studies}

Many questions are raised by these studies. Future studies should include looking more closely at the subgroups, which the present study was not powered to do.

It would be interesting to examine a larger group of subjects with overactive bladders, and in particular those with neurogenic detrusor overactivity, to see if they had different reactions to the test solutions.

It would also be useful to study whether a longer time of exposure to the test solutions could be more influential on the urodynamic test.

The study also raised the issue as to whether interventions with greater effect on intravesical biochemistry may have more influence. This could be achieved with more extreme solutions, and would require more work to analyse the effect during the studies. The effect on the true intravesical environment could be studied with $\mathrm{pH}$ probes and examination of the voided solutions. If more extreme solutions were used, it would also be necessary to examine the potential effect on blood biochemistry from any absorption. There would therefore need to be pilot studies to ensure safety.

It would also be useful to study voiding detrusor function, by including voiding studies in the next intervention study. This would therefore include motor function in the analysis, which could show a different effect from that on predominantly sensory variables that were studied. 


\subsection{Conclusions}

The absence of influence of filling solution on urodynamic variables could have several explanations.

There could be genuine effects on the muscle physiology, but the urodynamic technique itself may not be sensitive enough to pick these up. Pressure waves of less than $5 \mathrm{~cm} \mathrm{H}_{2} \mathrm{O}$ are difficult to detect on urodynamic equipment (Abrams 1999). Small changes in waves during filling may therefore not have been seen).

The alternative explanation is that the interventions that were made had no impact on detrusor physiology in vivo. It seems likely, in this case that the homeostatic mechanisms of the bladder are more powerful than the effect of the interventions. The blood flow around the bladder and the buffering effect of this may well have reduced the impact of the interventions. The impact of the biochemical interventions is much more difficult to assess in vivo than in vitro. The permeability of the bladder wall is likely to have contributed to the lack of effect. Patients were chosen from those referred for urodynamic studies, but not particularly those with likely bladder epithelial disease, who would have been more likely to have permeability problems. The assumptions made in the in vitro studies (Liston et al 1989) regarding the permeability of the detrusor cells to $\mathrm{CO} 2$ but not to bicarbonate probably do not hold for the present in vivo study. The buffering ability of the blood and extracellular fluid around the detrusor muscle may have made it difficult to influence intracellular $\mathrm{pH}$ in the same way as the in vitro studies.

On the basis of these results, it is not possible to reject the null hypothesis in any case. 
No manipulations to the intravesical environment had any statistically significant or interpretable effect on the results of urodynamic testing. The influences of these manipulations were equally ineffective in the presence of detrusor instability or a stable bladder. This is reassuring to those who practice or interpret urodynamics. The changes in biochemical environment which affect the bladder muscle in vitro seem to have no effect in vivo, and therefore this study strengthens the reliability data from urodynamic testing as well as the repeatability data. 


\section{REFERENCES}

Abrams P. Urodynamics. Springer (second edition) 1997

Abrams P, Blaivas JG, Stanton SL, Andersen JT (1988) Standardisation of terminology of lower urinary tract function. The International Continence Society committee on Standardisation of Terminology. Scandinavian Journal of Urology and Nephrology Supp 14: 5-19

Abrams P, Cardozo L, Fall M, Griffiths D, Rosier P, Ulmsten U, van Kerrebroeck P, Victor A, Wien A. (2002). The standardisation of terminology of lower urinary tract function: Report from the standardisation subcommittee of the International Continence Society. Neurourology and Urodynamics 21:167-178

Artibani W. (1997) Diagnosis and significance of idiopathic overactive bladder. Urology 50:25-32

Attwell D. (1986) The physical chemistry of acid base balance. In Acid base balance. Ed R Hainsworth. Manchester University Press.

Austin C, Wray S. (1993). Extracellular pH signals affect rat vascular tone by rapid transduction into intracellular $\mathrm{pH}$ changes. Journal of Physiology (Lond).

466: $1-8$ 
Austin C, Wray S. (2000). Interactions between $\mathrm{Ca}^{2+}$ and $\mathrm{H}^{+}$and functional consequences in vascular smooth muscle. Circulation Research. 86:355-363

Azadzoi KM, Pontari M, Vlatchiotis J, Siroky MB (1996). Canine bladder blood flow and oxygenation: changes induced by filling contraction and outflow obstruction. Journal of Urology 155: 1459-65

Batista JE, Wagner JR, Azadzoi KM, Krame RJ Siroki MB. (1996). Direct measurement of blood flow in the human bladder. Journal of Urology .155. $630-3$

Birder LA, Kanai AJ, de Groat WC. (1997). DMSO: Effect on bladder afferent neurons and nitric oxide release. Journal of Urology 1997. 158:1989-1995

Blaivas JG.(1992) Editorial comments on: Van Waalwijk van Doorn ESC, Remners A, Janknegt RA. Journal of Urology. 147: 1326

Bors E. (1958) Topical anaesthesia of the vesical mucosa as a tool for the management of the neurogenic bladder. Journal of Urology 79: 431-435

Brading A. (1987) Physiology of bladder smooth muscle. In Torrens M, Morrison JFB (eds). The biology of the lower urinary tract. Berlin, Springer Verlag, pp161-191 
Bristow SE, Neal DE. (1996) Ambulatory urodynamics. British Journal of Urology 77: 333-338

Cass AS, Ward BD, Markland C (1970) Comparison of slow and rapid fill cystometry using liquid and air. Journal of Urology 104: 104-106

Chambers GK, Fenster HN, Cripps S, Jens M, Taylor D. (1999). An assessment of the use of intravesical potassium in the diagnosis of interstitial cystitis. Journal of Urology. 162: 699-701

Chelsky MJ, Rosen SI, Knight LC, Maurer AH, Hanno PM, Ruggieri MR. (1994). Bladder permeability in interstitial cystitis is similar to that of normal volunteers: direct measurement by transvesical absorption of ${ }^{99 \mathrm{~m}}$ TechnetiumDiethylenetriaminepentaacetic acid. Journal of Urology 151:346-349.

Claridge M (1966). Analyses of obstructed micturition. Annals of the Royal College of Surgeons 39:30-53.

Drutz HP, Darling A, Unger FW .(1981) Carbon dioxide gas retrograde urethrocystometry versus catheter fill gas cystometry in assessing bladder capacity. American Journal of Obstetrics and Gynaecology. 140 ,5:570-2

Elbadawi A. (1997). Interstitial cystitis: a critique of current concepts with a new proposal for pathologic diagnosis and pathogenesis. Urology 49 (5a suppl):14-40 
Eldrup J, Thorup J, Nielsen SL, Hald T, Hainau B (1983). Permeability and Ultrastructure of Human Bladder epithelium. British Journal of Urology 55: 488-92.

Evans MS, Reid KH, Sharp JB (1993). Dimethylsulfoxide (DMSO) blocks conduction in peripheral nerve $\mathrm{c}$ fibers: a possible mechanism of analgesia. Neuroscience letters, 150: 145,

Ferguson DR. Kennedy I. Burton TJ. (1997) ATP is released from rabbit urinary bladder epithelial cells by hydrostatic pressure changes--a possible sensory mechanism?.Journal of Physiology. 505 ( Pt 2):503-11.

Ferguson DR.(1999) Urothelial function. BJU International; 84(3): 235-242

Finkbeiner AE, O’Donnell PD.(1990) Responses of detrusor smooth muscle to stretch and relaxation: in vitro study. Urology.;36:193-8

Fry CH, Liston TG, Cole RS. (1990) The effects of $\mathrm{pH}$ on urinary tract smooth muscle function. Frontiers in Smooth Muscle Research. Alan Liss Inc.:717-723

Fry CH and Wu C. (1998). The cellular basis of bladder instability. British Journal of Urology., 81:1-8. 
Gabella G. Davis C. (1998) Distribution of afferent axons in the bladder of rats. Journal of Neurocytology. 27(3):141-55,

Garty H and Palmer LG (1997) Epithelial sodium channels: function, structure and regulation Physiological Reviews.77:359-96.

Georgopoulos M, Schuster FX, Porpaczy P, Schramek P (1996). Evaluation of asymptomatic microscopic haematuria- influence and clinical relevance of osmolality and pH on urinary erythrocyte morphology. British Journal of Urology 78, 192-196

Godec CJ, Cass AS (1979). Rapid and slow-fill gas cystometry. Influence on bladder capacity and diagnosis of hyperreflexic bladder. Urology 13,1109-110 Greenland JE, Brading AF. (1996) Urinary bladder blood flow changes during the micturition cycle in the conscious pig model. Journal of Urology 1561858 61

Grist $\mathrm{M}$ and Chakraborty $\mathrm{J}$ (1994). Identification of mucin layer in the urinary bladder. Urology 44, 26-33.

Grynderup V (1966). Double cystometry in the uninhibited bladder. Acta Neurologica Scandinavica 42, Suppl 20, 67-77 
Hansen F Olsen L, Atan A, Jakobsen H, Nordling J (1997). Pressure flow studies, an evaluation of within testing reproducibility-validity of the measured parameters. Neurourology and Urodynamics 16:531-532

Hansen F, Olsen L, Atan A, Nordling J (1999). Pressure flow studies: short term repeatability. Neurourology and Urodynamics. 18: 205-214

Hicks RM, Ketterer B, Warren RC.(1974). The ultrastructure and chemistry of the luminal plasma membrane of the mammalian urinary bladder: a straucture with low permeability to water and ions. Philosophical Transactions of the Royal Society of London. Series B. Biological Sciences 268:23-38

Hohlbrugger G, Lentsch P. (1985) Intravesical ions, Osmolality and $\mathrm{pH}$ influence the volume pressure response in the normal rat bladder, and this is more pronounced after DMSO exposure. European Urology 11, 127-130

Hohlbrugger G, Lentsch P, Pfaller K, Madersbacher H. (1985) Permeability characteristics of the rat urinary bladder in experimental cystitis and after overdistension. Urology International 40: 211-216(1985)

Hohlbrugger G. (1987). Changes of hypo- and hypertonic sodium chloride induced by the rat urinary bladder at various filling stages. European Urology $13,83-89$ 
Hohlbrugger G (1994) Letter: comment on Chelsky et al 1994. Journal of Urology 152: 2105

Hohlbrugger G (1995). The vesical blood-urine barrier: a relevant and dynamic interface between renal function and nervous bladder control. Journal of Urology 154:6-15

Hohlbrugger G (1997). Disintegrity of the blood-urine barrier in interstitial cystitis: a vicious circle. in Interstitial cystitis . Grannum R Sant (ed) Lippincott- Raven, Philadelphia 1997.

Hohlbrugger $\mathrm{G}$ (1999). Urinary potassium and the overactive bladder. $B J U$ International. 83 Supp 2. 22-28

Hohlbrugger G, Frauscher F, Strasser H, Kollesselli K, Corvin S, Bartsch G. (1999) Vesical blood flow is modified by distension and intravesical potassium. Journal of Urology 157 (Supp) A664.

Hong SK, Boylan JW, Tannenberg AM, Rahn H. (1960) Total and partial gas tensions of human bladder urine. Journal of Applied Physiology 15(1), 115-120.

Irwin P and Galloway NT (1993) Impaired bladder perfusion in interstitial cystitis: a study of blood supply using laser doppler flowmetry. Journal of Urology 149: 890-892 
Jensen D. (1981) Pharmacological studies of the uninhibited neurogenic bladder. 1. The influence of repeated filling and various filling rates on the cystometrogram of neurological patients with normal and uninhibited neurogenic bladder. Acta Neurologica Scandinavica. 64, 145-174

Jonas U, Hofner K, Madersbacher H, Holmdahl TH. (1997). Efficacy and safety of two doses of tolterodine versus placebo in patients with detrusor overactivity and symptoms of frequency, urge incontinence and urgency: urodynamics evaluation. The International Study Group [published erratum appears in World Journal of Urology; 15(3):210] .World Journal of Urology 15:144-151]

Kerr WK, Barkin M, D’Aloisio J, Merczyk Z. (1963) Observations on the movements of ions and water across the wall of the human bladder and ureter Journal of Urology 89: 812-819

Klevmark B. Ambulatory urodynamics (letter). (1997) British Journal of Urology, 79: 490-1

Klevmark B. (1974) Motility of the urinary bladder in cats during filling at physiological rates. I. Intravesical pressure patterns studied by a new method of cystometry. Acta Physiologica Scandinavica ; 90:565-77 
Klevmark B (1977). Motility of the urinary bladder in cats during filling at physiological rates. II. Effects of extrinsic bladder denervation on intramural tension and on intravesical pressure patterns. Acta Physiologica Scandinavica, 101:176-84

Klevmark B (1980).. Motility of the urinary bladder in cats during filling at physiological rates III. Spontaneous rhythmic bladder contractions in the conscious and anaesthetised animal:influence of distension and innervation. Scandinavian Journal of Urology and Nehprology;14:219-24

Kulseng-Hanssen S, Klevmark B. (1996) Ambulatory urodynamic monitoring of women. Scandinavian Journal of Urology and Nephrology Supplement.. 179:27-37

Lewis SA, Diamond JM. (1975). Active sodium transport by mammalian urinary bladder. Nature, 253:747-748

Liston TG, Palfrey ELH, Raimbach SJ, Fry CH. (1991). The effects of pH changes on human and ferret detrusor muscle function . Journal of Physiology 432, $1-21$

Madsen FA, Rhodes PR, Bruskewitz RC. (1995) Reproducibility of pressure flow variables in patients with symptomatic benign prostatic hyperplasia. Urology 46:816-820 
Malek RS. Wahner-Roedler DL. Gertz MA. Kyle RA. Primary localized amyloidosis of the bladder: experience with dimethyl sulfoxide therapy. Journal of Urology. 168:1018-20

Malone-Lee JG, Shaffu B, Anand C, Powell C. (2001a). Tolterodine: Superior tolerability and comparable efficacy with oxybutynin in individuals $>50 \mathrm{yrs}$ with overactive bladder. A randomised controlled trial. Journal of Urology 165: $1452-6$

Malone-Lee JG. Walsh JB. Maugourd MF. (2001b) Tolterodine: a safe and effective treatment for older patients with overactive bladder. Journal of the American Geriatrics Society. 49:700-5

Moskowitz MO, Byrne DS, Callahan HG, Parsons CL, Valderrama E, Moldwin RM. (1994). Decreased expression of a glycoprotein component of bladder surface mucin (GPI) in interstitial cystitis. Journal of Urology 151: 343345

Nickel JC, Emerson L Cornish J. (1993) . The bladder mucus

(glycosaminoglycan) layer in interstitial cystitis. Journal of Urology 149: 716718

Nordling J, Walter S. (1977). Repeated rapid fill CO2 cystometry. Urological Research 5(3) :117-122 
Orchard CH, Kentish JC. (1990) Effects of changes of $\mathrm{pH}$ on the contractile function of cardiac muscle. American Journal of Physiology, 258, C967-981

Pandita RK, Andersson KE. (2002) Intravesical adenosine triphosphate stimulates the micturition reflex in awake, freely moving rats. Journal of Urology. 168(3): 1230-4.

Pandita RK. Mizusawa H. Andersson KE. (2000) Intravesical oxyhemoglobin initiates bladder overactivity in conscious, normal rats. Journal of Urology. 164(2):545-50.

Parsons CL, Greenspan C, Moore SW, Mulholland SG. (1977). Role of surface mucin in the primary antibacterial defense of the bladder. Urology $9.48-52$

Parsons CL, Mulholland G (1978) Bladder surface mucins. American Journal of Pathology. 93:423-432

Parsons CL, Schmidt JM, Pollen JJ. (1983). Successful treatment of interstitial cystitis with sodium pentosanpolysulfate. Journal of Urology 130. 51-53

Parsons CL, Boychuk D, Jones S, Hurst R Callahan H. (1990). Bladder surface glycosaminoglycans: an epithelial permeability barrier. Journal of Urology 143. $139-42$ 
Parson CL, Greenberger M, Gabal L, Bidair M, Barme G. (1998). The role of urinary potassium in the pathogenesis and diagnosis of interstitial cystitis. Journal of Urology 159: 1862-1867.

Peeker R. Haghsheno MA. Holmang S. Fall M (2000). Intravesical bacillus Calmette-Guerin and dimethyl sulfoxide for treatment of classic and nonulcer interstitial cystitis: a prospective, randomized double-blind study. Journal of Urology. 164:1912-5

Pitts RF, Ayer JL, Scheiss WA. (1949). The renal regulation of acid- base balance in man III. The resorption and excretion of bicarbonate. Journal of Clinical Investigation 28: 35-44

Pontari MA, Hanno PM, Ruggieri MR (1999). Comparision of bladder blood flow in pateints with and without interstitial cystitis. Journal of Urology. 162: 330-334.

Poulsen EU, Kirkeby, HJ, Djurhuus JC (1989). Short and long term reproducibility of cystometry. Urological Research, 17:197-198

Ramsden PD, Smith JC, Pierce JM, Ardran GM.(1977) The unstable bladderFact or artefact? British Journal of Urology, 49 633-639. 
Rhentzog L, Stanton SL, Cardozo L Nelson E, Fall M Abrams P (1998) .

Efficacy and safety of tolterodine in patients with detrusor instability; a dose ranging study. British Journal of Urology 81:42-8

Robertson AS, Griffiths CJ, Ramsden PD, Neal DE. (1994) Bladder function in healthy volunteers: ambulatory monitoring and conventional urodynamic studies. British Journal of Urology 73:242-249

Robertson AS, Griffiths C, Neal D.(1996) Conventional urodynamics and ambulatory monitoring in the definition and management of bladder outflow obstruction. Journal of Urology 155, 506-511

Rose DK. (1927). Determination of bladder pressure with the cystometer: a new principle in diagnosis. Journal of the American Medical Association 88:151-156

Rose DK (1936) The present status of cystometry. Journal of the American Medical Association. 107: 1534-1536

Rosier PWFM, de la Rosette JMCH, Koldewijn EL, Debruyne FMJ, Wijkstra H. (1995) variability of pressure flow analysis parameters in repeated cystometry in patients with benign prostatic hyperplasia. Journal of Urology 153:1520-1525

Ruggieri MR, Hanno PM, Samadzadeh S, Johnson E, Levin RM. (1986).

Heparin inhibition of increased bacterial adherence following overdistension, 
ischaemia, and partial outlet obstruction of the rabbit urinary bladder. Journal of Urology 136. 132- 135

Saito M, Kondo A, Gotoh M, Kato K.(1991) Age related changes in rat detrusor muscle: the contractile response to inorganic ions. Journal of Urology ;146: 891-894.

Sant GR, Theoharides TC (1999). Interstitial cystitis. Current Opinion in Urology. 9: 197-302

Sethia KK, Smith JC. (1987) The effect of $\mathrm{pH}$ and lignocaine on detrusor instability. British Journal of Urology 60: 516-518

Sibert L. Khalaf A. Bugel H. Sfaxi M. Grise P (2000) Intravesical dimethyl sulfoxide instillations can be useful in the symptomatic treatment of profuse hematuria due to eosinophilic cystitis Journal of Urology. 164:446

Sorensen SS, Nielsen JB, Norgaard JP, Knudsen LM, Djurhuus JC. (1984). Changes in bladder volumes with repetition of water cystometry. Urological Research 12(4) 205-208, 1984

Staehelin LA, Chlapowski FJ, Bonneville MA (1972). Luminal membrane of the mammalian urinary bladder. Journal of Cell Biology 53: 73-91 
Suigos JM, Matthews CD. (1977) Assessment and treatment of female urinary incontinence by cystometrogram and bladder retraining programs. Obstetrics and Gynaecology. 50:9-12

Swithinbank LV, James M, Shepherd A, Abrams P. (1999). Role of ambulatory urodynamic monitoring in clinical urological practice. Neurourology and Urodynamics 18: 215-222

Tang PC and Ruch TC (1955). Non-neurogenic basis of bladder tonus. American Journal of Physiology.181, 249-257

TheoharidesTC, Pang X, Letourneau R, Sant GR.(1998) Interstitial cystitis:a neuroimunoendocrine disorder. Annals of the New York Academy of Science 840: $619-634$

Thuroff JW, Bunke B, Ebner A, Faber P de Geeter P, Hannappell J, Heidler H, Madersbacher H, Melchior H Schafer W, Schwenzer T, Stockle M.

Randomised, double blind, multicentre trial on treatment of frequency urgency and incontinence related to detrusor hyperactivity: oxybutynin versus probanthilene versus placebo. Journal of Urology;145:813-16

Torrens MJ (1977). A comparative evaluation of carbon dioxide and water cystometry and sphincterometry. Proceedings of the International Continence Society 7:103-104 
Uvelius B (1985). Effects of variations in extracellular osmolality on spontaneous contractile activity and response to nerve stimulation in rat detrusor muscle in vitro. Urology International 40: 196-200

Uvelius B, Andersson PO, Malmgrem A. (1990) Effects of variations in extracellular $\mathrm{pH}$ on spontaneous contractile activity and response to nerve stimulation in smooth muscle from rat urinary bladder. Scandanavian Journal of Urology and Nephrology 24, 47-51

Van Waalwijk van Doorn ESC, Remners A, Janknegt RA. (1992) Conventional and extramural ambulatory urodynaimc testing of the lower urinary tract in female volunteers. Journal of Urology.;147, 1319-1326

Webb RJ, Griffiths CJ, Zachariah KK, Neal DE. (1991) Filling and voiding pressures measured by ambulatory monitoring and conventional studies during natural and artificial bladder filling. Journal of Urology 146: 815-818

Wein AJ, Hanno PM, Dixon DO, Raezer D, Benson GS. (1978). The reproducibility and interpretation of carbon dioxide cystometry. Journal of Urology 120:205-206

Wu C, Kentish JC, Fry CH.(1995) Effect of pH on myofilament Ca2+ sensitivity in alpha-toxin permeabilised guinea pig detrusor muscle. Journal of Urology 154, $1921-1924$. 
Wu C, Fry CH. (1998). The effects of extracellular and intracellular $\mathrm{pH}$ on intracellular $\mathrm{Ca}^{2+}$ regulation in guinea-pig detrusor smooth muscle. Journal of Physiology 508. 1:131-143

Wyndaele JJ. (1992) Are sensations perceived during bladder filling reproducible during cystometry. Urology International; 48:299-301

Wyndaele JJ (1998) The normal pattern of perception of bladder filling during cystometry studied in 38 young healthy volunteers. Journal of Urology 160(2): 479-81

Zimmern PE, Lin V, Mc Connell JD. (1996) Smooth muscle physiology. in Urological clinics of North America. 23,2 211-219 


\section{APPENDIX 1}

Patient information sheet

Consent form

Standardised neurological examination 


\section{INFORMATION SHEET A study on the effects of varying bladder filling solutions on bladder function}

You are suffering from problems affecting the bladder and causing you symptoms which you hope to have rectified. It is probable that we will be able to bring your symptoms under control. However, there remains a need to discover why your type of bladder problem arises. We are asking you to participate in a research study which is designed to explore the possible causes of your condition.

We will be asking you to agree to undergo a further modified urodynamic study. You have already experienced one study which lead to your diagnosis. The urodynamic study is a routine investigation which provides us with very useful detailed information on the behaviour of your bladder. As you have discovered, to achieve it we have to introduce a small tube inside the bladder under local anaesthetic. We also have to place a small tube into the back passage. We will then fill your bladder with water until you feel completely full. We will then ask you to pass water in private. A computer measures everything that is going on and analyses the information collected so as to draw a mathematical picture of your bladder behaviour.

We are asking you to agree to undergo a further test during which we will fill and then empty your bladder two or three times during the same sitting, using fluids which vary in composition. We need to study the effects of different fluids on the behaviour of your bladder. This may help us to understand bladder behaviour better and lead to improved treatment of persons with symptoms such as those you have experienced. This procedure is known to be well tolerated by patients, although a little undignified. It is not painful, but there is a slight risk of infection following the test. The risk is about 3 in 20 cases (15\%). We will instruct you on how to recognise the symptoms of infection (cystitis) and you will be provided with some tablets to take immediately should this happen. These will clear the problem for you.

The urodynamic study is part of you normal clinical management. The one or two further filling studies are additional and would not normally be done at the same time. you are unlikely to benefit directly from this study, but in participating you will help us in our efforts to find better treatments for the sort of condition from which you are suffering.

If you decide that you would not like to participate in the study, your decision will have no effect on your future care

Professor James Malone-Lee, MD FRCP Tim Gluck BSc MRCP, Senior Registrar 


\section{CONSENT FORM \\ A study on the effects of varying bladder filling solutions on bladder \\ function}

The nature and purpose of the study into the behaviour of the bladder was explained to me by Dr Gluck in words that I could understand. I have also been able to read and understand the patient information sheet.

I agree to participate in this study by allowing further filling studies to be done at the time of my urodynamic study. I understand that the initial part of my urodynamic study forms part of my normal clinical management. I realise that I may not obtain benefit from participating in this study but I appreciate that the information obtained may help in the treatment of others suffering from similar conditions.

It has been made clear to me that I am under no obligation to participate on this study. I may withdraw my consent at any stage. I also understand that if I withdraw my consent, or had not given consent at this stage, neither would have any effect on my clinical management, now or in the future.

My consent is being given freely

Signature of patient

Signature of witness

Signature of investigator

Date. 
FILING STIDYY

\section{PATIMNT NOUROLOAICAW HXAMINATION}

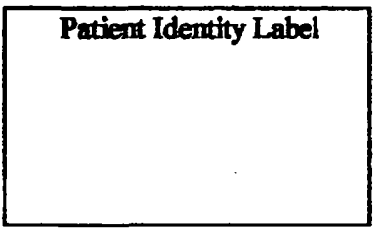

Pulse: $\quad$ BP Supine: —— Standing:

Valbalve mancouvre: Normal / Abnormal

LEGS:

Wasting: $\quad \mathrm{Y} / \mathrm{N} \quad$ Fasciculation: $\quad \mathrm{Y} / \mathrm{N}$

Power: L: $\quad 5 / 5 \quad 4 / 5 \quad 3 / 5 \quad 2 / 5 \quad 1 / 5$

R: $\begin{array}{lllll}5 / 5 & 4 / 5 & 3 / 5 & 2 / 5 & 1 / 5\end{array}$

Tone:

Normal / Abnormal

Anal tone: Normal / Abnormal

Senuntion: Lfght touch: Left: Normal / Abnormal Right: Normal / Aboormal Ptoprick: Left: Normal / Abnormal Right: Normal / Abnormal S1 / S2: $\quad$ Normal / Abnormal

Proprioreception: Left: Normal / Abnormal Right: Normal / Abnommal

Coordination: Lef: Normal / Abnormal Right: Normal / Abnormal

Referes:

\begin{tabular}{|c|c|c|}
\hline & Right & Left \\
\hline $\mathbf{K J}$ & & \\
\hline $\mathbf{A} J$ & & \\
\hline Plantar & & \\
\hline
\end{tabular}


APPENDIX 2

Data from Jensen (1981) used to calculate sample size 


\begin{tabular}{|l|r|r|r|r|}
\hline Patient Number & CC1 & CC2 & CC1-CC2 & \%CC difference \\
\hline $1973 / 78$ & 25 & 110 & -85 & -77.27272727 \\
\hline $1973 / 85$ & 75 & 100 & -25 & -25 \\
\hline $1973 / 94$ & 50 & 50 & 0 & 0 \\
\hline $1974 / 18$ & 100 & 120 & -20 & -16.66666667 \\
\hline $1974 / 24$ & 25 & 50 & -25 & -50 \\
\hline $1974 / 35$ & 10 & 40 & -30 & -75 \\
\hline $1974 / 37$ & 30 & 30 & 0 & 0 \\
\hline $1974 / 73$ & 30 & 50 & -20 & -40 \\
\hline $1974 / 76$ & 20 & 50 & -30 & -60 \\
\hline $1974 / 82$ & 30 & 90 & -60 & -66.66666667 \\
\hline $1974 / 84$ & 10 & 90 & -80 & -88.88888889 \\
\hline $1974 / 94$ & 125 & 160 & -35 & -21.875 \\
\hline $1974 / 97$ & 120 & 210 & -90 & -42.85714286 \\
\hline $1976 / 83$ & 190 & 240 & -50 & -20.83333333 \\
\hline $1975 / 60$ & 300 & 300 & 0 & 0 \\
\hline $1976 / 34$ & 400 & 400 & 0 & 0 \\
\hline $1977 / 74$ & 270 & 320 & -50 & -15.625 \\
\hline $1977 / 84$ & 300 & 300 & 0 & 0 \\
\hline $1977 / 88$ & 500 & 500 & 0 & 0 \\
\hline
\end{tabular}

\section{Appendix 2}

Table 7.1- data used for calculating sample size (from Jensen 1981) 


\section{APPENDIX 3}

Examples of urodynamic tracings 


\begin{tabular}{|c|c|c|c|c|c|}
\hline $\begin{array}{l}\text { Vinfus at First Desire to Void } \\
\text { Vinfus at Normal Desire to } \\
\text { Void } \\
\text { Vinfus at Strong Desire to Void } \\
\text { Vinfus at Max Cystoinctric } \\
\text { Capacity } \\
\text { Pdet at First Desire to Void } \\
\text { Pdet at Urgency } \\
\text { Pdet at Mux Cystometric } \\
\text { Capacity }\end{array}$ & $\begin{array}{r}81 \\
N . A \\
133 \\
196 \\
2 \\
2 . A \\
2\end{array}$ & $\begin{array}{l}\mathrm{ml} \\
\mathrm{ml} \\
\mathrm{ml} \\
\mathrm{ml} \\
\mathrm{cmH} 20 \\
\mathrm{cmH} 20 \\
\operatorname{cmH} 20\end{array}$ & $\begin{array}{l}\text { Mox Flow Roto } \\
\text { Voided Volume } \\
\text { Time to Max Flow } \\
\text { Pdat at Opening } \\
\text { Expected Reaidual Urime } \\
\text { Residual Urine }\end{array}$ & $\begin{array}{r}12.5 \\
85 \\
5 \\
17 \\
111 \\
\mathrm{~N} .1 .\end{array}$ & $\begin{array}{l}\mathrm{ml} / \mathrm{s} \\
\mathrm{ml} \\
\mathrm{cmH} \\
\mathrm{ml}\end{array}$ \\
\hline
\end{tabular}

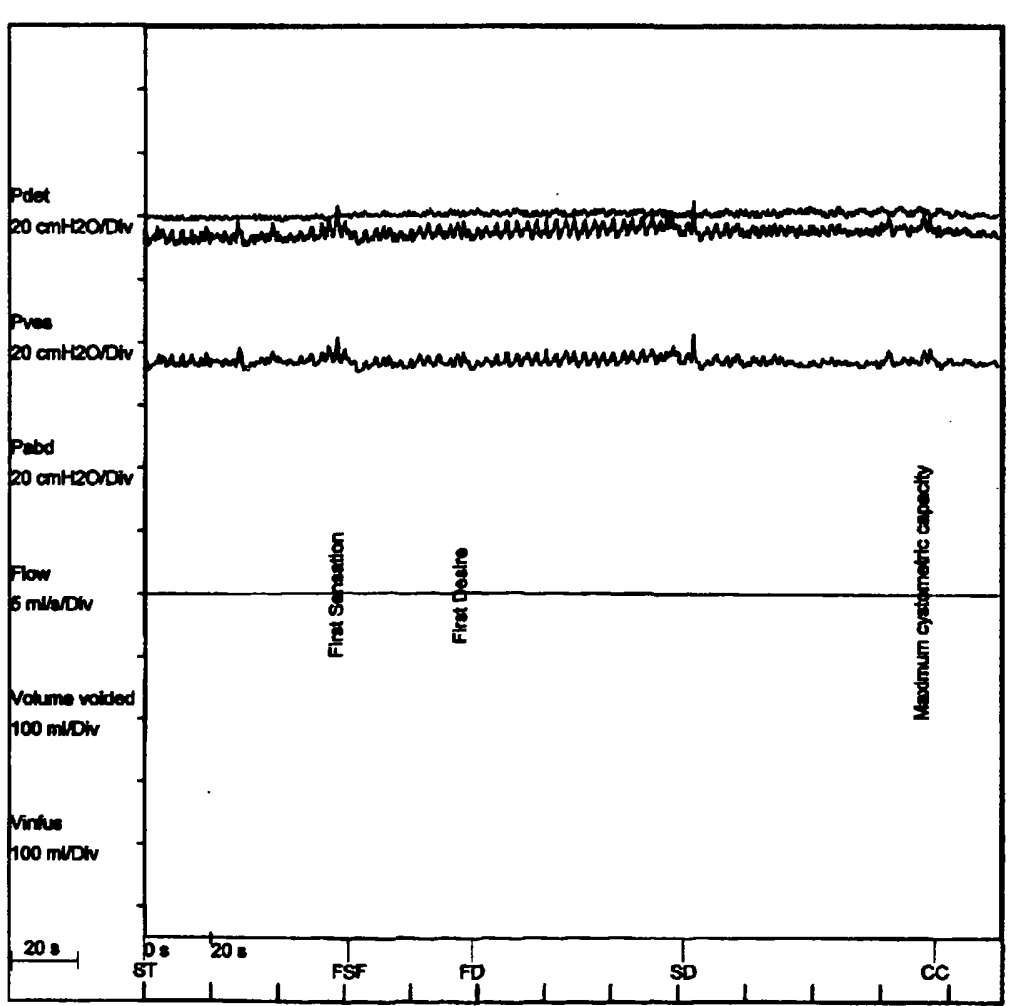

Stable urodynamics- Patient A1- hyperosmolar test fill- Dantec machine 
Puient ID

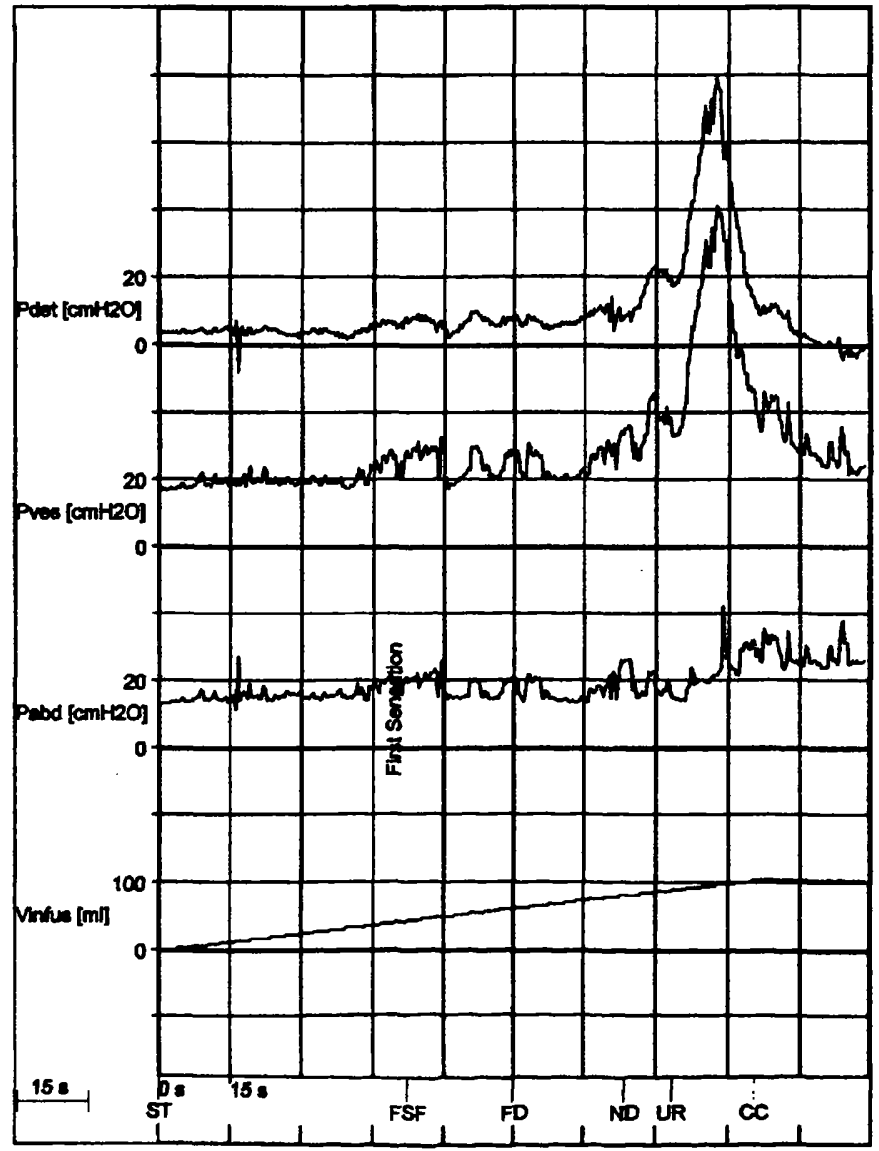

Unstable urodynamics- Patient A4- saline control fill- Dantec machine 
File: $\mathbf{5 0 0 1 1 4 7 . 0 0 2}$

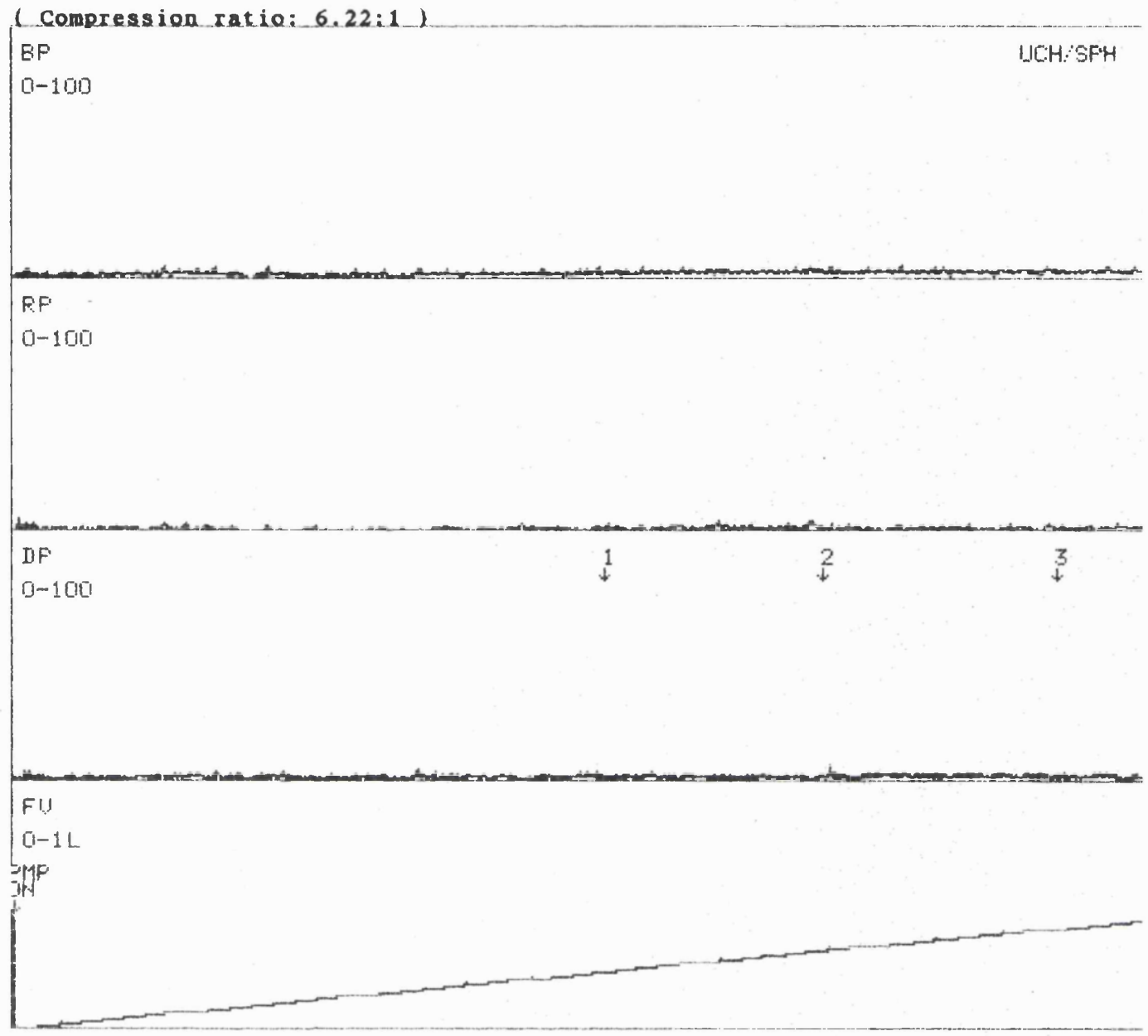

Stable urodynamics- Patient C23- saline control fill- St Pancras 486 machine 
File: $\$ 0001180.002$

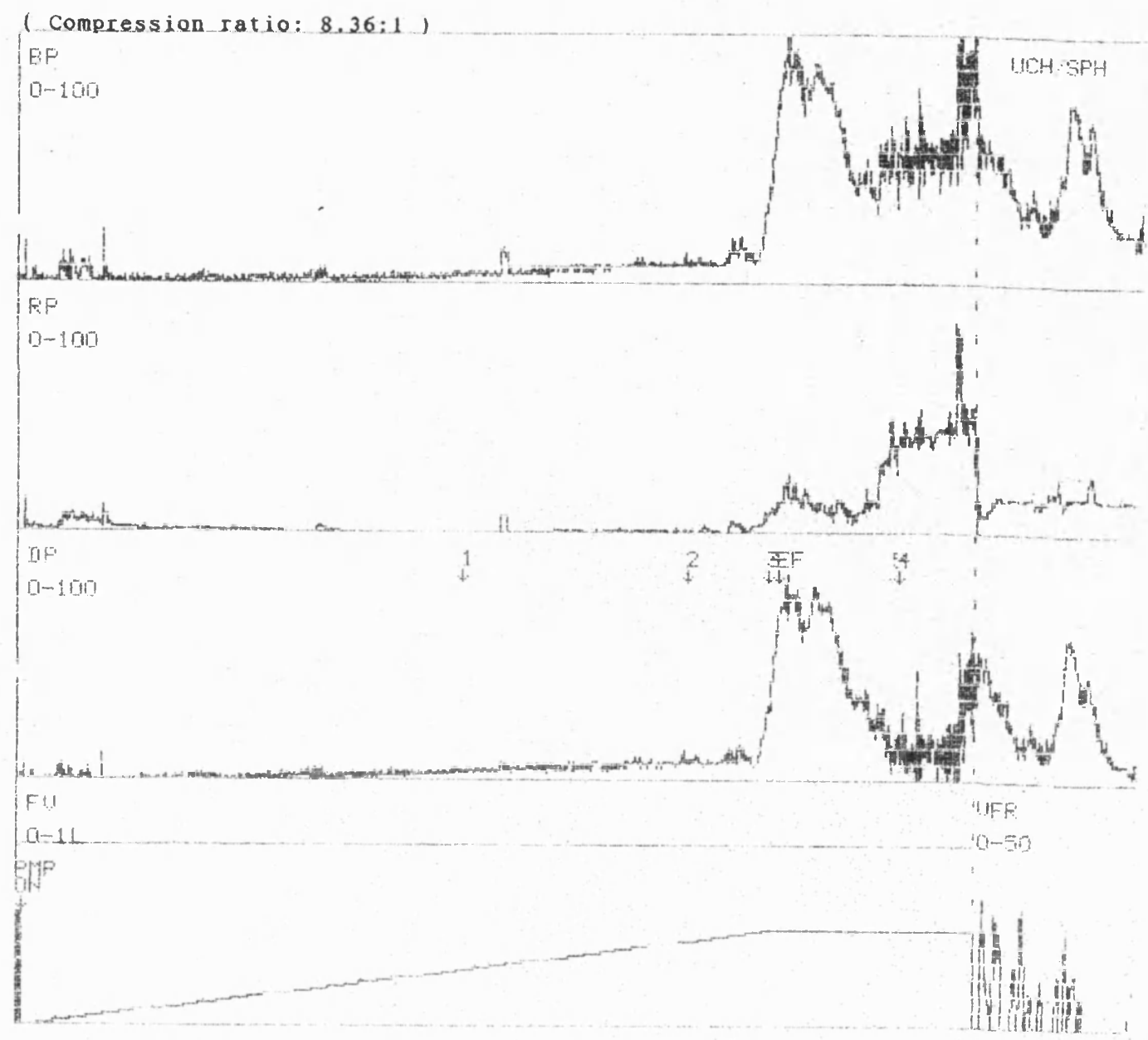

Unstable urodynamics- Patient- B2- Saline control fill- St Pancras 486 machine 
APPENDIX 4

Tables of parametric analysis 


\begin{tabular}{|c|c|c|c|c|c|c|c|c|}
\hline & & \multirow{2}{*}{ All subjects } & \multicolumn{2}{|c|}{ Urodynamic stability } & \multicolumn{4}{|c|}{ Urgency } \\
\hline & & & Stable & Unstable & 0 & 1 & 2 & 3 \\
\hline \multicolumn{2}{|c|}{ Number of subjects (n) } & 29 & 11 & 15 & 0 & 5 & 9 & 12 \\
\hline \multirow[t]{2}{*}{$\begin{array}{l}\text { FSF Control-FSF } \\
\text { Test }\end{array}$} & $\begin{array}{l}\text { Mean percentage change (\% } \\
\text { of control fill) }\end{array}$ & -66 & -65 & -67 & & -27 & -150 & -15 \\
\hline & 95\% Confidence intervals & $-134,2$ & $-168,37$ & $-167,34$ & & $-83,29$ & $-347,48$ & $-41,11$ \\
\hline \multirow[t]{2}{*}{$\begin{array}{l}\text { FDV Control-FDV } \\
\text { Test }\end{array}$} & $\begin{array}{l}\text { Mean percentage change (\% } \\
\text { of control fill) }\end{array}$ & -87 & -107 & -72 & & -22 & -195 & -26 \\
\hline & $\mathbf{9 5 \%}$ Confidence intervals & $-191,18$ & $-351,136$ & $-177,32$ & & $-60,16$ & $-509,118$ & $-74,20$ \\
\hline \multirow{2}{*}{$\begin{array}{l}\text { CC control-CC } \\
\text { test }\end{array}$} & $\begin{array}{l}\text { Mean percentage change (\% } \\
\text { of control fill) }\end{array}$ & -58 & -7 & -92 & & -2 & -100 & -49 \\
\hline & 95\% Confidence intervals & $-137,20$ & $-26,10$ & $-226,42$ & & $-25,22$ & $-323,121$ & $-137,38$ \\
\hline
\end{tabular}

Table 7.2- Parametric data analysis of hyperosmolar study 


\begin{tabular}{|c|c|c|c|c|c|c|c|c|}
\hline & & All subjects & Urodyna & tability & & & & \\
\hline & & & Stable & Unstable & 0 & 1 & 2 & 3 \\
\hline Number of subjects ( & & 28 & 16 & 10 & 0 & 4 & 12 & 5 \\
\hline $\begin{array}{l}\text { FSF Control-FSF } \\
\text { Test }\end{array}$ & $\begin{array}{l}\text { Mean percentage change (\% } \\
\text { of control fill) }\end{array}$ & -61 & -47 & -16 & & -12 & -50 & -7 \\
\hline & $95 \%$ Confidence intervals & $-135,11$ & $-180,86$ & $-48,14$ & & $-101,76$ & $-169,69$ & $-72,58$ \\
\hline $\begin{array}{l}\text { FDV Control-FDV } \\
\text { Test }\end{array}$ & $\begin{array}{l}\text { Mean percentage change (\% } \\
\text { of control fill) }\end{array}$ & -16 & -7 & -25 & & -20 & -10 & -26 \\
\hline & 95\% Confidence intervals & $-40,8$ & $-45,31$ & $-72,22$ & & $-151,111$ & $-43,22$ & $-119,68$ \\
\hline $\mathrm{CC}$ control-CC & $\begin{array}{l}\text { Mean percentage change (\% } \\
\text { of control fill) }\end{array}$ & -13 & -7 & -27 & & -11 & -6 & -44 \\
\hline test & $95 \%$ Confidence intervals & $-28,2$ & $-27,12$ & $-63,9$ & & $-32,10$ & $-25,12$ & $-130,41$ \\
\hline
\end{tabular}

Table 7.3- Parametric data analysis for extracellular alkalosis study 


\begin{tabular}{|c|c|c|c|c|c|c|c|c|}
\hline & & \multirow[t]{2}{*}{ All subjects } & \multicolumn{2}{|c|}{ Urodynamic stability } & \multicolumn{4}{|l|}{ Urgency } \\
\hline & & & Stable & Unstable & 0 & 1 & 2 & 3 \\
\hline \multicolumn{2}{|c|}{ Number of subjects (n) } & 24 & 22 & 2 & 7 & 7 & 6 & 2 \\
\hline \multirow[t]{2}{*}{$\begin{array}{l}\text { FSF Control-FSF } \\
\text { Test }\end{array}$} & $\begin{array}{l}\text { Mean \% change (\% of } \\
\text { control fill) }\end{array}$ & 13 & 13 & 22 & 23 & 14 & -12 & 51 \\
\hline & $95 \%$ Confidence intervals & $-5,33$ & $-8,33$ & & $-42,89$ & $-19,48$ & $-61,35$ & \\
\hline \multirow[t]{2}{*}{$\begin{array}{l}\text { FDV Control-FDV } \\
\text { Test }\end{array}$} & $\begin{array}{l}\text { Mean Percentage change (\% } \\
\text { of control fill) }\end{array}$ & 4 & 4 & 2 & 5 & 17 & -22 & 33 \\
\hline & $95 \%$ Confidence intervals & $-13,21$ & $-14,23$ & & $-29,39$ & $-19,54$ & $-70,24$ & \\
\hline \multirow{2}{*}{$\begin{array}{l}\text { CC control-CC } \\
\text { test }\end{array}$} & $\begin{array}{l}\text { Mean \% change (\% of } \\
\text { control fill) }\end{array}$ & -3 & -3 & 3 & -2 & -1 & -3 & -7 \\
\hline & $\mathbf{9 5 \%}$ Confidence intervals & $-11,6$ & $-13,6$ & & $-39,35$ & $-6,4$ & $-28,28$ & \\
\hline
\end{tabular}

Table 7.4 - Parametric analysis for normocapnic study 


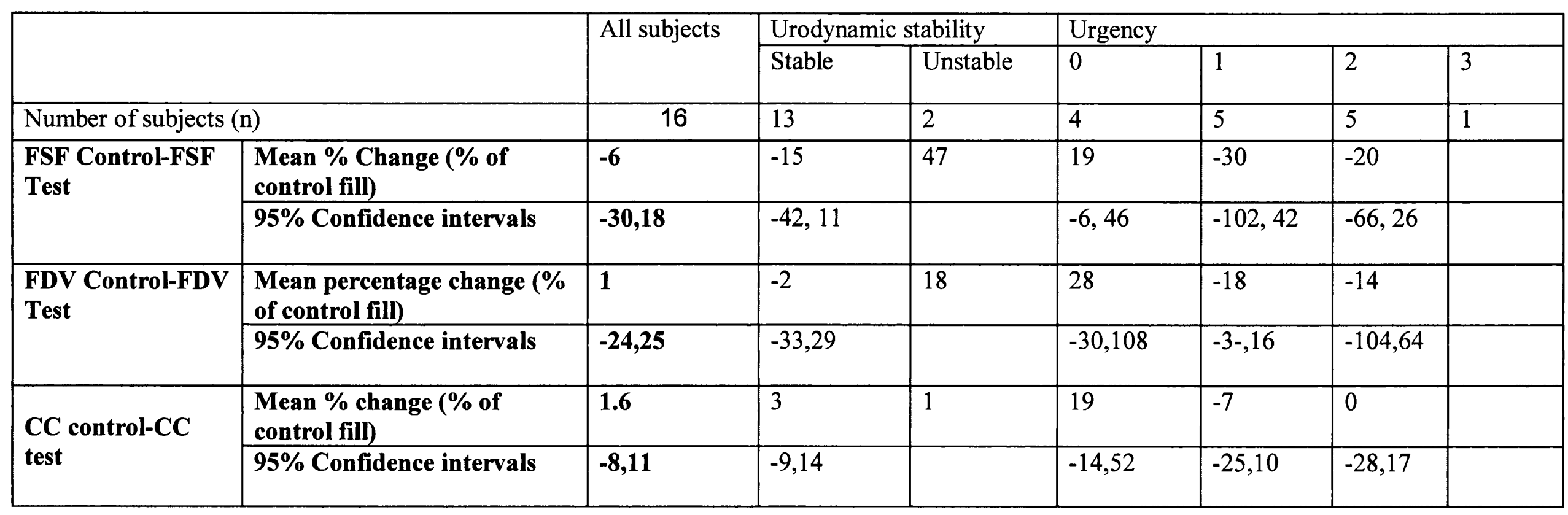

Table 7.5- Parametric data analysis for hypercapnic study 


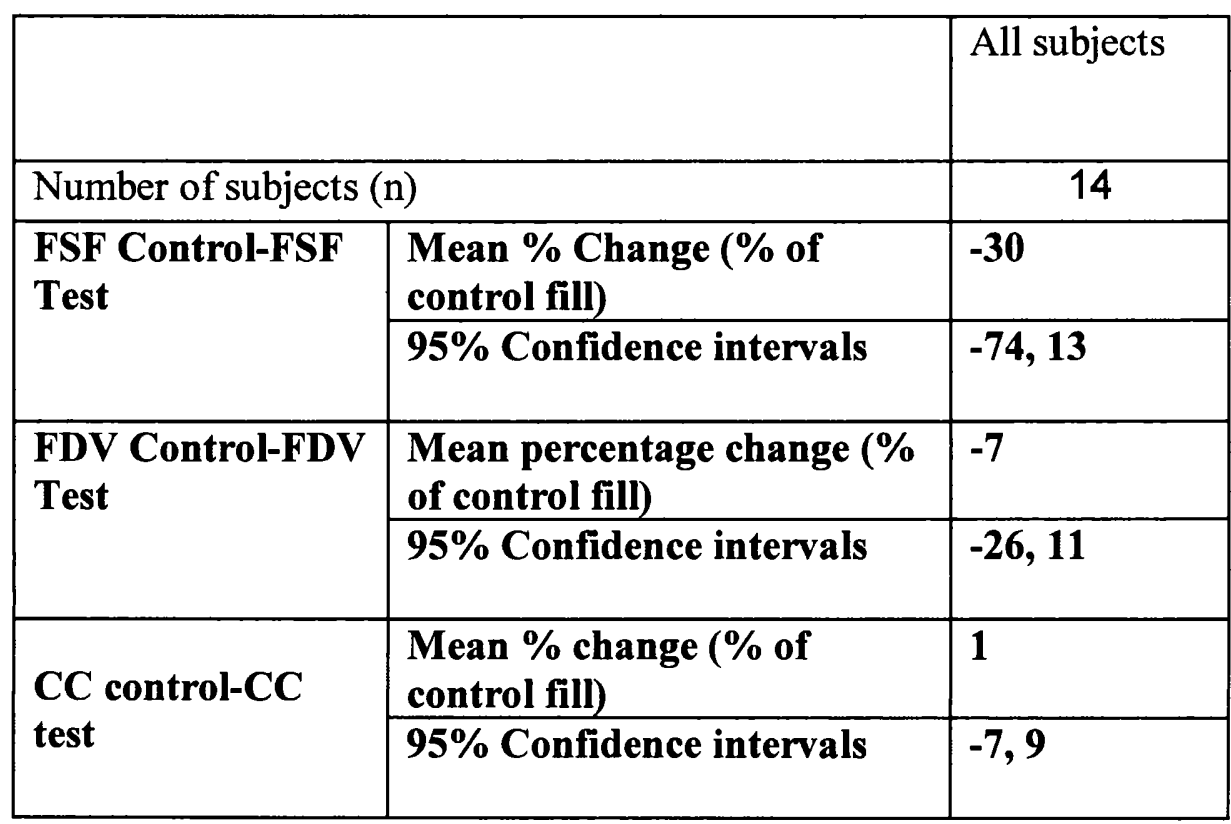

Table 7.6- Parametric data analysis of hypercapnic (test) vs normocapnic (control) studies 


\begin{tabular}{|c|c|c|c|c|c|c|c|c|}
\hline & & \multirow[t]{2}{*}{ All subjects } & \multicolumn{2}{|c|}{ Urodynamic stability } & \multicolumn{4}{|c|}{ Urgency } \\
\hline & & & Stable & Unstable & 0 & 1 & 2 & 3 \\
\hline \multicolumn{2}{|c|}{ Number of subjects (n) } & 13 & 6 & 6 & 0 & 3 & 6 & 3 \\
\hline \multirow[t]{2}{*}{$\begin{array}{l}\text { FSF Control-FSF } \\
\text { Test }\end{array}$} & $\begin{array}{l}\text { Mean percentage change (\% } \\
\text { of control fill) }\end{array}$ & -228 & 16 & -473 & & 15 & -3 & -922 \\
\hline & $95 \%$ Confidence intervals & $-712,255$ & $-39,72$ & $-155,642$ & & & $-66,60$ & \\
\hline \multirow[t]{2}{*}{$\begin{array}{l}\text { FDV Control-FDV } \\
\text { Test }\end{array}$} & $\begin{array}{l}\text { Mean percentage change (\% } \\
\text { of control fill) }\end{array}$ & 7 & 14 & 0 & & 2 & 20 & -12 \\
\hline & 95\% Confidence intervals & $-14,29$ & $-22,52$ & $-33,34$ & & & $-17,56$ & \\
\hline \multirow{2}{*}{$\begin{array}{l}\mathrm{CC} \text { control-CC } \\
\text { test }\end{array}$} & $\begin{array}{l}\text { Mean percentage change (\% } \\
\text { of control fill) }\end{array}$ & 1 & -13 & 15 & & 8 & -10 & 17 \\
\hline & $95 \%$ Confidence intervals & $-18,20$ & $-52,26$ & 0,30 & & & $-49,28$ & \\
\hline
\end{tabular}

Table 7.7 - Parametric data analysis of potassium study 


\begin{tabular}{|c|c|c|c|c|c|c|c|c|}
\hline & & \multirow{2}{*}{ All subjects } & \multicolumn{2}{|c|}{ Urodynamic stability } & \multicolumn{4}{|c|}{ Urgency } \\
\hline & & & Stable & Unstable & 0 & 1 & 2 & 3 \\
\hline \multicolumn{2}{|c|}{ Number of subjects (n) } & 94 & 55 & 35 & 8 & 23 & 37 & 22 \\
\hline \multirow[t]{2}{*}{ FSF 2- FSF 1} & $\begin{array}{l}\text { Mean percentage change (\% } \\
\text { of control fill) }\end{array}$ & -55 & -16 & -103 & 4 & -12 & -38 & -129 \\
\hline & $95 \%$ Confidence intervals & $-114,4$ & $-43,11$ & $-261,55$ & $-36,44$ & $-38,13$ & $-92,15$ & $-379,120$ \\
\hline \multirow[t]{2}{*}{ FDV 2 - FDV 1} & $\begin{array}{l}\text { Mean percentage change (\% } \\
\text { of control fill) }\end{array}$ & -6 & 1 & -19 & 11 & 0 & -15 & -5 \\
\hline & 95\% Confidence intervals & $-23,11$ & $-11,14$ & $-63,26$ & $-7,30$ & $-20,20$ & $-57,27$ & $-30,30$ \\
\hline \multirow[t]{2}{*}{$\mathrm{CC} 2-\mathrm{CC} 1$} & $\begin{array}{l}\text { Mean percentage change (\% } \\
\text { of control fill) }\end{array}$ & -20 & -7 & -44 & -30 & -8 & -27 & -25 \\
\hline & $95 \%$ Confidence intervals & $-40,-6$ & $-14,-1$ & $-100,11$ & $-50,-2$ & $-15,-1$ & $-75,21$ & $-68,17$ \\
\hline
\end{tabular}

Table 7.8 - Parametric data analysis of order of fill data 